\title{
LOS PEJERREYES (Familia ATHERINIDAE) EN LA FAUNA URUGUAYA, CON DESCRIPCION DE NUEVAS ESPECIES
}

\author{
Fernando de Buen
}

El estudio de los Aterínidos no se ha emprendido en la fauna uruguaya y en las próximas de Argentina y Brasil, con la minuciosidad deseada. Se ha intentado su conocimiento basándose en material obtenido accidentalmente en localidades dispersas y escasas, o al través de obras de conjunto, que en general y por desgracia suelen adolecer del empleo de métodos no usuales en la Ictiología, siendo bien difícil incorporar sus conocimientos a la Ciencia universal y realizar con los elementos sistemáticos aportados las comparaciones necesarias para resaltar diferencias entre las especies.

En estas páginas intentaremos reunir y seleccionar conocimientos sobre los Pejerreyes de aguas uruguayas, llevando a cabo el estudio comparativo de las formas recogidas y proponiendo su ordenación en la sistemática en boga.

Sabemos por propia experiencia las dificultades que se anteponen al trabajo que intentamos dentro de nuestro medio, donde el logro de material se hace difícil y la necesaria consulta bibliográfica no siempre puede llevarse a cabo con la oportunidad debida.

$\mathrm{Al}$ estudio de los Pejerreyes hemos aportado nuestra experiencia, disponiendo de material recolectado por nosotros mismos o amablemente proporcionado por las personas o entidades que oportunamente mencionaremos. La bibliografía ha tenido dos fuentes: he aprovechado íntegramente las obras reunidas en mi biblioteca particular, y he podido consultar las obras clásicas en el Museo de Historia Natural de Montevideo, por atención muy especial del Dr. Ergasto H. Cordeiro, que la Ciencia uruguaya acaba de perder, y por el deseo mantenido de fomentar la investigación científica del actual Director de aquel centro, el conocido botánico señor Diego Legrand.

Los Aterínidos tienen destacado interés, figuran en los mercados y son muy apreciados en el consumo, deben incluirse en la lista de peces deportivos, y la posibilidad de cultivarlos ha creado un capítulo especial dentro de la Piscicultura, la Aterinicultura.

No son pocos los autores que contribuyeron al conocimiento de nuestros Pejerreyes. Sobre escaso número de ejemplares los destacados autores 
Cuvier y Valenciennes (1835) crean tres especies : una de ellas (argentinensis) remitida de Montevideo por D'Orbigny, otra (bonariensis) enviada de Buenos Aires a Baillón, identificada con ejemplares aportados de Montevideo por D'Orbigny, y la tercera (lichtensteinii) también de Montevideo, remitida para su estudio por el prof. Lichtenstein de la colección del Museo de la Universidad de Berlín.

Aunque la "Histoire Naturelle des Poissons" lleva el nombre de los dos grandes autores franceses, sus páginas fueron escritas separadamente por Cuvier y Valenciennes. El tomo X (1835) corresponde, al parecer, únicamente a Valenciennes (Bailey 1931, p. 251). De ser así todas las Atherina descritas deberán llevar el nombre de Valenciennes, en Cuvier y Valenciennes (1835).

Los ejemplares colectados por Charles Darwin durante la campaña del Beagle, los separa Jenyns en dos especies (1842) : una (argentinensis ?) muy abundante en la bahia de Maldonado y otra (incisa) obtenida a varias millas de la costa, en situación $39^{\circ}$ Lat. S y $61^{\circ}$ Long. W.

No encontramos novedades en la gran obra de Günther (1861); sus descripciones están basadas en los autores precedentes acabados de mencionar.

Debemos al competente ictiólogo Steindachner (1867) una buena descripción de una de las especies de Valenciennes (bonariensis).

Estudiando los peces de Sud América en las colecciones del Museo Cívico de Historia Natural de Génova, Perugia (1891) asigna a nuestros Pejerreyes nombres de Aterínidos procedentes de otras faunas, complicando extraordinariamente la sistemática ictiológica para los autores que le siguieron. Ejemplares de Montevideo los clasifica como vomerina y laticlavia; a otros procedentes de la desembocadura de Rio Negro, logrados durante la Expedición Antártica Italiana, los llama argentinensis, y bonariensis a los proporcionados por el Dr. Spegazzini de la laguna de Iberá, cerca de Corrientes.

La primera obra de conjunto de esta zona de Sud América se debe a Berg (1895), quien acertadamente describe una nueva especie platensis. Dejándose influir por los autores que le precedieron extiende la forma exótica vomerina por la costa patagónica, Mar del Plata y Montevideo, concediendo la misma distribución geográfica a microlepidotus; dá a laticlavia como localidades Mar del Plata y cercanías de la isla de Flores, y otorga dilatada extensión dispersiva a argentinensis (Barra del rio Negro, Cabo San Antonio, Montevideo y Maldonado), suponiendo que bonariensis vive en Montevideo, Maldonado y Mar Chiquita.

Acaso la publicación que ha originado mayor desconcierto entre los autores sudamericanos se debe a Evermann y Kendall (1907), donde describen a Odontesthes perugiae sobre un ejemplar de localidad mal conocida, pues únicamente sabemos que pertenece a la fauna argentina y seguramente procede de aguas dulces, donde encontramos formas semejantes. 
La influencia del género Odontesthes ha sido decisiva; tiene supremacía sistemática sobre los intentos posteriores de agrupar genéricamente las especies, con el grave inconveniente de estar basado en una especie típica, ejemplar único que no ha vuelto a aparecer en las abundantes exploraciones argentinas, cuyos autores creyeron identificar a perugiae, en formas indudáblemente distintas.

La descripción de Odontesthes perugiae (Evermann y Kendall 1907, p. 94) y la figura que publican (fig. 3), corresponden a un Pejerrey de cuerpo largo, con dorsales muy retrasadas, caudal de lóbulos poco pronunciados, mandíbulas dotadas de dientes relativamente largos, con escamas enteras y aleta pectoral corta, que no llega hasta el origen de las ventrales. La presencia de dientes en el vómer ha sido considerada por autores posteriores como característico de la especie, identificando con perugiae formas morfológicamente diferentes, pero con dientes vomerinos, cuya presencia varía con la edad, además que su observación sobre ejemplares conservados no es siempre concluyente.

Al catalogar Eigenmann (1909) los peces dulceacuícolas tropicales de Sud América y de la Patagonia, duda de la presencia de microlepidota en Montevideo, señala como distribución de bonariensis los lagos argentinos y describe una Menidia hatcheri, que luego pretende incluir en el nuevo género Patagonia, que cambia por Patagonina al darse cuenta que ya había sido empleado en la sistemática zoológica.

Menidia hatcheri descrita sobre un ejemplar de 219 milímetros de longitud estándar, procede del lago Pueyrredón, de Argentina, y tiene la primera dorsal avanzada, comenzando casi sobre el extremo de las ventrales y sobre el ano de posición muy avanzada, sus aletas pectorales cortas quedan distanciadas, en su extremidad, del origen de las ventrales; posee dientes menudos agrupados en estrechas bandas, corto número de radios en la anal (1/16) y gran número de escamas en serie longitudinal (68-70).

En la voluminosa obra de Miranda Ribeiro (1915), dedicada a la fauna de peces del Brasil, se describen como nuevos dos Pejerreyes, uno de ellos (pág. 11) capturado en Rio Grande do Sul (Pseudothyrina iheringi), muy cerca de nuestras costas del Este, y el otro (pág. 10), al que dá el nombre de Kronia iguapensis, obtenido en São Paulo. Más tarde, el mismo autor (1918) identifica con la primera especie un ejemplar procedente del Mercado de Montevideo.

Entre los peces capturados en la campaña del Albatross, Thompson (1916) llama bonariensis a ejemplares procedentes de Buenos Aires y dá el nuevo nombre de Menidia alburnus, que autores posteriores consideran sinónima de Atherina nigricans Richardson, a ejemplares con escamas de forma oval, sin ángulos en la zona embutida, pero con cuatro a cinco líneas radiales y el borde libre festoneado; cuentan con gran número de escamas a lo largo de la línea longitudinal (98 a 105) y de 21 a 22 en serie transversal.

Llegamos a una obra fundamental para el conocimiento de los Pejerreyes. Nos referimos a la revisión realizada por Jordan y Hubbs (1919), en cuyas 
páginas encontramos para Brasil, Uruguay y Argentina, la mención de las siguientes especies:

Hepsetia stipes, en Brasil con duda.

Thyrina brasiliensis, de Rio de Janeiro.

Pseudothyrina iheringi, de Rio Grande do Sul.

Kronia iguapensis, de São Paulo.

Odontesthes perugiae, de Argentina, probable en aguas dulces.

Odontesthes platensis, de Mar del Plata.

Odontesthes argentinensis, de Uruguay y Argentina.

Austromenidia bonariensis, de Uruguay, Argentina y posiblemente SE de Brasil.

Austromenidia hatcheri, de aguas dulces argentinas.

Austromenidia nigricans, de Sur de Argentina.

El género Austromenidia Hubbs 1918, basado en Basilichthys regillus Abbott, sinónimo de Atherina regia Humboldt, es de fecha posterior a Odontesthes Evermann y Kendall (1906).

Para el estudio de las especies incluídas en el género Thyrina, llamado hoy Thyrinops Hubbs 1918, en substitución del anterior ya empleado en la nomenclatura zoológica, puede consultarse con provecho la clave publicada por Hubbs (1920).

$\mathrm{Al}$ enumerar las especies uruguayas, Devincenzi (1924) respeta la autoridad de Berg y acepta su criterio, mencionando a bonariensis, perugiaí y platensis. Describe como nueva Menidia uruguayensis, de cuerpo alargado y con numerosas escamas en línea longitudinal, representándola gráficamente (Devincenzi 1939, a, figura 7) según la técnica preconizada por Lahille.

En la primera parte del "Album Ictiológico del Uruguay" (Devincenzi y Barattini, 1928) se figuran de manera incompleta y poco precisa las especies antes mencionadas, y el propio Devincenzi $(1939$, b) al comentar la clásica obra de Norman (1937) disiente en la colocación genérica de la especie smitti de Lahille.

Lahille (1929) publica un voluminoso trabajo, útil de consultar para conocer en detalle la bibliografía existente hasta aquellas fechas, y aún las descripciones originales de los autores que extraeta o copia, pero de comprensión dificil al crear un método propio de trabajo con numerosas cifras y figuras esquemáticas. Incluye las especies uruguayas y argentinas en el género único Basilichthys, creando numerosas variedades, algunas de ellas de poca consistencia.

Tratando de las especies uruguayas mencionaremos buena parte del trabajo de Lahille; ahora nos contentaremos con aprovechar sus datos para distinguir los Pejerreyes argentinos con gran número de escamas en línea longitudinal.

Según Lahille deben aceptarse las siguientes especies y variedades :

1. Con 88 a 105 escamas en línea longitudinal $\ldots \ldots \ldots \ldots \ldots \ldots \ldots \ldots \ldots \ldots 2$

2. La distancia del orígen de la segunda dorsal a la última vértebra, mayor del 35 por ciento de la longitud estándar. El término de la segunda dorsal, más 
avanzado que el término de la anal. Base de la anal 20-24 por ciento de la

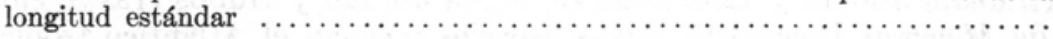

- La distancia del orígen de la segunda dorsal a la última vértebra, menos del 35 por ciento de la longitud estándar. Términos de la segunda dorsal y de la anal al mismo nivel. Base de la anal 16-17 por ciento de la longitud estándar

3. Del morro al extremo de la pectoral apoyada el 45 por ciento de la longitud estándar, igual a la distancia entre el extremo del morro y el origen de las

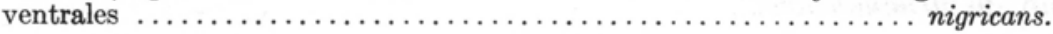

- Del morro al extremo de la pectoral apoyada el 50 por ciento de la longitud estándar, mayor que la distancia entre el extremo del morro y el origen de

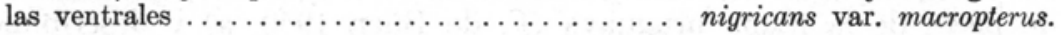

4. Del término de la anal a la última vértebra el 21-23 por ciento de la longitud

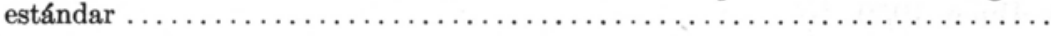

- Del término de la anal a la última vértebra el 17 por ciento de la longitud

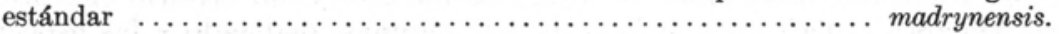

5. Base de la segunda dorsal el 7 por ciento o más de la distancia entre el morro

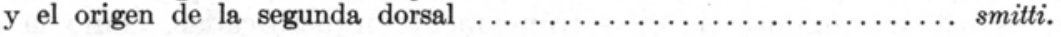

- Base de la segunda dorsal el 6.09 por ciento de la distancia entre el morro y el origen de la segunda dorsal .................. smitti var. australis.

Estudiando los Pejerreyes de Puerto Quequén hace Lahille (1930) un buen estudio comparado de incisus, argentinensis, platensis y smitti.

Com muy abundante material, en su mayoría obtenido en campañas científicas, emprende J. R. Norman (1937) en las páginas del "Discovery Reports" el estudio de los peces costeros de Sud América. Aunque el trabajo se refiere especialmente a la región patagónica, islas Malvinas y estrecho de Magallanes, tiene mayor amplitud, tratando de la fauna de peces marinos de las costas uruguaya, argentina y chilena. Dentro de la familia Atherinidae únicamente hace referencia a los Pejerreyes con gran número de escamas (90-105) en línea longitudinal, que aloja en solo dos especies, incluídas en el género Austromenidia: A. smitti (Norman 1937, pág. 120 , fig. $66 \mathrm{~A}$ ) y $A$. nigricans (pág. 121, fig. $66 \mathrm{~B}$ ).

Para Norman (1937) las especies y variedades dadas a conocer por Lahille y que mencionáramos antes, deben alojarse en las sinonimias respectivas. Considera idéntica a smitti descrita por Lahille, la variedad australis y con ciertas dudas la especie madrynensis. Supone iguales a nigricans la especie de Günther Atherinichthys alburnus, Menidia patagoniensis Eigenmann, y variedad macropterus de Lahille.

$\mathrm{Al}$ enumerar los Aterínidos marinos de la fauna argentina, Pozzi y Bordalé (1935) mantienen las variedades preconizadas por Lahille, que no acepta más tarde Pozzi (1945) al tratar de los peces de agua dulce de la misma fauna y comentar (págs. 246-248) la repartición de las especies en grupos genéricos.

Fowler (1943) aloja en el género Kirlandia la especie uruguayensis de Devincenzi. 
Kirlandia Jordan y Evermann es, según Jordan y Hubbs (1919), sinónima de Membras Bonaparte, cuyas especies pueblan el Atlántico tropical de América, teniendo de común con la especie de Devincenzi la presencia de prolongaciones irregulares en el borde libre de sus escamas. Esa característica es igualmente aparente en Hubbesia Jordan, del Pacífico tropical de América, pero ambos géneros ostentan otras características que los separan de uruguayensis.

En un trabajo de Schultz (1948) se revisan los géneros y se reparten en varias subfamilias dentro de Atherinidx. Nosotros publicamos la lista de peces de la fauna uruguaya (F. de Buen 1950, a) y describimos una especie nueva de Pejerrey al que asignamos el nombre de orientalis (F. de Buen 1950, b).

Con escasísimo conocimiento de la sistemática, y sin criterio científico, publica Marrero (1950) un volumen de 157 páginas, dedicado a las especies argentinas, para las cuales improvisa nombres vulgares y asigna denominaciones científicas, algunas de ellas fráncamente injustificadas, como la de proponer el nuevo Basilichthys microather Marrero para substituir a Odontesthes perugiae Evermann y Kendall.

Aunque Marrero (1950) desconoce el valor del género, demostrado en sus gratuitas afirmaciones, por ejemplo al decir : "Constituyendo algunas verdaderas anomalias científicas, como Odontesthes, que permite classificar los adultos de un género y los jóvenes de otro... ", y además no precisar la especie genotípica, debemos aceptar su Austroatherina para alojar por lo menos a Atherina incisa Jenyns.

\section{ATERINICULTURA}

Uno de los capítulos de interesante estudio en los Pejerreyes es la investigación biológica, con tendencia a mejorar su cultivo o Aterinicultura. Los conocimientos sobre su ontogenia son pobres y pocas las informaciones controlables acerca de la ecología de esos peces.

Según nuestras informaciones la Aterinicultura ha tenido su cuna en Argentina, sin excluir a otros paises que emprendieron seriamente los estudios pertinentes, con tendencia al cultivo de especies pertenecientes a la familia Atherinidae. Tenemos buen ejemplo en México, donde bajo mi dirección se cultivaron Charales (Eslopsarum) y Pescados Blancos (Chirostoma), lográndolos de óvulos maduros y fecundados natural o artificialmente.

En el que llamábamos (F. de Buen 1945, p. 506) Eslopsarum bartoni bartoni, sobre individuos procedentes del Lago de Pátzcuaro (Michoacán, México), pudimos seguir los principales rasgos de su desarrollo ( $F$. de Buen 1940, pp. 1-14, láms I-IV). El óvulo maduro y fecundado es esférico, con diámetro de 1,00 a 1,10 milímetros, tiene poco espacio perivitelino, conteniendo el vitelo una sola gota oleosa de 0,25 a 0,30 milímetros, a la que puede acompañar otra de menudo tamaño o disponer de varias. 
Mediante largos filamentos capsulares, la puesta natural se abraza en intrincados enlaces a los objetos submergidos, principalmente a la vegetación. En las aguas del Lago de Pátzcuaro la incubación dura de nueve a diez dias, y en su transcurso el casquete blastodérmico invade sucessivamente el vitelo (figuras 1 y 2 ), se esboza el embrión (figuras 3 y 4 ) y en avanzadas etapas aparecen las cápsulas ópticas incoloras, pulsa el corazón, se activa la circulación vitelina (figura 5) y el embrión rodea y rebasa el vitelo, yá con las cápsulas ópticas pigmentadas (figura 6). Transcurridas las sucesivas etapas que acabamos de compendiar, fáciles de seguir durante el desarrollo dentro del huevo, nace una cría de cinco milímetros de larga, transparente, con trazo de cromatóforos negros a lo largo del borde ventral (figura 7), con amplias y salientes cápsulas ópticas y reducido vitelo con una gota oleosa incolora.

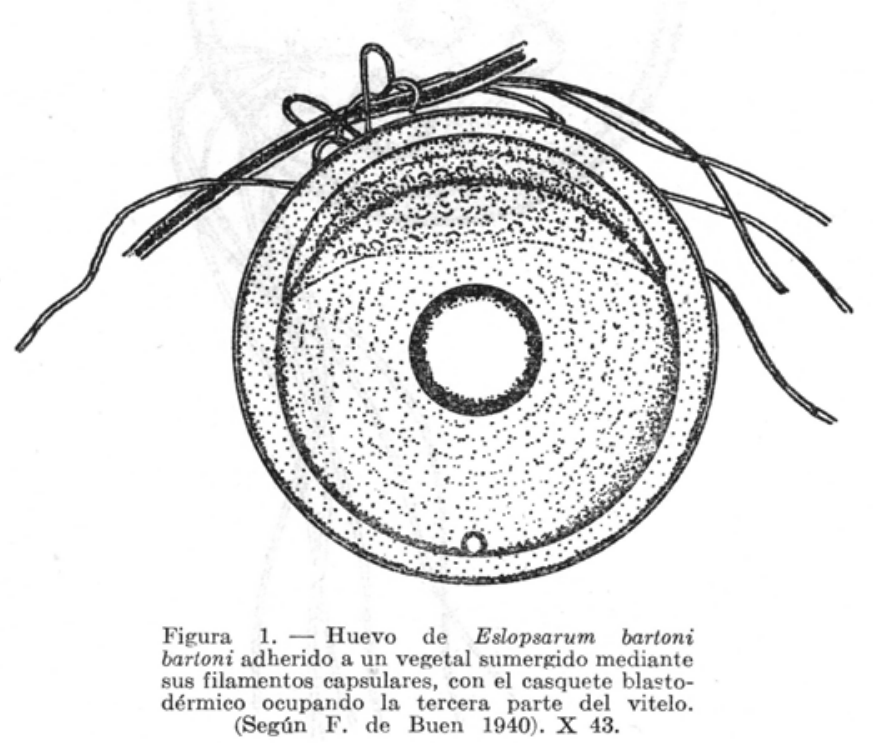

El Charal recién nacido no cae al fondo del recipiente que lo contenga, se agita para remontar manteniendo el cuerpo inclinado y la cabeza hacia arriba.

Pocas variaciones morfológicas se observan al transcurrir 48 horas desde el nacimiento (fig. 8). Se ha reducido en extremo el vitelo, inexistente al transcurrir ocho días (fig. 9), se pigmenta la parte alta de la vejiga natatoria y se forman las mandíbulas.

Ejemplares cultivados en los estanques de la Estación Limnológica de Pátzcuaro medían 10 milímetros a los cuatro meses de edad, con esbozo de los radios de la segunda dorsal, anal y caudal, plateándose el iris y mostrando cromatóforos larvarios sobre la mancha cerebral, en los labios, en la zona branquial y en el cuerpo, formando trazos longitudinales sobre el lomo, a mitad de los flancos y a lo largo del vientre (fig. 10). A la misma 
edad, individuos de más rápido crecimiento, con 16,5 milímetros de longitud, habían perdido las características embrionarias de las pectorales y las restantes aletas se constituían definitivamente (fig. 11), a semejanza de lo observado en la fase juvenil (fig. 12), diferente de la de Chirostoma grandocule (fig. 13), que puebla como la anterior especie las aguas del Lago de Pátzcuaro.

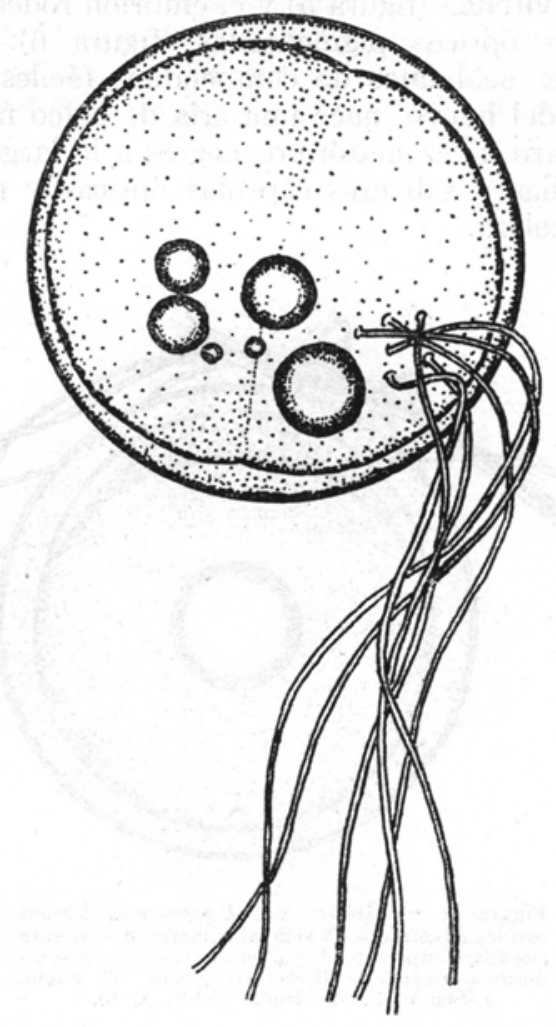

Figura 2, - Llega el casquete blastodérmico bartoni (Según F. de Buen 1940). X 43 .

Ringuelet (1943) publica buenas fotografías del desarrollo de los óvulos fecundados del Pejerrey argentino de aguas dulces (Ringuelet, figuras 6-19), en las cuales se puede observar que a las dos horas de la fecundación se ha formado un modesto casquete blastodérmico y hay en el vitelo numerosas gotas oleosas, y que al cuarto día de incubación el embrión esbozado no tiene pigmentación en las cápsulas ópticas. Es de observar en coincidencia con las formas mexicanas, la sucessiva disminución del número de gotas oleosas alojadas en el vitelo.

En los Estados Unidos, Kuntz y Radcliffe (1918) describen la forma del huevo, el desarrollo embrionario y sus características larvarias en Menidia 
menidia notata, y más tarde Hildebrand (1923), en especies de igual género, destaca diferencias en los filamentos capsulares, numerosos, delgados e iguales entre sí en Menidia menidia, y abundantes, de mayor grosor y desi-

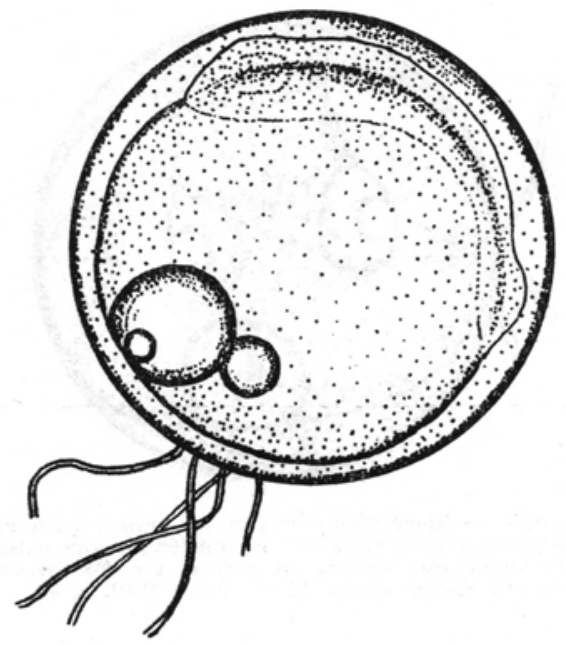

Figura 3. - Se esboza el embrión y se reduce el número de gotas oleosas, en Eslopsarum bartoni bartoni (Según F. de Buen). X 43.

guales en Menidia beryllina. En un estudio dedicado a los peces de la bahía de Chesapeake, Hildebrand y Schroeder (1928) aprovechan la información gráfica antes mencionada (Hildebrand 1923); Bigelow y Welsh (1925,

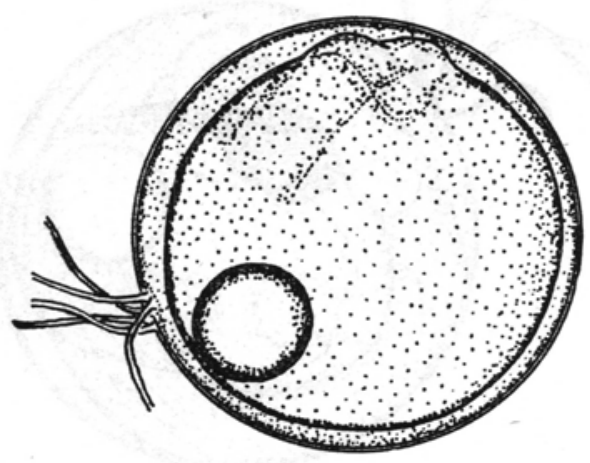

Figura 4. - Una sola gota oleosa en el vitelo. en Eslopsarum bartoni bartoni

(Según F. de Buen 1940). X 43. 
figs. 83 a 86) figuran el huevo, la larva, la postlarva y el adulto, en la especie que llaman Menidia notata, y Clark y Moulton (1949) dan a conocer la circulación vitelina en el embrión de Menidia.

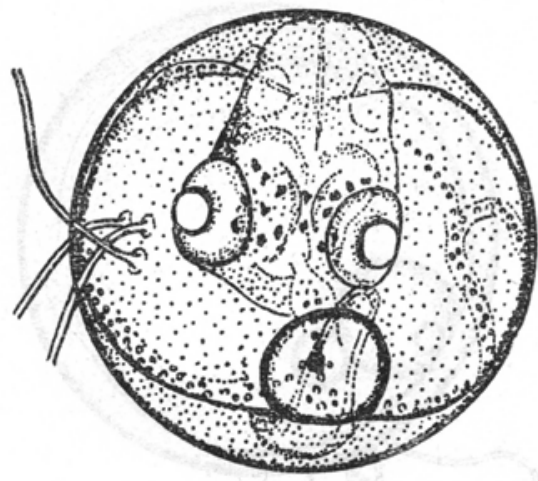

Figura 5. - El embrión tiene cápsulas 6pticas incoloras y rodea totalmente el vitelo. El corazón anterior pulsa y la circulación vitelina es activa. En Eslopsarum bartoni bartoni según F. de Buen 1940. X 43.

Para el cultivo del Pescado Blanco y del Charal en la Estación Limnológica de Pátzcuaro, se disponía de tres tipos de estanques: de cría los más pequeños, para formas larvarias los medianos, y para adultos los de mayor amplitud (fig. 14).

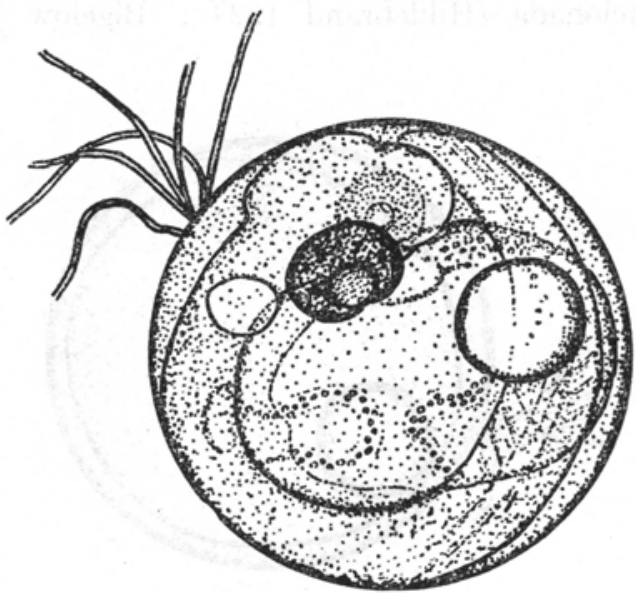

Figura 6 - El embrión de Eslopsarum bartoni bartoni rodea y rebasa el vitelo, pigmentándose las cápsulas ópticas. (Según F. de Buen 1940). $\mathrm{X} 43$. 
Sin insistir sobre la Aterinicultura intensiva realizada en México (F. de Buen 1944), intentaremos una noción general del tema refiriéndonos al Pejerrey de aguas dulces de Argentina, apelando a las informaciones procuradas por Ringuelet (1943) y Regalado y Masterrigo (1949).

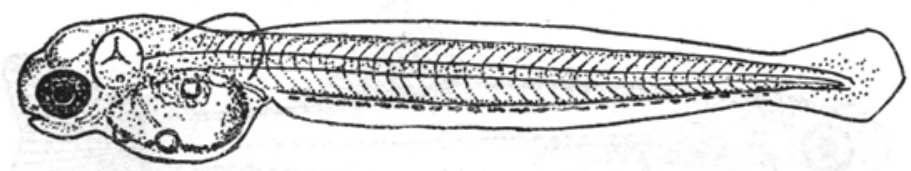

Figura 7. - Cría recién nacida de Eslopsarum bartoni bartoni según F. de Buen, 1940. X 17 .

El Pejerrey puede lograr su madurez al primer año de vida, contando en los ovarios de las hembras de esa edad de 2000 a 3000 óvulos. A los cuatro años la cifra se eleva a $45.000-50.000$.

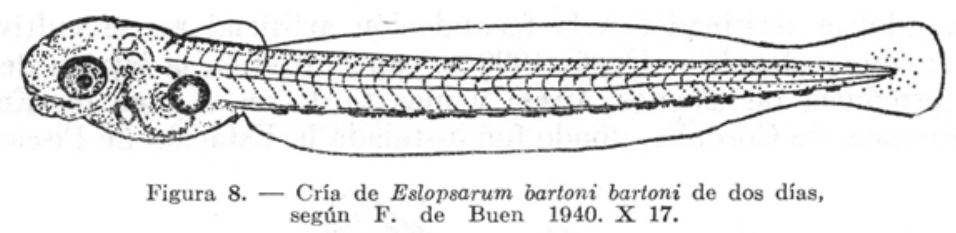

Se señalan en aguas de Argentina dos períodos de puesta, debidos al parecer a la existencia de dos grupos de individuos, formados acaso por clases de edad, por razas diferentes y aún pudiera ser por especies distintas. La época de puesta más intensa corresponde, con las lógicas variaciones, a los meses de septiembre, octubre y noviembre, no faltando reproductores desde julio a diciembre. La segunda temporada de reprodución, con puestas de menor volume, se limita a los meses de marzo y abril.

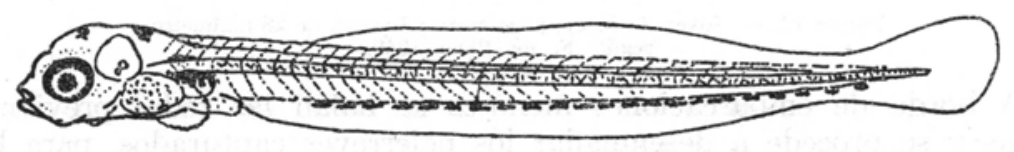

Figura 9. - Comienzos de la fase larvaria (prelarva) en Eslopsarum bartoni bartoni, según F. de Buen 1940. X 17.

Según Teague, en Devincenzi y Teague (1942), el Pejerrey del rio Uruguay, en proximidades de Paysandú, desova en los meses de agosto y septiembre en fondos pedregosos.

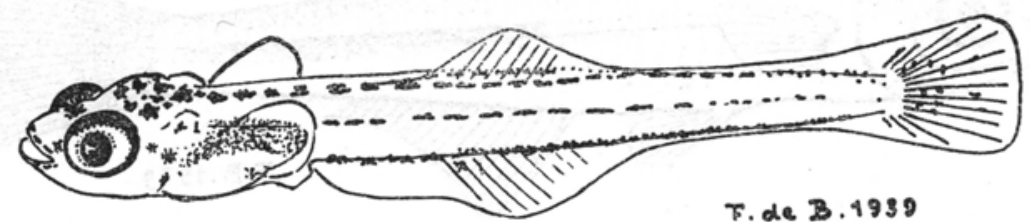

Figura 10. - Larva de Eslopsarum bartoni bartoni de unos cuatro meses de vida, según $\mathrm{F}$. de Buen 1940. $\mathrm{X} 10$. 
El ovulo del Pejerrey cultivado en Argentina mide de promedio 1,6 milímetros de diámetro, tiene color amarillo verdoso y posee 4 a 6 filamentos capsulares, que emplea para enredarse en la vegetación sumergida, en objetos de lo más diversos y aún sobre las piedras.

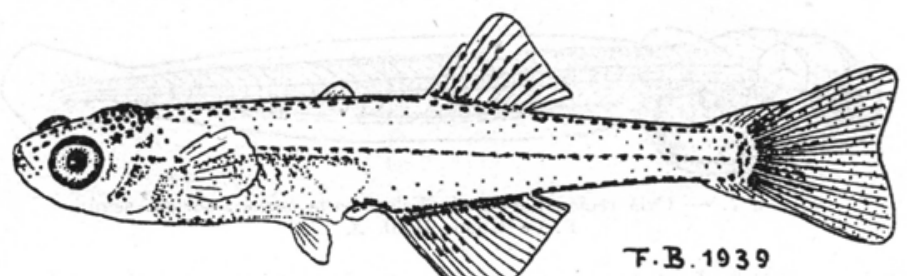

Figura 11. - Término de la fase larvaria (postlarva) en Eslopsarum bartoni bartoni, según F. de_Buen 1940. $\mathrm{X} 5$.

Los adultos destinados a la fecundación artificial no se cultivan, se pescan en zonas elegidas. Hasta 1939 se capturaron en la laguna de Chascomús (provincia de Buenos Aires) y más tarde en el lago de Embalse, de la provincia de Córdoba, donde fué instalada la Estación de Piscicultura.

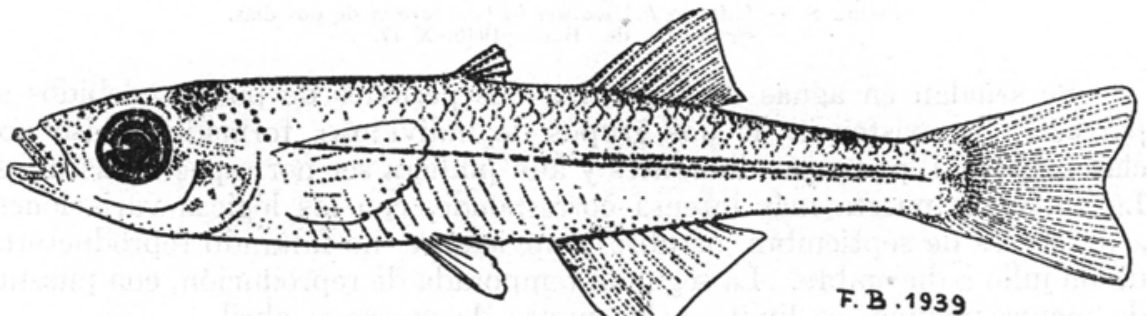

Figura 12. - Joven de Eslopsarum bartoni bartoni, de 28 milimetros, según F. de Buen 1940.

A bordo de embarcaciones menores se halan las redes previamente caladas y se procede a desenmallar los pejerreyes capturados, para hacer la fecundación artificial siguiendo métodos bien conocidos.

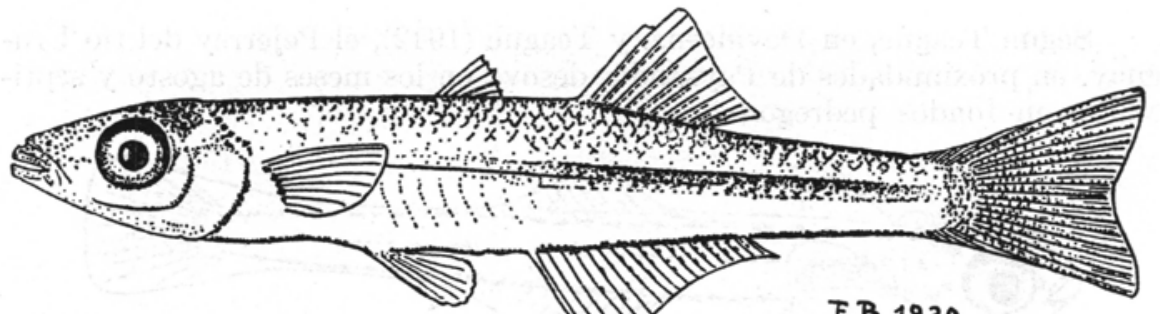

F.B.1939

Figura 13. - Joven Chirostoma grandocule de 45 milimetros de longitud y unos seis meses de edad, según F. de Buen 1940. 
En el laboratorio o Estación se lleva a cabo :
A. Limpieza.
B. Separación.
C. Nueva limpieza.
D. Recuento.
E. Incubación.

Transladados los óvulos fecundados al centro de incubación se someten a la acción de suave corriente de agua, que los limpia y dá turgescencia, con duración de una o dos horas.

Dentro de un recipiente y a golpe de tijera se separan los huevos de la maraña de filamentos capsulares, procediendo a la cuidadosa limpieza, que puede completarse por decantaciones sucesivas y aún por cernido, separando cuanto cuerpo extraño se entremezclara.

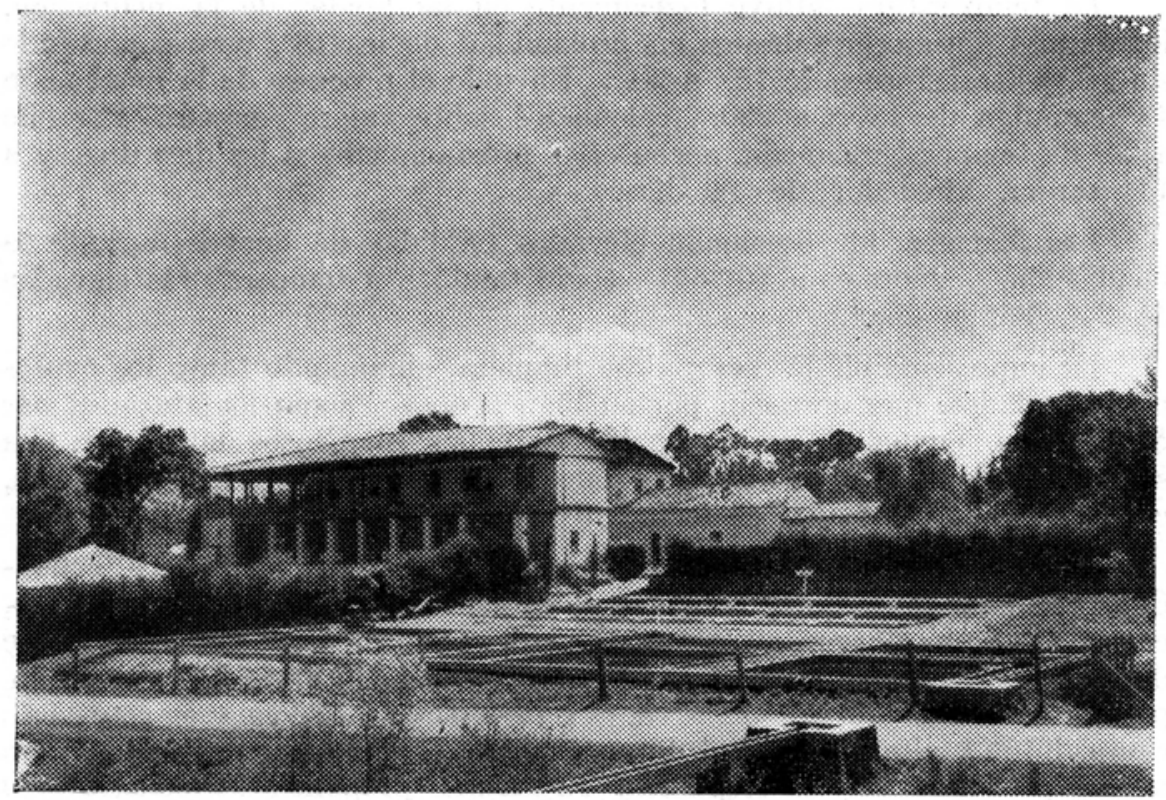

Figura 14. - La Estación Limnológica de Pátzcuaro, México y los estanques de cultivo. Al fondo estanques de mediano y pequeño volumen.

La práctica ha permitido saber que aproximadamente caben 200 huevos en un centímetro cúbico. A base de esa cifra se determina el número dejándolos caer dentro de una probeta graduada.

La incubación se lleva a cabo dentro de copas llenas de agua, que circula haciendola llegar por el fondo, mediante un tubo de vidrio, y dándola salida 
por un pico de la parte alta de la copa. De esa forma la masa de huevos se agita bajo el impulso de la corriente ascendente y se dispone del necesario oxígenio disuelto.

El agua empleada en la incubación de los Pejerreyes no debe tener exceso de sales y poseer abundante oxígenio disuelto, con ausencia de materia orgánica que lo consuma. Las aguas limpias o excepcionalmente filtradas, no deben llevar consigo cantidad de bacterias, que por sus fermentaciones pueden crear un medio asfixiante y aún ocasionar la destrucción de los huevos.

Los frascos empleados en Argentina para la incubación tienen 44 centímetros de altura, su fondo es regularmente cóncavo y sus contornos redondeados, evitando la existencia de peligrosos rincones de dificil limpieza ; su diámetro máximo mide 12 centímetros. Aproximádamente pueden incubarse por fraseo 40.000 a 45.000 huevos y se calcula el consumo de agua por hora en 95 litros al comenzar los trabajos y en 110 litros a su término.

La temperatura influye lógicamente en la rapidez de la incubación, lográndose óptimos resultados en proximidad de los $18^{\circ}$, pero soportando sin graves transtornos de $15 .^{\circ}$ a $20 .^{\circ}$. En todo el processo de la incubación se acumulan de $180 .^{\circ}$ a $220 .^{\circ}$, calculados sobre valores medios. Por ello a $20^{\circ}$ de temperatura media nacen crías próximamente a los diez dias, y a $14^{\circ}$ tardan alrededor de 14 días.

Las águas a $14^{\circ}$ ocasionan elevadas pérdidas de huevos durante la incubación, y enormes a $10^{\circ}-11^{\circ}$, como también a temperaturas elevadas de $24^{\circ}, 25^{\circ}$ y $26^{\circ}$.

Es imprescindible la escrupulosa limpieza, eliminando tanto los óvulos no fecundados, que destacan por su blanco opaco, como los atacados por Saprolegnia, envueltos por un halo de tenues filamentos miceliares. La separación de los huevos muertos puede hacerse por simple decantación, cuidando de desinfectar el recipiente que los contenía.

Al nacer las crías la corriente mantenida dentro de los frascos incubadores las empuja, y conduce a uno o varios recipientes puestos al efecto, cuyo desagüe ha de cerrarse con malla suficiente fina para evitar el escape de los muy menudos Pejerreyes. El momento de la absorción del vitelo, paso de la fase de cría a la de larva, es crítico para la especie, y en cautiverio causa de muy alta mortandad de no procurar alimentación adecuada y un medio propicio. En la República Argentina proponen la construcción de estanques de 15 a 16 metros de largo, por 3 a 5 de anchura, y profundidad media de 1,20 a 2,20 metros, inclinando el fondo para dar mayor espesor a la capa de agua en la zona de desagüe.

En México logramos éxitos en la Piscicultura intensiva del Pescado Blanco y el Charal en las primeras fases de su vida libre, poblando los estanques de vegetación sumergida, que además de proporcionar oxígeno abumdante en horas de insolación, procuraban la menuda fauna necesaria para alimentar crías y larvas. Las formas larvarias más crecidas o postlarvarias recibían abundante ración de Cladóceros, previamente cultivados 
en estanques poco profundos, mantenidos en penumbra, y de aguas muy cargadas de materia orgánica, que suministraba un lecho de estiércol fuertemente oreado.

Los autores argentinos aconsejan la alimentación lograda en infusiones de hojas de lechuga y cáscaras de banana, abonadas con nitratos y fosfatos, y materia orgánica procedente de estiércol, con raciones complementarias de pulpa de hígado. A las formas más crecidas se las podría alimentar con Cladóceros, Anguilula, Tubifex, residuos frescos de Crustáceos Decápodos de agua dulce o Gasterópodos y también con productos secos obtenidos con Daphnias, Crustáceos Decápodos, Acestrorhynchus reducidos a harina, y otros.

De retener los reproductores son necesarios muy amplios estanques de agua dulce o muy débilmente salobre, a temperatura cercana a los $18^{\circ}$, tolerando bien de $10^{\circ}$ a $20^{\circ}$.

Las experiencias llevadas a cabo en Argentina y México me permiten señalar ciertas posibilidades de mejoramiento de la Aterinicultura actual. Sería de interés comparar los resultados obtenidos con la fecundación artificial y con huevos depositados naturalmente sobre colectores dispuestos al efecto. Nuestras exploraciones en México permiten afirmar que el Pescado Blanco selecciona las áreas de puesta, zonas donde sería posible fondear artefactos para que las hembras enmarañaran la puesta, luego fecundada por los machos.

En el lago de Pátzcuaro las crías, larvas y jóvenes pululan entre la vegetación sublitoral, perseguidos y devorados por numerosos enemigos. En amplios estanques de agua circulante, con población de plantas sumergidas podrían repetirse las condiciones naturales y la ausencia de animales devoradores evitaría de paso la merma intensiva en libertad.

Antes de poblar una masa de agua que por su volumen y otras características tenga condiciones para la vida y prosperidad de los Pejerreyes, sería aconsejable asegurarse de las posibilidades de la zona sublitoral y en casos desfavorables acondicionar refugios para las primeras fases del desarrolo de la especie.

Los adultos persiguen presas, son voraces, y es necesario proporcionárselas en cantidades suficientes para obtener el progresivo aumento de la población de Pejerreyes. Ello podría lograrse cultivando previamente una o varias especies que prosperaran con rapidez y abundancia y sirvieran de alimento a los Pejerreyes.

La falta de alimentos apropiados y suficientes es causa de desarrollo precario y aún anormal en los peces, llegando a falta de otras presas a practicar el canibalismo. También la selección de los reproductores es imprescindible para lograr generaciones abundantes y fuertes. Ringuelet (1942) nos describe un caso típico, refiriéndose al que llama Odontesthes bonariensis procedente del embalse de Rio III, en Córdoba, y sembrado artificialmente en el embalse de Anzulón. Son ejemplares raquíticos, caníbales o accidentalmente devoradores de vegetales. Su contenido estomacal en un 98.57 por ciento de los casos estaba formado por restos de Pejerreyes. 


\section{BIOMETRIA EN LOS PEJERREYES}

$\mathrm{Al}$ describir las especies hemos cuidado de observar normas invariables, con tendencia a facilitar las comparaciones. Cada mitad del cuerpo o "flanco" se ha considerado dividido en una parte dorsal o "lomo" y otra ventral o "vientre", separados en los Aterínidos por una "banda" plateada, que naciendo en la axila de la pectoral, se extiende a todo lo largo del pez, hasta terminar próximamente sobre la última vértebra (fig. 15).

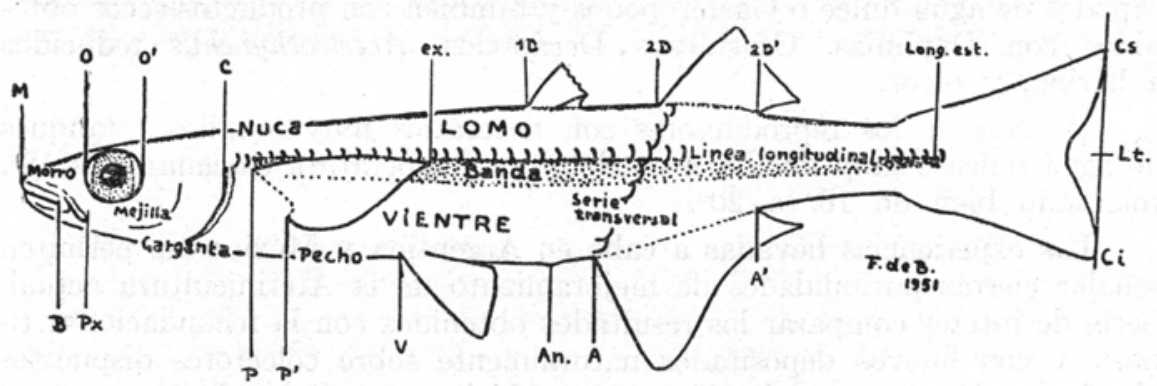

Figura 15. - Areas en el cuerpo de los Atherinidae y puntos base de medidas.

Hemos tomado dos medidas máximas. Una de ellas la "longitud total" desde el punto más avanzado de la cabeza, sobre la extremidad del morro y aún en el bordo labial si fuera más saliente, hasta el término de la aleta caudal, que en estas especies queda limitado en la intersección de dos rectas imaginarias, la que prolonga la línea media de los flancos y la transversal que une los dos puntos más salientes de los lóbulos de la caudal (fig. 15, Lt). Se entiende que la aleta caudal debe estar abierta, normalmente extendida y sin forzar. La otra medida máxima es la "longitud estándar" o longitud total sin la caudal de los antigos autores; comienza como la longitud total en la extremidad del morro y acaba en la última vértebra (fig. 15, long. est.) o prácticamente al finalizar la masa muscular, facilmente de limitar en un trazo vertical donde disminuye bruscamente el grosor y bien aparente observando el pez por encima.

En la región cefálica, aparte de la longitud, se toman medidas para delimitar en varias direcciones la posición de los ojos y el tamaño o extensión de la boca. La longitud de la cabeza o simplemente "cabeza" se mide lateralmente, desde el extremo del morro hasta el borde libre del opérculo (figura 15, M a C), no teniendo en cuenta la membrana branquióstega, que en la casi totalidad de los Pejerreyes bordea y sobresale. Ojo, diámetro ocular u "órbita" se mide sobre el diámetro horizontal (Fig. 15, O a O'), sea directamente o de haber párpados adiposos que cubran parte del ojo, por transparencia. La menor distancia, entre el ojo y el morro es el espacio preorbitario o simplemente "preórbita" (fig. 15, M a O), el ojo y el borde libre del opéreulo, descartada la membrana branquióstega, el espacio postorbitario o "postórbita" (fig. 15, O' a C), y dorsalmente entre los ojos la "interórbita". 
Al medir la boca debe mantenerse cerrada, calculando su terminación comparándola con la línea vertical o altura, trazada a partir del borde ocular anterior, punto el más avanzado de los ojos. Desde el extremo del morro hasta donde llega, lateralmente, la abertura bucal le damos el nombre de "hendedura bucal" (fig. 15, M a B) y medimos el premaxilar en su extremidad saliente y más baja (fig. 15, Px).

Mencionando el origen de las aletas nos referimos al pié del primer radio o radio más avanzado (fig. 15 , puntos $1 \mathrm{D}, 2 \mathrm{D}, \mathrm{P}, \mathrm{V}$ y A) y el término de la aleta justo en la base del radio último (fig. 15, puntos 2 D', P' y $\mathrm{A}^{\prime}$ ), que deben apreciarse levantando la aleta de encontrarse caida.

Del origen al término se mide la base de las aletas. En los Pejerreyes nos referimos a la base de las pectorales (fig. 15, entre P y P'), de la segunda dorsal (entre 2 D y 2 D') y de la anal (entre A y A').

Partiendo de la extremidad del morro y terminando en el origen de las aletas, puede medirse la distancia "predorsal" (fig. 15, de M a $1 \mathrm{D}$ ), preventral o preanal. El espacio que media entre los orígenes de las dorsales (fig. 15, entre $1 \mathrm{D}$ y $2 \mathrm{D}$ ) la llamamos "entre dorsales".

En ciertos casos los lóbulos de la aleta caudal no son simétricos en los Pejerreyes. Para establecer diferencias medimos a partir de la última vértebra o término de la longitud estándar y el ápice de cada uno de los lóbulos de la caudal (fig. 15, entre long. est. y Cs y long. est. y $\mathrm{Ci}$ ).

Se cuentan las escamas a lo largo de la línea longitudinal y en serie transversal. La "línea longitudinal" que en los Aterínidos no coineide con la línea lateral formada por escamas perforadas por tubos mucosos, se inicia justo encima del comienzo de la hendidura branquial y sigue a todo lo largo del cuerpo paralelamente a la banda pigmentada de los flancos, que puede invadir en parte, hasta terminar en proximidad de la última vértebra. Deben contarse dos a tres pequeñas escamas del comienzo de la línea longitudinal y no tener en cuenta aquellas de pequeño tamaño que invaden el limbo de la caudal.

Al contar las escamas seriadas en línea longitudinal se observarán las series transversales sucesivas, resolviendo las dudas que pudieran presentarse, y aún en casos extraordinarios tener en cuenta el espacio ocupado por una escama perdida. Solo como recurso extremo, y haciéndolo constar, puede apelarse a los estuchos dérmicos para conocer aproximadamente el número de escamas en línea longitudinal.

Hemos elegido como "serie transversal" la que comienza en el primero o segundo radios de la anal, dirigiéndose inclinada hacia la base de la segunda dorsal (fig. 15). En ningún caso contamos en serie transversal dos porciones separadas, una por encima y otra por bajo de la línea lateral, teniendo en cuenta que esta última es fráncamente irregular en nuestros Pejerreyes.

Las escamas muestran variaciones dignas de tenerse en cuenta al describir las especies, por ello y para proporcionar caracteres comparativos apreciamos partes diferentes. Nos referimos, salvo indicación en contrario, 
a escamas arrancadas en mitad del lomo, próximamente debajo de la primera dorsal.

Esas escamas están en parte cubiertas por la piel, y en otra parte quedan libres. La superficie oculta o "zona embutida" (fig. 16) tiene delicadas "estrias" paralelas y muy proximas entre sí, que faltan en la superficie libre o "zona libre" generalmente lisa. En ejemplares crecidos pueden apreciarse discontinuidades concéntricas, que responden al paso de los inviernos con retraso en el aumento de talla; son las que conocemos por "líneas de crecimiento".

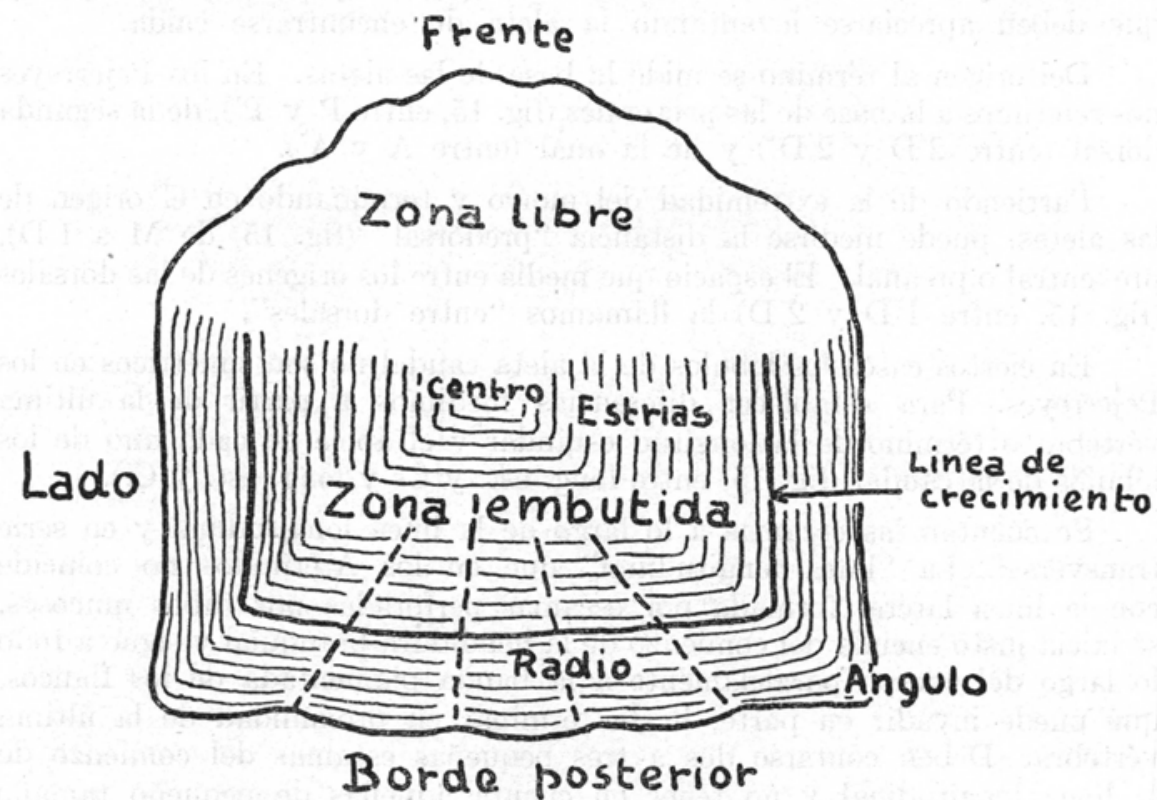

Figura 16. - Elementos descriptivos de una escama del lomo de un Pejerrey.

En la zona libre, el borde o "frente" (fig. 16) presenta en las diferentes especies las siguientes variaciones principales:

-- "Frente liso", sin irregularidad alguna.

- "Frente irregular", con el borde no totalmente recto, presentando discontinuidades de poca cuantía y escasa profundidad, distribuidas irregularmente.

- "Frente ondulado", presentando modestos salientes redondeados y de distribución regular.

- "Frente mamelonado", con salientes redondeados muy importantes, con tendencia a ser digitiformes, sin lograrlo.

- "Frente dentado", los salientes del borde tienen extremidad aguda, repartiendose con regularidad "regularmente dentado" o sin ella "irregularmente dentado". 
La zona embutida de la escama podemos limitarla en los "lados" y el "borde posterior". Del "centro", rodeado por las primeras estrias dispuestas en semicírculo o círculo completo, se dirigen hacia el borde posterior, cuando los hay, los "radios", trazos abiertos en abanico que llegan al borde posterior y son causa de su ondulación. Lados y borde se ponen en contacto en los "ángulos" (fig. 16).

Con extremo cuidado, especialmente al tratarse de ejemplares de Museo o largo tiempo mantenidos en líquidos conservadores, deben desarticularse el premaxilar y mandíbula para proceder a su estudio, separando las muchas adherencias que los ligan. En ambos huesos podemos distinguir la rama principal o "cuerpo" que soporta los dientes, implantados en la "banda dentaria”.

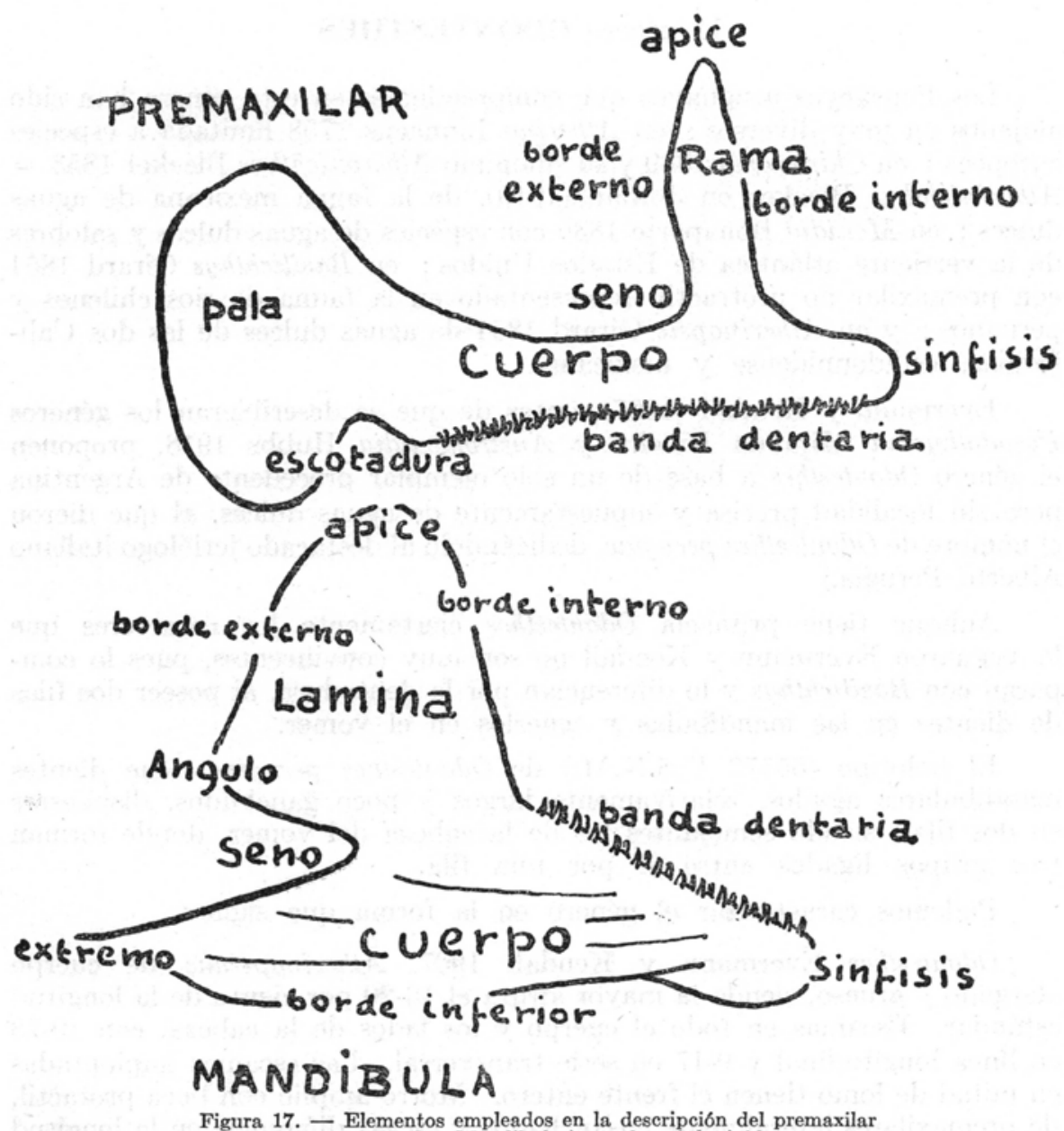

Figura 17. - Elementos empleados en la descripcion del premaxilar y la mandíbula (Mandibular) en los Atherinidae. 
En el premaxilar, el cuerpo se ensancha hacia fuera en "pala", que puede tener una muesca o seno, la "escotadura", al terminar la banda dentaria. Surge por encima del cuerpo un processo o "rama", rematado en "ápice" y de acuerdo con la posición del premaxilar en el pez con "borde interno" y "borde externo" ; este último forma con el cuerpo un entrante o "seno".

La mandíbula, que lleva por encima y delante la banda dentaria, muestra variaciones en su "borde inferior", estrechado hacia su límite externo sobre el "extremo". El processo destacado por encima del cuerpo es amplio "lámina", pudiendo distinguirse él "ápice" y bordes externo y interno, así como un seno que forma "ángulo" con el borde externo (fig. 17).

\section{El género ODONTESTHES}

Los Pejerreyes uruguayos que comprendemos en este género han sido alojados en muy diversos : en Atherina Linnaeus 1758 limitada a especies europeas ; en Chirostoma 1839 y su sinónimo Atheronichthys Bleeker $1853=$ Atherinichthys Bleeker en Jordan (1919), de la fauna mexicana de aguas dulces ; en Menidia Bonaparte 1836 con especies de aguas dulces y salobres de la vertiente atlántica de Estados Unidos; en Basilichthys Girard 1854 con premaxilar no protractil, representado en la fauna de rios chilenos y peruanos; y en Atherinopsis Girard 1854 de aguas dulces de las dos Californias, estadounidense y mexicana.

Evermann y Kendall (1907), antes de que se describieran los géneros Pseudothyrina Miranda Ribeiro y Austromenidia Hubbs 1918, proponen el género Odontesthes a base de un solo ejemplar procedente de Argentina pero sin localidad precisa y supuestamente de aguas dulces, al que dieron el nombre de Odontesthes perugiae, dedicándolo al destacado ictiólogo italiano Alberto Perugia.

Aunque tiene primacía Odontesthes ciertamente los caracteres que le asignaron Evermann y Kendall no son muy convincentes, pues lo comparan con Basilichthys y lo diferencian por la dentadura, al poseer dos filas de dientes en las mandíbulas y tenerlos en el vomer.

El holotipo (55572 U.S.N.M.) de Odontesthes perugiae tiene dientes mandibulares agudos, relativamente largos y poco ganchudos, dispuestos en dos filas, siendo semejantes los de la cabeza del vomer, donde forman tres grupos ligados entre si por una fila.

Podemos caracterizar el género en la forma que sigue:

Odontesthes Evermann y Kendall 1907. Atherinopsinae de cuerpo alargado y grueso, siendo la mayor altura el 13-20 por ciento de la longitud estándar. Escamas en todo el cuerpo y los lados de la cabeza, con 49-78 en línea longitudinal y 9-17 en serie transversal. Las escamas implantadas en mitad de lomo tienen el frente entero. Morro amplio con boca protactil, de premaxilares lateralmente ensanchados y escasa diferencia en la longitud 
de las mandíbulas. Dientes pequeños y aún extremadamente pequeños (en $O$. perugiae de boca amplia y mandíbulas agudas, algo más fuertes). Origen de la primera dorsal en proximidad de la vertical trazada desde el orificio anal, y éste separado del primer radio de la aleta anal. Las pectorales apoyadas no llegan a las ventrales o rebasan poco su origen. La segunda dorsal francamente retrasada, comenzando proximamente por encima de la mitad de la base de la anal. Caudal con ramas de ápice agudo próximamente iguales en longitud. De 47-49 vértebras. Con 22-25 branquispinas en la rama baja del primer arco branquial. El premaxilar posee rama bien desarrollada y pala amplia. La mandíbula (dentario) destacan su lámina. Genotipo: Odontesthes perugiae Evermann y Kendall, 1907.

Podemos separar claramente dos grupos subgenéricos, incluyendo en cada uno de ellos las siguientes especies de la fauna uruguaya:

Tupa De Buen, nov. subg. De 77-78 escamas en línea longitudinal, y 16-17 en serie transversal. Las escamas de mitad del lomo con numerosos radios. Cuerpo alto, $18.3-18.6 \%$ de la longitud estándar y grosor $12.6-14.7 \%$ de la longitud estándar (tipo Atherinichthys platensis Berg 1895).

Ojos de poco diámetro, $19.8-22.6 \%$ de la cabeza. Muy pequena primera dorsal, con su origen distanciado del morro el $59-59.3 \%$ de la longitud

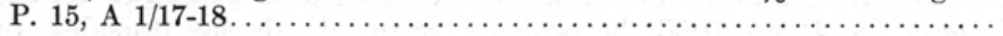

Odontesthes platensis (Berg).

Subgénero Odontesthes Evermann y Kendall, 1907. De 50-61 escamas en línea longitudinal y 9-13 en serie transversal. Las escamas de mitad del lomo sin radios (Los grandes ejemplares de $O$. bonariensis los poseen incompletos).

1. Cuerpo largo, de poca altura (13.8-16.3\% de longitud estándar). Estrecho espacio interorbitario $(28-33.5 \%$ de la cabeza) y postorbitario $(37-44.5 \%$ de la cabeza).

50-54 escamas en línea longitudinal y 9-10 en serie transversal, sin escamas sobre el limbo de la segunda dorsal y anal. Distancia predorsal 60.5$63 \%$ de la longitud estándar. Radio más largo de la segunda dorsal 34.7-42 por ciento de la cabeza. Branquispinas $5+20=25$. Embudo hemal con hemapófisis poco dilatada

Odontesthes orientalis De Buen.

- Cuerpo más corto, altura el $16-20 \%$ de la longitud estándar y el grosor $11-14 \%$ de la longitud estándar. Espacio postorbitario $42-50.5 \%$ de la

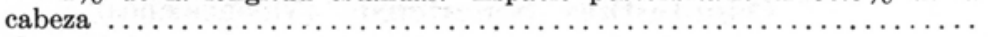

2. Las pectorales apoyadas en los flancos rebasan la posición del origen de las ventrales más que medio diámetro ocular. Morro romo.

Máxima altura del cuerpo 17 por ciento y mayor grosor 12.6 de la longitud estándar. Espacio interorbitario 38.6 y postorbitario 46.2 por ciento de la cabeza. 61 escamas en línea longitudinal y 12 en serie transversal. Pequeñas escamas sobre el limbo de la segunda dorsal y anal. Distancia predorsal 57.3 por ciento de la longitud estándar. Radio más largo de

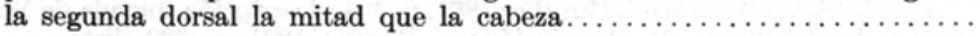


- Las aletas pectorales apoyadas en los flancos no llegan al origen de las ventrales. Morro agudo. Máxima altura del cuerpo 16-20 por ciento y mayor grosor 11-14, de la longitud estándar. Espacio interorbitario 29.3-42 y postorbitario $42-50.5$, por ciento de la cabeza. 53-60 escamas en línea longitudinal y 9-13 en serie transversal. Radio más largo de la segunda dorsal $43.5-54.5$ por ciento de la cabeza...................

3. Con $7+25=32$ branquispinas en el primer arco branquial. $24+23=$ $=47$ vértebras. Morro agudo $\mathrm{y}$ origen de la primera dorsal separado del extremo del morro como el 59.4-62.5 por ciento de la longitud estándar

Odontesthes bonariensis (Valenciennes)

- Con $6+16=22$ branquispinas en el primer arco branquial. $26+23=$ = 49 vértebras. Morro avanzado en bisera y origen de la primera dorsal separado del extremo del morro como el 56-59 por ciento de la longitud estándar.

Odontesthes humensis De Buen

Dentro del subgénero Odontesthes seguramente deberán alojarse otras especies de la fauna chilena, argentina y del Sur del Brasil.

El genotipo, Odontesthes perugiae Evermann y Kendall 1907, ha sido nuevamente encontrado por Marrero (1950) en las aguas dulces de Argentina, asignándole injustificadamente el nuevo nombre de Basilichthys microather Marrero, pero señalado uno de los caracteres que lo distingue del Odontesthes orientalis De Buen 1950, la posición retrasada de las dorsales, quedando el origen de la primera por detrás de la altura del orificio anal.

A base de la descripción de Pseudothyrina iheringi Miranda Ribeiro (1915, pp. 11 y 12) y la revisión llevada a cabo por el prof. Paulo de Miranda Ribeiro, dada a conocer en el trabajo de Schultz (1948, p. 46, fig. 8), parece lo más lógico darle el nombre de Odontesthes iheringi (Miranda Ribeiro), y aproximarla a Odontesthes bonariensis (Valenciennes), teniendo en cuenta que ambas especies poseen escamas en el cuerpo con frente irregular y la caudal con lóbulos desiguales.

Acaso pudiera mantenerse como subgénero Patagonina Eigenmann 1927, para alojar Menidia hatcheri Eigenmann (1909 a, p. 281, lám. XXXVII, fig. 4), aproximándose al subgénero Tupa De Buen por el número de escamas (68-70) en serie longitudinal, pero con otras características diferenciales.

\section{Subgénero ODONTESTHES Evermann y Kendall}

\section{Odontesthes bonariensis (Valenciennes)}

Atherina bonariensis Valenciennes, en Cuvier y Valenciennes, X, 1835, p. 348 (primera descripción, anatomia, alimentación).

Atherina argentinensis Valenciennes, en Cuvier y Valenciennes, X, 1835, p. 350 (primera descripción).

Atherina lichtensteinii Valencionnes, en Cuvier y Valenciennes, X, 1835, p. 353 (primera descripción).

Atherinichthys bonariensis Günther 1861, p. 404 (descripción tomada de V alenciennes)

- Steindachner 1867, p. 31 (descripción) - Perugia 1891, p. 620 (lista) - Berg 1895,

p. 30 (sinonimia, distribución). En parte. 
Chirostoma bonariensis Eigenmann y Eigenmann 1892, p.66 (lista, localidades). Chirostoma argentinensis Eigenmann y Eigenmann 1892, p. 66 (lista, localidades). Atherinichthys argentinensis Berg 1895, p. 29 (bibliografia, distribución). En parte. Menidia bonariensis Thompson 1916, p. 403 (localidades), p. 406 (corta descripción) - Devincenzi 1924, p. 204 (medidas, número de radios y escamas) - Devincenzi y Barattini 1928, lám. XX (figura defectuosa e incompleta).

Atherinopsis bonariensis Eigenmann 1909 b, p. 466 (lista).

Austromenidia bonariensis Jordan y Hubbs 1919, p. 65 (lista, sinonimia, distribución geográfica).

Menidia argentinensis Devincenzi 1924, p. 205 (lista) - Devincenzi y Barattini 1928 lám. XX (figura defectuosa e incompleta).

Odontesthes perugiai Devincenzi 1924, p. 206, lám. XIV (medidas, número de escamas y radios) - Devincenzi y Barattini 1928, lám. XX (figura deficiente e incompleta).

Odontesthes argentinensis Jordan y Hubbs 1919, p. 64 (lista, sinonimia, distribución) - Pozzi 1945, p. 247 (localidades) - De Buen 1950 a, p. 100 (lista, localidades, sinonimia).

Basilichthys bonariensis Lahille 1929, p. 299 (descripciones), p. 341 (sinonimia), diagramas 1, 4-7 - Pozzi 1945, p. 248 (localidades), p. 265 (lista), p. 276 (distribución), p. 281 (nombre vulgar) - Evermann y Kendall 1907, p. 95 (medidas) - Marrero 1950, p. 58, fig. (descripción, distribución).

Basilichthys bonariensis var. argentinensis Lahille 1929, p. 310 (descripción), p. 342 (sinonimia, distribución), diagrama 8 - Lahille 1930, p. 98, fig. 12 (descripción) Pozzi y Bordalé 1935, p. 19 (lista) y p. 40. diagrama 3 .

Basilichthys bonariensis var. chascomunensis Lahille 1929, p. 341 (características),

Basilichthys bonariensis var. puntanus Lahille 1929, p. 341 (caracteres, distribución), diagrama 2.

Basilichthys bonariensis vàr. propinquus Lahille 1929, p. 320 (mención), p. 343 (distribución), diagrama 12 - Pozzi y Bordalé 1935, pp. 19 y 40 (lista).

Menidia (Basilichthys) bonariensis Devincenzi, en Devincenzi y Teague 1942, p. 83, fig. (caracteres diferenciales y observaciones).

Odontesthes bonariensis De Buen 1950 a, p. 100 (lista, localidades, sinonimia).

Basilichthys argentinensis Marrero 1950, p. 83, fig. (descripción, distribución).

\section{Incertae sedis}

Atherina lessoni Valenciennes, en Cuvier y Valenciennes, X. 1835, p. 350 (descripción sobre un dibujo).

? Atherina argentinensis Jenyns 1842, p. 77 (descripción).

Atherinichthys argentinensis Günther 1861. III, p. 405 (descripción basada en Jenyns) - Perugia 1891, p. 620 (lista).

Atherinichthys laticlavia Perugia 1891, p. 620 (lista) - Berg 1895, p. 29 (sinonimia, distribución).

Atherinichthys vomerina Perugia 1891, p. 261 (lista) - Berg 1895, p. 26 (sinonimia, algunos caracteres, distribución).

Pseudothyrina iheringi A. de Miranda Ribeiro 1918, p. 763 (lista) - Pozzi 1945, p. 247 (localidades).

Atherina regia Larrañaga 1923, p. 388 - Larrañaga, en Devincenzi 1925, p. 315.

Menidia regia Devincenzi 1924, p. 203 (lista) - Devincenzi y Barattini 1928, lám. $\mathrm{XX}$ (deficiente).

Basilichthys bonariensis var. cuyanus Lahille 1929, p. 323 (descripciones), p. 343 (caracteres, distribución), diagrama 15. 
Odontesthes perugiae Fowler 1943, p. 326 (localidades) - Pozzi 1945, p. 247 (localidades) - De Buen 1950, p. 99 (incluido con dudas en la fauna uruguaya).

Odontesthes bonariensis Lourenço Gomez 1947, p. 36 (lista).

Odontesthes iheringi De Buen 1950, p. 99 (lista).

Localidad Tipo - Buenos Aires.

Distribucion - Costas del Uruguay (desde Punta del Este a Nueva Palmira) y de la Argentina (de Buenos Aires a Bahia Blanca).

MATERIAL - Ejemplares :

- Uno de 339 milímetros de longitud total y 280 milímetros de longitud estándar (V/T/ 1002 M.H.N.M.). Rio de la Plata (Montevideo). 19 julio 1923 (Pejerrey).

- Uno de 193 milímetros de longitud total y 160 de longitud estándar (V/T/ 1003 M.H.N.M.). Rio de la Plata (Montevideo). 1920. Pejerrey.

- Uno de 111 milímetros de longitud total y 91.5 de longitud estándar (V/T/1004 M.H.N.M.). Rio de la Plata (Montevideo). Pejerrey.

- Uno de 465 milímetros de longitud estándar (V/T/ 1037 M.H.N.M.). Rio de la Plata.

- Uno de 197 milímetros de longitud total (V/T/ 1008 M.H.N.M.). Rio Uruguay en Nueva Palmira. Coletor F. de Buen.

- Seis de 124 a 142 milímetros de longitud total (V/T/1070-1075). Pejerrey común. Julio 1945. Montevideo.

DEsCRIPCION - Cuerpo alto, grueso y relativamente corto, con marcada curva ventral (figura 18). La mayor altura, que mide el 16 - 20 por ciento de la longitud estándar, se extiende por detrás de las pectorales apoyadas, hasta el ano. El máximo grosor, 11 - 14 por ciento de la longitud estándar, se encuentra desde la mitad de las pectorales hasta el origen de las ventrales. El pedúnculo caudal alto y corto, mide de altura mínima el 27.7-46 por ciento de la cabeza, y su longitud el 15.1 - 18.9 por ciento de la longitud estándar.

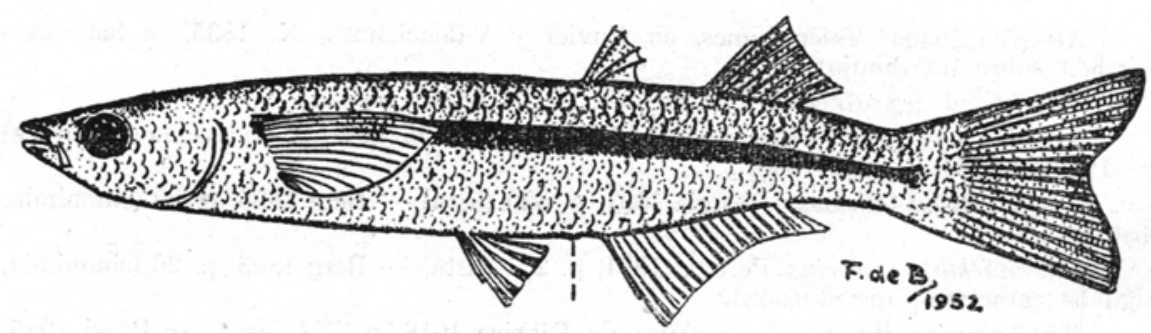

Figura 18. - Odontesthes bonariensis (Valenciennes) de 193 milimetros de longitud total. Montevideo.

Cabeza alargada de extremidad roma, ligéramente convexa por arriba, señalando modesta foseta longitudinal cerca de los ojos, y marcando bien el paso a la zona nucal. Mide la cabeza el 21.2 - 27.5 por ciento de la longi- 
tud estándar. La boca no es excesivamente protráctil, tiene la hendedura caida y curva, y la prolongación lateral del maxilar queda en buena parte oculta bajo la piel, con la boca cerrada. El borde anterior del maxilar tiene ligera escotadura y por encima una cresta redondeada, terminando en espátula roma.

La distancia del nivel del borde anterior del ojo a la terminación de la hendedura bucal es como un diámetro ocular. El maxilar, con boca cerrada, se aparta de la vertical trazada desde el borde más avanzado del ojo como la mitad, o algo menos, del diámetro ocular.

Los orificios nasales anteriores se levantan en tubo, con el borde posterior realzado, y los orificios posteriores son ojales cortados en incisión transversal.

La órbita, el 12.7 - 31.3 por ciento de la cabeza, tiene párpados adiposos, que cubren en parte los bordes anterior y posterior del ojo. De la cabeza son por ciento : la preórbita el 33.5 - 38, la postórbita el 42 - 50.5 y la interórbita el $29.3-42$.

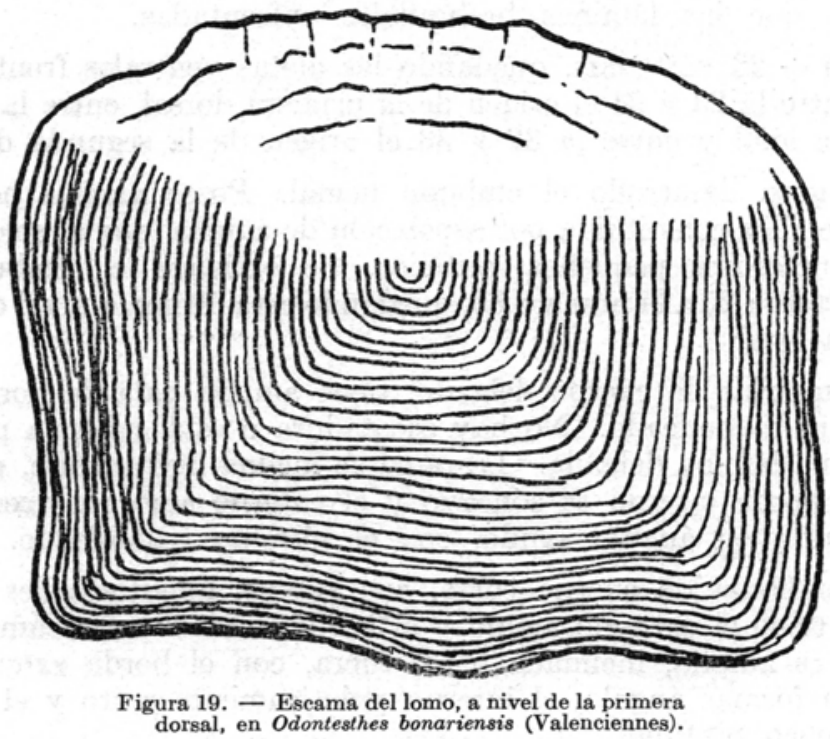

Las escamas cubren todo el cuerpo e invaden el limbo de la caudal. No las hay en la base de la segunda dorsal y de la anal en los ejemplares más jóvenes, observando su presencia en los de mayor talla. El morro y el espacio preorbitario son desnudos. En el dorso de la cabeza avanzan hasta los orificios nasales, dejando a los lados sin escamas los bordes adiposos de los ojos. Hay tres series longitudinales de escamas debajo de los ojos.

La línea lateral doble y muy irregular. Uno de sus tramos, corto, está por encima de la banda pigmentada de los flancos, el otro sigue el borde ventral, remontando sus trazos hasta llegar al centro del pedúnculo caudal. 
En línea longitudinal se cuentan $53-60$ escamas y en serie transversal 9 - 13. Hay 8-10 series transversales desde los orígenes de la primera y segunda dorsales.

Las escamas del lomo son cuadrangulares (figura 19) con zona libre poco saliente y frente liso o con pequeñas irregularidades. La zona embutida está exenta de radios ; sus lados son casi rectos y el borde posterior posee una sola ondulación poco saliente; la separación entre las zonas libre y embutida no es precisa.

En las escamas del ejemplar de más talla se observan radios incompletos, que no llegan al borde posterior. En el mismo se descubren claramente cinco líneas invernales de crecimiento, que permiten calcular las siguientes longitudes estándar: primer invierno 114 milímetros, segundo 203 , tercero 293 , cuarto 362 , quinto 420 , y parte estival del sexto año, hasta el momento de la captura (22 junio 1921) 465 milímetros.

Sobresale la membrana branquióstega del borde opercular.

En dos ejemplares hay $7+25$ branquispinas en el primer areo branquial, más cortas que las láminas branquiales enfrentadas.

Con $24+23$ vértebras, quedando las aletas ventrales frente a la número 16, entre la 23 y 24 el origen de la primera dorsal, entre la 26 y 27 el origen de la anal y entre la 32 y 33 el origen de la segunda dorsal.

Tiene gran desarrollo el embudo hemal. Posee anchas hemapófisis, cada una de ellas constituida por asociación de agujas, que al soldarse entre sí dejan numerosos pequeños orificios. Se extiende el embudo hemal desde la vértebra 25 a la número 36 , quedando esta última a nivel del término de la aleta anal.

El premaxilar de cuerpo delgado, tiene amplia pala de borde externo saliente, pero redondeado. No hay escotadura o está cubierta por la existencia de una lámina delgada. La rama se inclina ligéramente, posee ápice romo y su borde interno es cóncavo y el externo algo convexo. Limitan el seno bordes en ángulo agudo, con el término redondeado.

La mandíbula de cuerpo corto, con crestas longitudinales muy pronunciadas, tiene el extremo agudo y el borde inferior prácticamente recto. La lámina es amplia, inclinada hacia fuera, con el borde externo apenas convexo sin formar ángulo, el interno prácticamente recto y el seno muy abierto y poco profundo.

Los dientes mandibulares son pequeños, ganchudos, agrupándose en tres o cuatro filas de distribución irregular. En el centro de ambas mandíbulas hay un espacio sin dientes.

$\mathrm{El}$ origen de la primera dorsal queda una escama por delante del orificio anal. La aleta pequeña, de poca altura, está sostenida por 4-5 radios, midiendo la distancia predorsal el 59.4-62.5 por ciento de la longitud estándar.

La segunda dorsal con 1/9-10 radios comienza a nivel de la mitad anterior de la anal, sobre su décimo radio blando, y termina antes que esa 
aleta, avanzando el espacio de una escama. La base mide el 36.3-42 por ciento de la cabeza y su radio más largo el $43.5-54.5$ por ciento.

Las pectorales apoyadas en los flancos no llegan al nivel de las ventrales, mediando como 2 a 3 series transversales. Miden de longitud las pectorales el 71 - 109 por ciento de la cabeza y su base el 21 - 33.5 de la misma. Cuentan con $14-15$ radios.

Las ventrales con $1 / 5$ radios, están muy cortamente unidas entre sí por una membrana y tienen de largo el 40.3 - 53.2 por ciento de la cabeza. El orificio anal se distancia de la aleta que le sigue como dos tercios o algo más del diámetro ocular.

Aleta anal con 1/17 - 20 radios, base el 64 - 104 por ciento de la cabeza, y el radio más largo el $39.5-59.2$ por ciento de la misma.

La caudal tiene lóbulos ligeramente desiguales. Desde el término de la longitud estándar hasta el ápice del lóbulo superior se mide el 100.9 - 115 por ciento de la cabeza, y hasta el lóbulo inferior el 100 - 100.3 por ciento.

Color de los ejemplares largamente conservados pálido amarillento, con la banda longitudinal ancha como una escama y el lomo suávemente punteado en el borde de los estuches dérmicos de las escamas. El espacio interorbitario es translúcido y están suávemente manchadas las pectorales, dorsales y el borde libre de la caudal.

Discusion - Valenciennes en Cuvier y Valenciennes (1835) describe diversas especies incluyéndolas en el género Atherina. Entre ellas cuatro especies que comentaremos, la primera $A$. bonariensis (1) con primacía sobre las restantes.

Atherina bonariensis remitida de Buenos Aires a Baillón, logra buenas tallas, midiendo el ejemplar tipo seis pulgadas. Es de cuerpo esbelto, con perfiles en curva suave (más rectilíneo que en Menidia según su autor). La cabeza de morro puntiagudo y ojos de poco diámetro, solo la sexta parte de ella. Dientes menudos, en felpudo o cardan, faltando sobre el paladar. La primera dorsal con seis radios, se origina por delante del comienzo de la anal, justo a nivel del ano. La segunda dorsal se inicia sobre la segunda mitad de la anal y cuenta con una espina y 9 a 11 radios blandos. Pectorales con 15 radios, llegan hasta el origen de las ventrales, y la anal tiene 1/16 - 18 radios. A lo largo del cuerpo hay 12 líneas longitudinales de escamas.

Las medidas proporcionales por Valenciennes permiten comparar entre si sus especies, suponiendo que las realizara siempre desde los mismos puntos sobre el cuerpo del pez, pero desconocemos la verdadera longitud total, acaso medida desde el extremo del morro al ápice de los radios medios de la caudal. Con estos salvedades, la altura del cuerpo es seis veces y medio la longitud del pez, y la cabeza está comprendida en esa longitud cuatro veces y media. Añade otras medidas facilmente comparables : cabeza dos veces y media más larga que alta, su grosor tres cuartas partes de su altura, y el grosor del cuerpo la mitad de su propria altura.

(1) - En la página 348 de la "Histoire Naturelle des Poissons" consultada por nosotros, pero en otras ediciones en la página 469 . 
Incluye Valenciennes en bonariensis varios ejemplares obtenidos por D'Orbigny cerca de Montevideo.

En la página 350 (471 de otra edición), en el mismo tomo $\mathrm{X}$, tiene Valenciennes la poca fortuna de describir una especie con el nombre de Atherina lessoni sobre un dibujo remitido por Lesson, Naturalista de la expedición Duperrey. Evitando mayores errores hemos incluído la especie en incertae sedis.

Otras de las especies descritas por Valenciennes en la obra de Cuvier y Valenciennes (1835) tenía 19 pulgadas de largo y fué enviada de Montevideo al Museo de la Universidad de Berlín, cediéndola para estudio el prof. Lichtenstein, a quien fué dedicada (página 353, en otra edición página 476).

Atherina lichtensteinii indudáblemente muy próxima a bonariensis, pudiera diferenciarse de ella por tener más larga la cabeza, que mide un cuarto de la longitud tomada desde el extremo del morro al fondo de la hendedura de la aleta caudal ; el morro es más comprimido y los maxilares alargados, curvos y terminados en punta; ojos más pequeños, midiendo la septima parte de la cabeza ; dientes en felpudo o cardan, ocupando estrecha banda, ausentes en el vomer y en el palatino. La primera dorsal en la segunda mitad del cuerpo, las pectorales amplias, de longitud aproximada a dos tercios de la cabeza, con su extremidad a nivel del origen de las ventrales y segunda dorsal sobre los últimos radios de la anal, con base igual a la sexta parte de la longitud del pez; las ventrales poco más de la mitad de las pectorales. La fórmula radial difiere poco: D.5-1/10. A 1/19. P. 15.

La diferencia entre las dos especies de Valenciennes parecen corresponder a variaciones de edad. Es más joven bonariensis que lichtensteinii.

La cuarta especie de Valenciennes en Cuvier y Valenciennes (1835. X. p. 350, en otra edición p. 472), que llama Atherina argentinensis, está descrita sobre ejemplares de seis pulgadas de largo remitidos de Montevideo por D'Orbigny.

Según Valenciennes argentinensis es próxima a lessoni del mismo autor, pero más alargada. Es de recordar que esta última fué descrita a base de un dibujo. Dá para las aletas la fórmula: D. $5-1 / 8$; A. $1 / 18$ o 19, siendo la altura del cuerpo la sexta parte de su longitud y la cabeza una quinta parte y media. El cuerpo dos veces y medio más alto que grueso. Los dientes en cardan poseen la fila externa más fuerte. Sus escamas tienen borde liso. El origen de la primera dorsal queda a la altura del ano, y la segunda dorsal comienza sobre la parte posterior de la anal. Aparece según su autor en los límites oceanicos del Mar de Solís ("l'embouchure de la Plata"), manteniéndose en ellos durante todo el verano, para desaparecer al aproximarse la estación fría. Prende en los anzuelos gracias a su gran voracidad y es muy estimado por los habitantes de Montevideo.

En las características que acabamos de mencionar no encontramos elementos de juicio para separar las especies de Valenciennes entre si, y tampoco al estudiar los ejemplares de que hemos podido disponer. 
Darwin durante la campaña del Beagle obtuvo ejemplares de una especie muy común en Maldonado, que Jenyns (1842) identifica con dudas con Atherina argentinensis. Aún siendo extensa la descripción no podemos decidir sin dudas a la especie a que se refiere, pero parece más semejante a Kronia alba que a Atherina argentinensis.

Günther (1861) hace constar que la descripción de su Atherinichthys bonariensis la tomó de Valenciennes. Atherinichthys argentinensis la toma de Jenyns, influyendo decididamente en los autores que le siguen. La gran autoridad de Günther lleva a aceptar como Atherina argentinensis Valenciennes a Atherina argentinensis Jenyns, cuya descripción no parece corresponder a la misma especie.

Son también dudosas las especies mencionadas o cortamente descritas por Perugia (1891). Su Atherinichthys bonariensis fué capturado por el Dr. Spegazzini en la laguna de Iberá, cerca de Corrientes, y Atherinichthys argentinensis se logró en la desembocadura del Rio Negro durante la Expedición Antártica Italiana.

Solo en parte podemos incluír Atherinichthys bonariensis de Berg (1895) que supone abundante en lagunas y rios, escasa en aguas saladas, alcanzando gran talla, y extendida por Montevideo, Maldonado y Mar Chiquita. De la misma manera Atherinichthys argentinensis Berg (1895) debe ser mezcla de por lo menos dos especies, poblando las aguas saladas, lagos salobres y en comunicación con el mar, en amplia zona geográfica : Barra del Rio Negro, Cabo San Antonio, Montevideo y Maldonado.

Thompson (1916) dá el nombre de Menidia bonariensis a seis ejemplares de Buenos Aires, que entre otros caracteres, cuentan con $10+30$ branquispinas, 50 vértebras y 60 escamas en línea longitudinal.

Los ejemplares que tuvieron en sus manos Evermann y Kendall (1907) de 7.25 - 21.5 pulgadas de longitud total, que llamaron Basilichthys bonariensis, poseian 54-61 escamas en línea longitudinal y en sus aletas : 1D. 3-6, 2D. $9-10$ (19?), A. $16-19$.

Al estudiar monográficamente los Atherinidae, Jordan y Hubbs (1919) alojan los dos principales especies que comentamos en dos géneros distintos. Austromenidia bonariensis de Argentina, Uruguay y probablemente Brasil, y Odontesthes argentinensis de Argentina y Uruguay.

Con duda alojamos en proximidad de esta especie a Atherina regia Larrañaga (1923) (no Humboldt 1835), que más tarde comenta Devincenzi (1925).

$\mathrm{Al}$ enumerar las especies uruguayas Devincenzi (1924) menciona Menidia argentinensis, refiriéndose a Berg al no haber logrado ejemplar alguno, y Menidia bonariensis la distribuye por rios, arroyos y lagunas del pais.

La revisión de los Aterínidos existentes en la colección del Museo de Historia Natural de Montevideo, me ha permitido identificar a los ejemplares que Devincenzi (1924, p. 206-207) llamó Odontesthes perugiai con Odontesthes bonariensis. 
La obra de Lahille (1929) es extensa y de complicado desarrollo. Pretende en el preámbulo ridiculizar la obra sistemática de otros autores, a quienes califica de "especiógrafos", achacándoles el intento de "inventar nuevas especies". Pero aparejado a sus censuras, en la mayoría de los casos injustificadas, crea su propia y complicada nomenclatura precisando medidas, que para comprenderlas al detalle fuerza a un tedioso y prolongado trabajo.

La publicación de Lahille plagada de números, signos y siluetas de Pejerreyes, no deja de tener interés. En sus muchas páginas volcó la mayoría de las descripciones originales de los principales autores, que pueden consultarse sin acudir a los textos originales no siempre a mano, y tuvo la virtud de precisar características de especies, antes dudosas o no tenidas en cuenta por los autores.

Aloja Lahille (1929) en Basilichthys bonariensis un ejemplar macho procedente del Rio Paraná frente a San Pedro, que medía 474 milímetros de longitud total y pesaba 725 gramos (diagrama 1, p. 365). Dí el nombre de Basilichthys bonariensis var. puntanus (diagrama 2, p. 366) a un macho originario de Chascomús, pescado en fechas posteriores en la laguna de Zapalle, provincia de San Luis, a donde fué transportado en forma de huevos fecundados; medía 515 milímetros y pesaba 885 gramos. Incluye en otra variedad chascomunensis dentro de la misma especie, a un macho procedente de Chascomús (diagrama 3. p. 367) que tenía 278 milímetros de longitud total.

Con la inseguridad que origina el empleo por parte de Lahille de un solo ejemplar en el estudio de cada forma, nos encontramos al parecer con dos especies o subespecies diferentes y un ejemplar procedente de fecundación artificial. El Pejerrey del Paraná (bonariensis) tiene boca grande y pectoral corta, distanciándose el extremo de esa aleta del origen de las ventrales, posee las dorsales retrasadas, la segunda dorsal sobre el término de la base de la anal, y pequeño diámetro ocular. El ejemplar de Chascomús (var. chascomunensis) tiene comparativamente boca pequeña, larga pectoral que rebasa hacia atrás el origen de las ventrales, dorsales avanzadas, comenzando la segunda sobre el primer cuarto de la base de la anal y ojo de mayor diámetro.

Con Pejerreyes del Mar del Plata que tenían 56-57 escamas en línea longitudinal y medían por ciento de la longitud estándar : 13 entre orígenes de ambos dorsales, 70 entre el extremo del morro y el origen de la segunda dorsal, 82 del morro al término de la anal, 18 la máxima altura del cuerpo y 31 desde el origen de la segunda dorsal hasta la última vértebra (diagrama 12, p. 376) crea el Basilichthys bonariensis var. propinquus.

Identifica Lahille (1929) con el nombre de Basilichthys bonariensis var. argentinensis numerosos ejemplares procedentes de Mar de la Plata, 20 de ellos de 121 a 285 milímetros de longitud y peso de 16 a 240 gramos ; 10 de 104 a 163 milímetros de longitud estándar con peso de 13 a 48 gramos. Uno de 261 milímetros de longitud total y 124 gramos de peso lo representa en el diagrama 8 , p. 372 . 
Es interessante señalar que Lahille (1929) revisó en el Museo Nacional Argentino el ejemplar que Berg había identificado como Atherinichthys vomerina, y más tarde etiquetado como Chirostoma humboldtianum, observando muchas semejanzas con argentinensis. Precisamente con ese ejemplar de Berg (diagrama 11. p. 375) crea el Basilichthys bonariensis var. charruanus Lahille.

Al estudiar los Pejerreyes de Puerto Quequén vuelve Lahille (1930) a describir su Basilichthys bonariensis var. argentinensis sobre sumerosos ejemplares de 25 a 170 milímetros de longitud estándar.

Sin apartarnos del criterio de Lahille, y para facilitar la consulta en futuras investigaciones, expresaremos en el lenguaje usual en Ictiología las características diferenciales de las variedades propuestas por el autor :

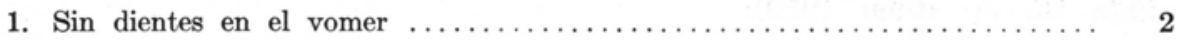

- Con dientes en el vomer. Línea longitudinal con 49-70 escamas ......... 4

2. Cabeza el 26 por ciento de la longitud estándar. De la longitud estándar, por ciento : 24 desde el origen de la segunda dorsal a la última vértebra, el 76 desde el morro hasta el origen de la segunda dorsal y el 10 la base de la segunda dorsal (De la laguna de Chascomús, poblando la laguna de Zapalle)

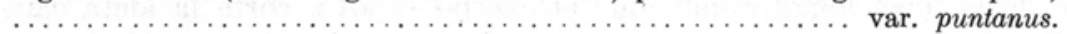

- Cabeza el 22 por ciento de la longitud estándar . . . . . . . . . . . . . . .

3. De la longitud estándar, por ciento : 27 desde el origen de la segunda dorsal a la última vértebra, 74 desde el morro al origen de la segunda dorsal, y el 9 la base de la segunda dorsal (Río Paraná, frente a San Pedro) var. bonariensis

- De la longitud estándar, por ciento: 34 desde el origen de la segunda dorsal a la última vértebra, 67 desde el morro al origen de la segunda dorsal, y el 12 la base de la segunda dorsal (Laguna de Chascomús) ...vvar. chascomunensis

4. De la longitud estándar, por ciento : 70 desde el morro al origen de la segunda dorsal, el 82 desde el morro al término de la anal, y el 18 la altura máxima del cuerpo (Mar del Plata) ......................... var. propinquus

- De la longitud estándar, por ciento: 73-77 desde el morro al origen de la segunda dorsal, el 82-83 desde el morro al término de la anal, y el 16-19 la altura máxima del cuerpo (Mar del Plata) ....... var. argentinensis

Pozzi y Bordalé (1935) al enumerar las especies marinas de la fauna argentina mantienen el criterio de Lahille aceptando las variedades propuestas. Pozzi (1945) asigna a Odontesthes argentinensis la distribución siguiente : costas del Uruguay, boca del Mar de Solís, Mar del Plata, Neocochea, Bahía Blanca y boca del rio Negro.

El Pejerrey del rio Uruguay, a la altura de Paysandú, recibe de Devincenzi (1942) el nombre de Menidia (Basilichthys) bonariensis. Lourenço Gomez (1947) menciona seis ejemplares obtenidos en Lagoa dos Quadros, en Rio Grande do Sul, Brasil, identificados por C. L. Hubbs como Odontesthes bonariensis.

En nuestra lista de Peces del Uruguay (F. de Buen 1950 a) incluímos en el género Odontesthes las dos especies mencionadas por los autores: $O$. bonariensis y $O$. argentinensis.

A formas semejantes a bonariensis Valenciennes se le han dado nombres de especies exóticas: Atherina laticlavia Valenciennes, de la costa chilena ; 
Atherina vomerina Valenciennes, sinónima de Atherina humboldtiana, de la fauna lacustre de México; Pseudothyrina iheringi Miranda Ribeiro, de Rio Grande do Sul en Brasil ; Atherina regia Humboldt de las costas de Perú.

El Pejerrey de 40 centímetros, procedente de Montevideo, a que Perugia (1891) dió el nombre de Atherinichthys vomerina, como acaso también su Atherinichthys laticlavia de la misma localidad, pudieran ser bonariensis de Valenciennes.

Berg (1895) llamó Atherinichthys laticlavia a ejemplares procedentes de las cercanías de la isla de Flores, próxima a Montevideo, lo que llevó a Devincenzi (1924) a incluirla entre las especies uruguayas como Menidia regia, e igualmente nosotros, pero bajo interrogante para señalar nuestra duda (F. de Buen 1950).

Procedentes de la laguna de Huanacache, Sur de la provincia de San Juan, recibió Lahille (1929) cinco ejemplares de la especie descrita por Burmeister, que incluye como var. cuyanus del Basilichthys bonariensis, haciendo notar que sus escamas son pequeñas y numerosas (70-80) a lo largo de la línea longitudinal, que el cuerpo es alto, corta la aleta caudal, amplio el espacio entre origenes de ambas dorsales y comparativamente corta la distancia entre el origen de la segunda dorsal y la última vértebra (diagrama 15, p. 379, Lahille 1929).

El Basilichthys bonariensis var. cuyanus Lahille, que según Pozzi (1945, p. 247) difiere poco de bonariensis Valenciennes, a juicio nuestro está más bien emparentado con Odontesthes hatcheri (Eigenmann).

A. de Miranda (1918) dá el nombre de Pseudothyrina iheringi a ejemplares procedentes del Mercado de Montevideo, lo que lleva seguramente a Pozzi (1945) a inclúrla en su lista de Atherinidae (p. 247) y de acuerdo con la opinión de este autor, F. de Buen (1950 a, p. 99), le dá el nombre de Odontesthes iheringi dentro de la fauna uruguaya.

Odontesthes humensis De Buen, nov. sp.

Holotipo - Ejemplar de 164 milímetros de longitud total y 137 milímetros de longitud estándar, V/T/1053 M.H.N.M.

Localidad Tipo - Pesca número 2 de la expedición de Rio Negro, julio de 1947 (Dr. Fernando de Buen).

Pesca con red de playa, sobre fondo arenoso, al pie de un médano sobre el bañado de Legrand, en la presa de Rio Negro.

Descripcion - Cuerpo esbelto con vientre poco abultado (figura 24). Su mayor altura, en el espacio comprendido entre las ventrales y la primera dorsal, mide 18.4 por ciento de la longitud estándar. El grosor máximo, a nivel de las pectorales, es igual al 13.6 por ciento de la longitud estándar. El pedúnculo caudal tiene moderada altura, siendo el valor 
mínimo de ella el 38.4 por ciento de la cabeza, y la longitud, medida a partir del término de la segunda dorsal hasta la última vértebra, el 18.7 por ciento de la longitud estándar.

La cabeza, que es el 25 por ciento o cuarta parte de la longitud estándar, tiene forma prismática con aristas redondeadas. La zona dorsal es plana, con ligera convexidad. El morro ancho y agudo, la boca protractil y los labios gordezuelos. El maxilar apenas saliente.

Se elevan en pequeño brocal los orificios nasales anteriores y los posteriores se abren sin realce.

Ojos de tamaño medio, bordeados de muy modesto borde adiposo. Mide la órbita horizontalmente el 23.6 por ciento de la cabeza. Por ciento de la cabeza son : la preórbita el 35.4, la postórbita el 44.3 y la interórbita el 35.4.

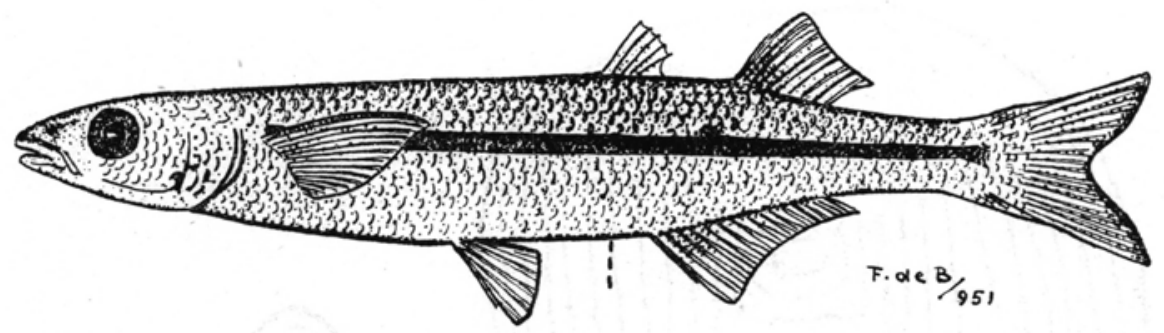

Figura 24 - Odontesthes humensis De Buen, holotipo de 164 milimetros de longitud total.

Las escamas cubren todo el cuerpo, invaden casi toda la región cefálica y se extienden ampliamente por la base de la aleta caudal, invaden más modestamente la segunda dorsal y la anal. En línea longitudinal se cuentan 60 escamas y en serie transversal 12. Entre los orígenes de las dorsales comienzan 12 series transversales.

La parte anterior de la cabeza está libre de escamas. El morro, por delante de los orificios nasales y lateralmente en la región preórbitaria, es desnudo.

Dos son las series de escamas, con repartición irregular, dotadas de tubos mucosos, una dorsal y ventral la otra. La serie dorsal comienza en la cuarta escama de la serie longitudinal y termina a distancia de 13 a 14 transversales del origen de la primera dorsal. Tienen tubos mucosos las escamas 4 y 6 , colocadas una escama por encima de la banda pigmentaria longitudinal de los flancos, y las $8,10,11,14,15$ y 16 colocadas dos escamas por encima.

La serie ventral de escamas tubuladas se inicia inmediátamente después de la hendedura branquial, sigue paralélamente al borde ventral, con sucesivos ascensos que la permiten entrar en el pedúnculo catudal. Sobre el origen de las ventrales pasa tres escamas por encima, al término de esa aleta sube una más. En el comienzo de la anal sigue el ascenso, primero 
una escama más, luego dos, colocándose sobre la quinta longitudinal al terminar la base de la anal.

Las escamas del lomo, arrancadas hacia la mitad del cuerpo, tienen forma cuadrangular con la zona libre poco saliente (figura 25). Su frente es entero, liso o con irregularidades bien moderadas. Faltan radios en la zona embutida, y por ello el borde posterior señala una sola ondulación extensa ; los lados no son iguales, uno es convexo y cóncavo el otro, señalándose apenas los ángulos.

Las escamas sobre el limbo caudal disminuyen de tamaño y de forma. Las extremas de lados sinuosos, tienen adelantada en ángulo romo la zona libre, y el frente entero ; poseen radios, tres a lo menos, y el borde posterior con mamelones salientes.
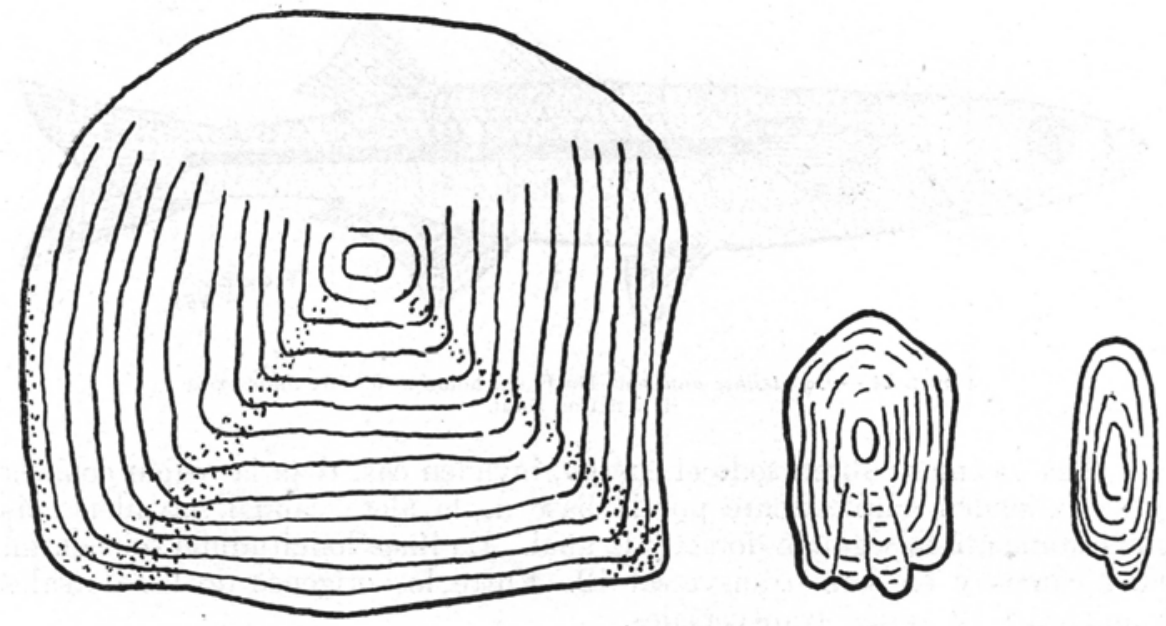

Figura 25. - Escamas de Odontesthes humensis De Buen. De izquierda a derecha : del lomo hacia mitad del cuerpo, del extremo de invasión sobre el limbo de la caudal, y de la aleta anal.

Sobre la aleta anal las escamas se diferencian alargándose extraordináriamente y disminuyendo de tamaño. Adquiren forma oval con un saliente posterior que recuerda la terminación de algún radio ahora inexistente.

La membrana branquióstega sobresale del borde opercular, con mayor anchura en la parte más alta.

La primera dorsal con 5 radios, queda muy poco por delante de la posición del ano, avanzando el espacio ocupado por una escama. La segunda dorsal con 1/10 radios, se origina a la altura del octavo radio blando de la anal y el término de las dos aletas queda prácticamente sobre la misma vertical. El espacio predorsal, entre el extremo del morro y el origen də la primera dorsal, es el 59,5 por ciento de la longitud estándar. La base de la segunda dorsal mide 41.4 por ciento de la cabeza y su radio más largo 
47.2 por ciento. El espacio que media entre las dos dorsales es igual al 59 por ciento de la cabeza.

Pectorales con 15 radios, siendo su longitud el 76.7 por ciento de la cabeza, y su base el 23.6 por ciento de la misma. Apoyadas en los flancos no llegan hasta las ventrales, las falta un espacio igual al ocupado por una escama y media.

Ventrales con 1/5 radios, largas como el 48.6 por ciento de la cabeza, están cada una de ellas ligadas al cuerpo por una membrana y entre sí, con escamas transformadas, por otra corta membrana solo basal.

El orificio anal está próximo al origen de la aleta que sigue. Media un espacio algo menor del diámetro ocular.

La caudal con 17 radios centrales, posee lóbulos de igual longitud y forma, por ello, la distancia entre cada una de las puntas y la última vértebra son idénticas.

El ejemplar holotipo conservado es de color pálido con tinte amarillento; el vientre y las aletas fijas a él no tienen pigmentación. El lomo únicamente se obscurece algo por la presencia de delgados trazos en el borde de los estuches dérmicos de las escamas, que no llegan a formar una red de mallas regulares. Sobre la cabeza la mancha cerebral es poco intensa, y el espacio entre los ojos y por delante, sobre el morro, son translúcidos, y están muy suávemente obscurecidos. Hay una mancha entre las narices, se obscurecen la parte alta del maxilar y el borde del labio superior, siendo muy escasos los cromatóforos sobre el limbo de las dorsales y en el radio superior de la pectoral. La aleta caudal se ennegrece ligeramente en su borde libre.

La banda media de los flancos, ocupando el ancho de una escama, tiene intensa pigmentación en su recorrido, desde la parte alta de la pectoral hasta la base de la caudal, manteniendo casi uniforme su anchura, estrechándose poco a su término y finalmente ensanchando algo, antes de difuminarse.

El nombre que hemos dado a la especie deriva de "hum" o Rio Negro de los indigenas.

VARIACION (Paratipos) - Doce ejemplares de 112 a 191 milíme’ros de longitud total, capturados en la misma localidad del holotipo. Pesca con red de playa en fondo arenoso, al pie de un médano en el bañado de Legrand (presa de Rio Negro). V/T/1055-1066 M.H.N.M.

Uno de los paratipos cuenta 22 branquispinas sobre el primer arco branquial, de ellas 6 en la rama superior, correspondiendo a la fórmula $6+16$. Son digitiformes, con dientecitos poco marcados, y más cortas que las láminas branquiales opuestas, estando comprendidas 1.4 veces en la longitud de las láminas branquiales.

En el mismo paratipo se cuentan 49 vértebras, de ellas 26 abdominales y 23 caudales. 
La cavidad visceral es amplia, alojándose la vejiga natatoria en el embudo hemal, que llega próximamente hasta la mitad de la base de la aleta anal.
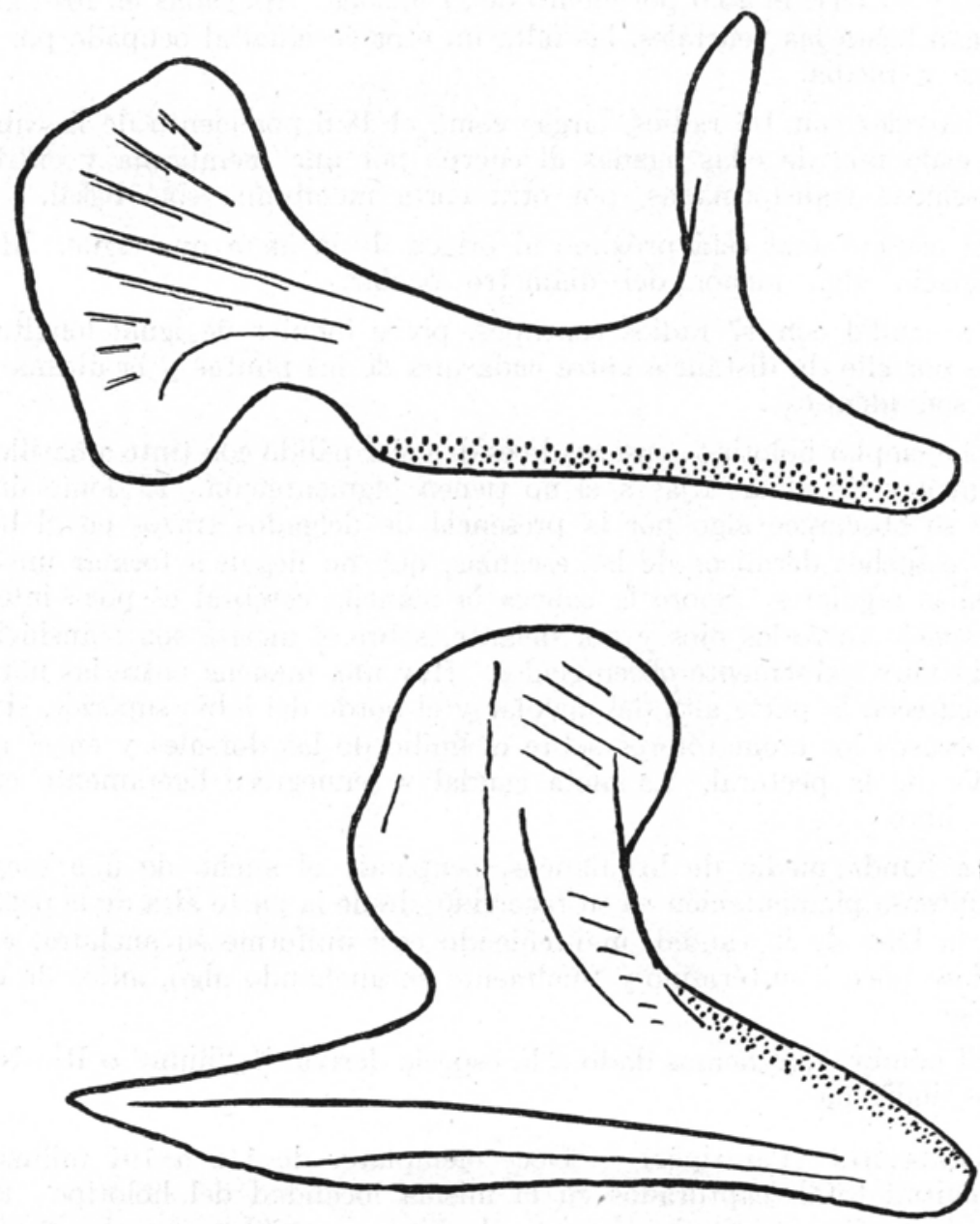

Figura 26. - Premaxilar arriba y mandíbula abajo de Odontesthes humensis De Buen. Banda dentaria punteada.

Cuerpo del premaxilar moderádamente ensanchado en la pala y con pronunciada escotadura (figura 26). El borde terminal de la pala sinuoso, con ángulo muy abierto en la mitad superior. La rama sobresale en altura a la pala, no se inclina, pero marca ligera sinuosidad debido a que su borde interno es cóncavo y el externo convexo, además el ápice es redondeado.

La mandíbula, de cuerpo ancho, tiene extremo en punta no bien definida. Su lámina, de forma redondeada irregular, posee en el borde externo un 
modesto saliente y el seno tiene los bordes curvos ; el borde interno avanza en lámina en su mitad alta.

Dientes en ambas mandíbulas pequeños, en la superior se disponen en dos filas, intercalándose entre ellas algún diente, en la inferior pueden contarse claramente tres filas muy próximas entre si.

En la totalidad de los paratipos se observan las siguientes características:

De la longitud estándar, por ciento :

Altura máxima del cuerpo

$17.2-18.8$

Grosor máximo del cuerpo ......................... 12.3 - 13.6

Distancia predorsal, hasta el origen de la primera dorsal .........

Longitud del pedúnculo caudal, desde el término de la segunda dorsal

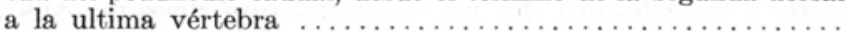

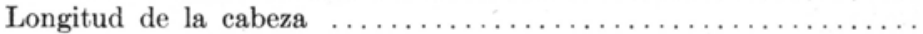

De la longitud de la cabeza, sin membrana branquióstega, por ciento :

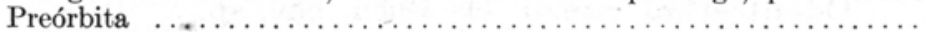

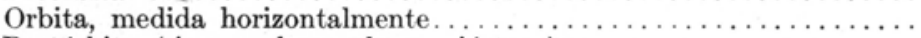

Postórbita (sin membrana branquióstega) . . . . . . . . . . .

Interórbita . . . . . . . . . . . . . . . . . . . . . . . .

Distancia entre orígenes de ambas dorsales $\ldots \ldots \ldots \ldots \ldots \ldots \ldots$

Altura mínima del pedúnculo caudal $\ldots \ldots \ldots \ldots \ldots \ldots \ldots \ldots \ldots$

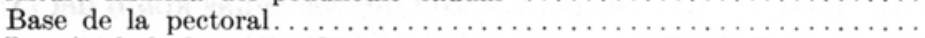

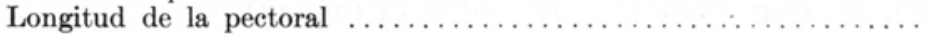

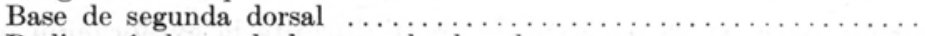

Radio más largo de la segunda dorsal . . . . . . . . . . . . . . .

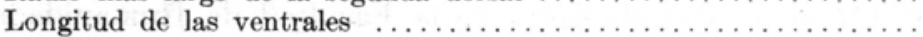

Base de la anal

$32.3-39.5$

$21-28.2$

$42.2-47.5$

$34.5-39.5$

$61.6-70.2$

$35-38.8$

$23.4-31$

$74-81$

$39-48.6$

$45.4-48.6$

$48-53.6$

$77.5-84$

Escamas, en

línea longitudinal $\ldots \ldots \ldots \ldots \ldots \ldots \ldots \ldots \ldots \ldots \ldots . \ldots \ldots$. sal

$55-57$

$11-12$

líneas transversales entre ambas dorsales

$10-13$

Radios en las aletas,

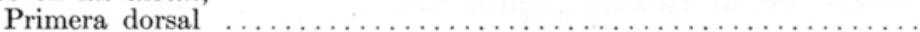

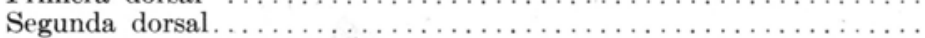

Pectoral

5

$1 / 9-11$

$14-15$

Anal

$1 / 16-17$

Otros Ejemplares - Consideramos como perteneciente a esta especie un ejemplar capturado en el mismo lugar de las formas típicas, pero en otra redada (V/T/1067 M.H.N.M.). Parece diferir solamente por la mayor fortaleza del cuerpo y poseer algunos caracteres extremos. De la longitud estándar es su altura máxima el 19.3 por ciento y el mayor grosor el 13.6. Cuenta con 58 escamas en línea longitudinal, 1/16 radios en la anal, y 1/9 en la segunda dorsal.

Acaso representa una población diferente de la típica, dentro del Odontesthes humensis, que acudió al embalsarse las aguas del Rio Negro procedente de otros afluentes de la misma cuenca.

Es de esperar que en el futuro las posibles hibridaciones apaguen estas modestas diferencias. 
De gran interés es otro ejemplar capturado en el arroyo Conventos por el señor J. Santibañez, el 28 de noviembre de 1941, y donado al Museo de Historia Natural de Montevideo. Mide 193 milímetros de longitud total y 167 milímetros de longitud estándar. El porte recuerda las formas típicas del Odontesthes humensis, pero de cuerpo más bajo (siendo la altura máxima el 16.9 por ciento de la longitud estándar) y menos grueso (grosor máximo 11.9 por ciento de la longitud estándar); el pedúnculo caudal es más corto (17.6 por ciento de la longitud estándar). Cuenta con 55 escamas en línea longitudinal y 10 en serie transversal, 1/11 radios en la segunda dorsal y $1 / 17$ en la anal.

El arroyo Conventos pasa por las cercanías de Melo (Departamento de Cerro Largo) y es afluente del rio Tacuarí, que derrama sus aguas en la laguna Merin.

Odontesthes guazu De Buen, nov. sp.

Holotipo - Ejemplar de 139 milímetros de longitud total y 112 de longitud estándar, V/T/1049. M.H.N.M.

Localidad TiPo - Rio Uruguay a 200 metros aguas abajo del arroyo Espinillar, en el Departamento de Salto (Uruguay).

En el mismo lugar, el 28 de abril de 1950, durante la exploración organizada por el Curso de Hidrobiología de la Facultad de Humanidades y Ciencias, se encontró una Loricaria nueva, descrita por J. Soriano (1950).

DESCRIPCION - Cuerpo alargado de poca altura, con vientre no abultado. La máxima altura del cuerpo, colocado a nivel de la primera dorsal, es el 17 por ciento de la longitud estándar. El mayor grosor, casi en el extremo de las pectorales, mide el 12.6 por ciento de la longitud estándar. El pedúnculo caudal no disminuye brúscamente de altura, siendo su mínimo el 40.5 por ciento de la cabeza (figura 27).

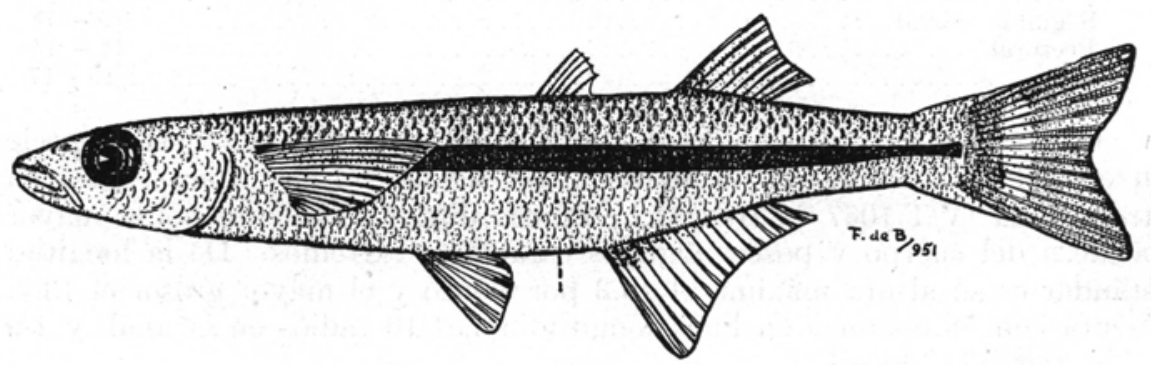

Figura 27. - Odontesthes guazu De Buen. Holotipo de 139 milimetros de longitud total.

Cabeza dorsalmente aplanada, con borde ventral redondeado y morro romo. Mide, sin la membrana branquióstega, el 23.3 por ciento de la longitud estándar. Labios poco gruesos. Boca protractil y hendedura bucal curva. La piel del labio inferior no cubre el término del superior, pero lo 
bordea. Lateralmente se prolonga el maxilar, de borde anterior recto, sin escotaduras, y por encima con quilla poco saliente.

El término de la hendedura bucal se distancia del borde anterior del ojo, como dos tercios del diámetro ocular, y el extremo del maxilar, prolongado hacia abajo, queda a nivel del borde anterior de la órbita.

Orificios nasales anteriores levantados en brocal, con la abertura hundida transversalmente. Los orificios posteriores en forma de cortas fosetas inclinadas transversalmente.

Los ojos, cuyo diámetro horizontal mide el 27 por ciento de la cabeza, están rodeados y en parte cubiertos por amplios párpados adiposos. De la cabeza son, el 38.6 por ciento la preórbita, el 46.2 por ciento la postórbita, y el 38.6 por ciento la interórbita.

Cubren las escamas todo el cuerpo, parte de la región cefálica y modéstamente el comienzo de las aletas segunda dorsal y anal. Invaden ampliamente la aleta caudal.

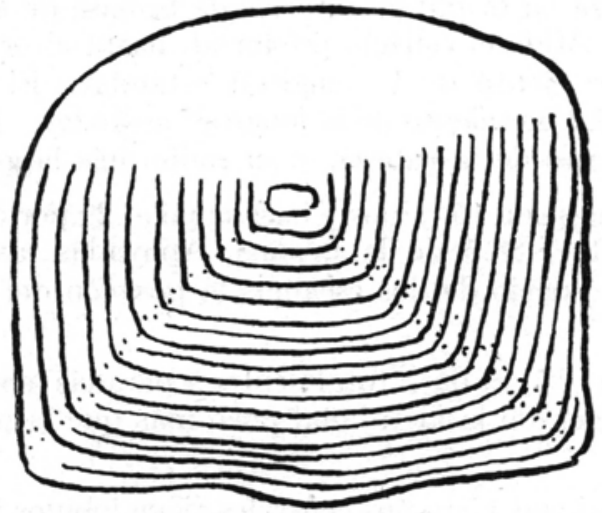

Figura 28. - Escama del lomo de Odontesthes guazu De Buen.

Todo el morro es desnudo, avanzando las escamas por el espacio interorbitario hasta el nivel de los orificios nasales posteriores y dejando a ambos lados zonas desnudas. Bajo los ojos llegan hasta mitad de su diámetro dos series longitudinales.

En línea longitudinal se cuentan 61 escamas y en serie transversal, extendida del origen de la anal a la segunda dorsal, 12. Entre los orígenes de ambas dorsales se inician 12 series transversales.

Las escamas arrancadas en el lomo son cuadrangulares, con la zona libre apenas saliente y el frente entero (figura 28). En la zona embutida no hay radios y los lados rectos o muy ligeramente cóncavos, prolongan sin gran discontinuidad el frente. En el borde posterior se destaca una suave sinuosidad media, y en los extremos ángulos redondeados, casi rectos. 
En la línea longitudinal iniciada inmediátamente por encima de la banda pigmentaria de los flancos, las escamas 1,3 y 5 tienen tubos mucosos, siguiendo una serie longitudinal por encima las escamas $7,9,10,13,15$, 16,18 y 22 . Esta última escama se distancia 5 series transversales de la primera dorsal.

La serie ventral de escamas con tubo mucoso es regular en su comienzo, no señalando discontinuidades. En llegando a las aletas ventrales sube una longitudinal y sobre la base de la anal se encuentra en la cuarta longitudinal, con algunas escamas fuera de la línea principal.

Dientes extremádamente pequeños en ambas mandíbulas, apenas salientes de la mucosa que los envuelve.

La membrana branquióstega sobresale del borde opercular y posee a mitad de su longitud el borde súavemente ondulado.

Primera dorsal con 5 radios, originada delante del orificio anal, sin llegar hasta el ápice de las ventrales apoyadas. La segunda dorsal con 1/9 radios, comienza en la mitad anterior de la base de la anal, a la altura del noveno radio. Mide el espacio predorsal, hasta el origen de la primera dorsal, el 57.3 por ciento de la longitud estándar. El pedúnculo caudal tiene de largo el 20.2 por ciento de la longitud estándar. Base de la segunda dorsal 38.6 por ciento de la cabeza, y su radio más largo el 50 por ciento.

Aletas pectorales con 15 radios y base igual al 29 por ciento de la cabeza, siendo su longitud el 88.5 de la misma. Apoyadas las pectorales en el cuerpo rebasan el espacio de dos escamas la posición del origen de las ventrales.

Ventrales con $1 / 5$ radios, totalmente separadas entre si. El orificio anal queda del origen de la aleta anal poco más que la mitad del diámetro ocular.

La aleta caudal con 17 radios centrales tiene lóbulos iguales en longitud $\mathrm{y}$ borde posterior poco profundo. A partir de la última vértebra los extremos de los lóbulos quedan distanciados igual al 98.5 por ciento de la cabeza, y el extremo del radio medio al 54 por ciento de la misma.

Aleta anal con 1/16 radios, midiendo su base el 86.6 por ciento de la cabeza, y su radio más largo el 61.7 por ciento.

Cuerpo blanquecino en el ejemplar conservado, con suave tonalidad rojiza en la parte anterior ventral. Lomo ligéramente obscurecido por la presencia de trazos cromáticos en el borde de los estuches dérmicos de las escamas. Muy obscura la mancha cerebral. Desde ella hasta el extremo del morro la piel translúcida. Se manchan los bordes altos del labio superior y suávemente entre los orificios nasales.

Banda longitudinal ancha como la altura de una escama, adelgazada hacia su final y ensanchando al término. A continuación se ennegrece el limbo de la aleta caudal, dejando una zona vertical incolora. 
No se manchan las aletas pectorales, las ventrales y la anal, ligéramente las dorsales.

El nombre específico se deriva del indigena "Guazu" o grande, empleado en diversos rios.

\section{Odontesthes orientalis De Buen}

Odontesthes orientalis De Buen 1950 b, p. 149, figs 1-2 (primera descripción). De Buen $1950 a$, p. 99 (observaciones).

Localidad Tipo - Fxtremidad del médano del Bañado de Legrand en el embalse de Rio Negro.

Distribuicion - Cuenca del Rio Uruguay (R. O. del Uruguay), frente a Paysandú y Nueva Palmira. Embălse de Rio Negro.

Material - 21 ejemplares de 47 a 127 milímetros de longitud total, capturados por el Dr. Fernando de Buen en la localidad tipo. Holotipo V/T/1054 M.H.N.M.

Rio Uruguay, frente a Paysandú. Mayo 1934 (Teague). V/T/1019. M.H.N.M. 108 milímetros de longitud total.

Rio Uruguay, frente a Paysandú. Agosto 1933 (Dr. De Medina). V/T/1013-1016. M.H.N.M. 84-121 milímetros de longitud total.

Rio Uruguay, frente a Nueva Palmira (Dr. F. de Buen) V/T/1017. M.H.N.M. 106 milímetros de longitud total.

DesCRIPCION - Cuerpo muy alargado y suávemente comprimido (figura 20). La mayor altura del cuerpo, a nivel del ano, el 13.8-16.3 por ciento de la longitud estándar. El mayor grosor del cuerpo el 10.3-11.2 por ciento de la longitud estándar. Pedúnculo caudal angosto, midiendo la altura mínima el 32-36 por ciento de la cabeza.

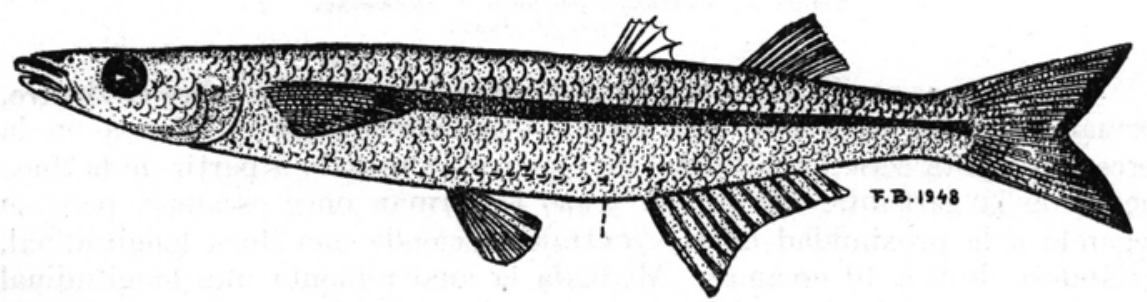

Figura 20. - Odontesthes orientalis De Buen. Holotipo

Cabeza muy aguda de forma prismática triangular con aristas redondeadas, mide el 22.5-26 por ciento de la longitud estándar. Morro saliente. Labios gruesos y abultados, ligeramente más avanzado el superior. Hendedura bucal abierta horizontalmente. Boca muy protractil. El maxilar tiene en su borde anterior marcada escotadura. 
El término de la hendedura bucal se aparta del borde ocular tanto como dos tercios del ojo. El maxilar desciende oblicuamente y llega hasta el nivel anterior de la órbita o poco por delante.

Orificios nasales anteriores realzados en brocal ligeramente más altos detrás, los orificios posteriores en foseta.

Orbita grande, midiendo horizontalmente el 22.5-28 por ciento de la cabeza. De la longitud de la cabeza son : la preórbita el 34.5-43 por ciento, la postórbita el 37-44.5 por ciento y la interórbita el 28-33.5 por ciento. El espacio entre los ojos es suávemente convexo.

Las escamas fuértemente adheridas al cuerpo, invaden en la región cefálica las piezas operculares y el espacio interorbitario. El morro es desnudo por delante de los orificios nasales y en el espacio preorbitario. En la línea longitudinal hay 50-54 escamas y transversalmente, desde el origen de la aleta anal, 9-10.

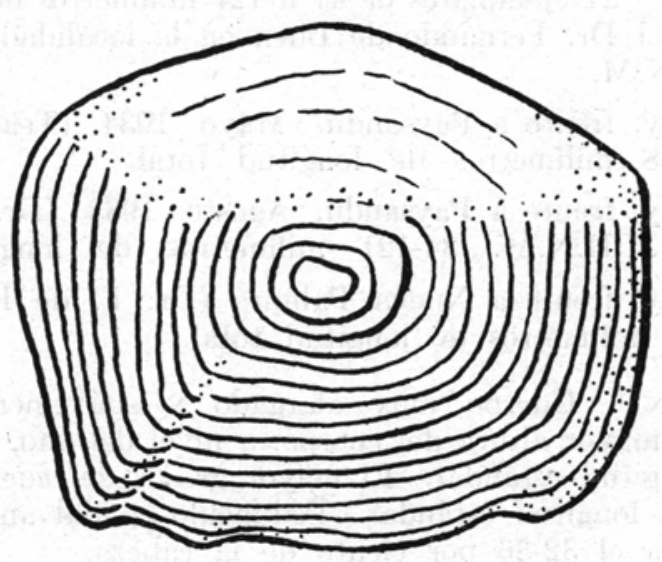

Figura 21. - Escama del lomo de Odontesthes
orientalis De Buen.

Las escamas con tubos mucosos de la línea lateral están sobre el vientre, formando trazos cada vez más altos. Originalmente se encuentra en la tercera o cuarta serie longitudinal de escamas, contando a partir de la línea media de la garganta. El primer trazo lo forman once escamas, pero en llegando a la proximidad de las ventrales asciende una línea longitudinal, seriándose de 9 a 10 escamas. Mediada la anal remonta una longitudinal mas, y sube otra a la altura de la segunda mitad de la misma aleta. Llegando al pedúnculo caudal es fráncamente irregular.

Hay escamas en las piezas operculares. Bajo las dorsales no cambian de tamaño y entre los orígenes de esas aletas se inician 8 a 10 series transversales.

En el lomo las escamas son cuadrangulares, con la zona libre poco avanzada (figura 21). Sobre la zona embutida faltan los radios. Los lados 
son rectos o poco convexos, marcándose apenas los ángulos. El borde posterior posee pocas y muy modestas ondulaciones.

A excepción de la caudal no hay escamas sobre las aletas. En la caudal avanzan desde la base en buen trecho, disminuyendo de tamaño y perdiendo sus características. Las más cercanas al pedúnculo caudal poseen radios en la zona embutida, los lados son suávemente cóncavos y los ángulos romos. Las más retrasadas se alargan notablemente, pierden los radios y adquieren forma oval, siendo extremádamente pequeñas en los límites de su invasión (figura 22).

En el borde opercular la membrana branquióstega es bien aparente.

Sobre el primer arco branquial hay veinticinco branquispinas, según la fórmula $5+20$. Poseen de 47 a 48 vértebras.

Maxilar largo, de poca altura, con amplia pala y sin escotadura. Rama delgada y algo inclinada hacia fuera (figura 23).

Mandíbula con extremo al término de una de sus quillas longitudinales. Borde inferior en suave curva cóncava. Lámina inclinada hacia fuera y modestamente amplia, con borde interno ligéramente cóncavo y con seno de margenes redondeados.
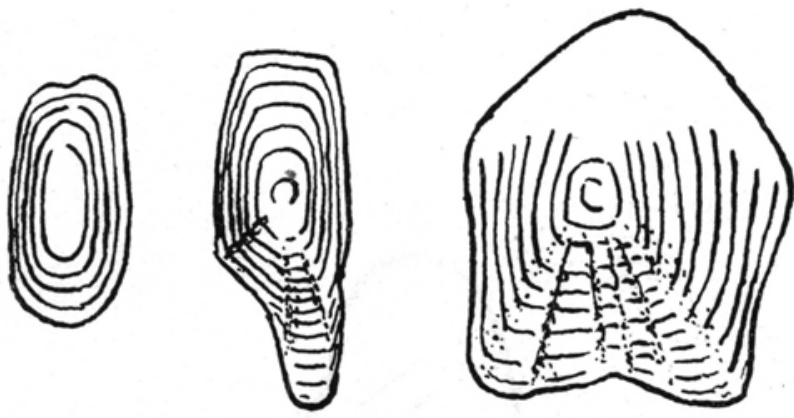

Figura 22. - Escamas del limbo de la aleta caudal, en Odontesthes orientalis De Buen.

Dientes muy pequeños en ambas mandíbulas. En la mandíbula superior, sobre el premaxilar, se disponen en fila única, teniendo detrás algunos dientes sueltos. En la mandíbula inferior forman doble serie muy junta. Todos los dientes son rectos o suávemente ganchudos.

La primera dorsal, con 4-5 radios, tiene su origen algo por delante de la anal, precisamente a nivel del ano. La segunda dorșal, con 1/9-10 radios, comienza a la altura de la primera parte de la segunda mitad de la anal. El espacio predorsal, desde el extremo del morro al origen de la primera dorsal, es el 60.5 - 63 por ciento de la longitud estándar. La distancia entre el origen de ambas dorsales es el 62.5-69.5 por ciento de la cabeza. La base de la segunda dorsal mide el 32.5-42 por ciento, y el radio más largo el $34.7-42$ por ciento, de la cabeza. 
Aletas pectorales con 12 - 14 radios, midiendo su base el $19.3-25$ por ciento de la cabeza, y de ella tambien el 65-83.5 por ciento su longitud. Apoyadas las pectorales en los flancos del cuerpo no llegan al comienzo de las ventrales, distanciándose un espacio menor al diámetro del ojo.
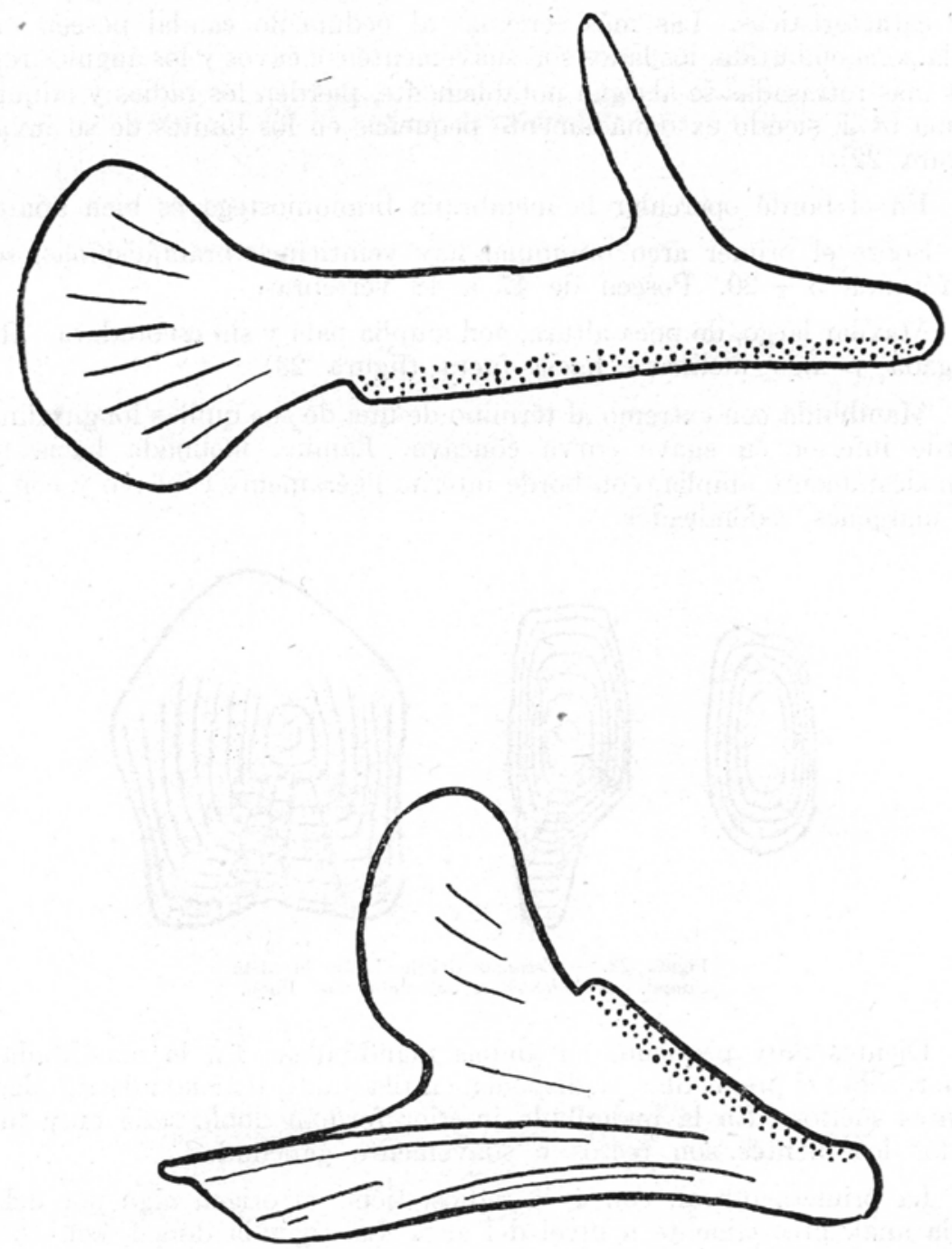

Figura 23. - Premaxilar arriba, mandíbula abajo, en Odontesthes orientalis De Buen. (Banda dentaria punteada).

Las ventrales, con $1 / 5$ radios, son libres, no se unen entre si por intermedio de una membrana, y el espacio entre ellas está cubierto de escamas. Miden de longitud el 40.5 - 50 por ciento de la cabeza. 
La aleta caudal con 17 radios centrales, tiene lóbulos iguales, que miden la misma longitud desde la última vértebra hasta cualquiera de los dos ápices.

La aleta anal con 1/15 - 17 radios comienza a la altura de la membrana que une al cuerpo el último radio de la primera dorsal, y tiene de base el 70-83 por ciento de la cabeza.

Con amplia vejiga natatoria, alojada hacia atrás en el embudo hemal de hemapófisis sencillas, y llegando hasta mediar la base de la aleta anal.

Hacia delante la vejiga natatoria disminuye rápidamente de volumen, ocupando amplio espacio sobre las vísceras y volviendo a estrecharse hacia atrás. Amplia masa hepática, que llega adelgazada hasta un punto equidistante de las ventrales y la anal.

En ejemplares bien conservados el color es blanquecino, con el lomo de tonalidad amarillenta, cubierto de suave reticulación cromática, y vientre blanco azulado. La banda longitudinal, del ancho de una escama, se angosta al término, para ensancharse luego y desvanecerse al pie de los radios de la caudal.

En la cabeza, de color blanco lechoso, es obscuro el lomo, la mancha cerebral, la interórbita, la zona mandibular y el borde superior del labio. Entre las narices hay manchas y una banda incolora transversal.

Ventrales sin pigmentación, y las restantes aletas finamente punteadas. A lo largo de la base de la anal un delgado trazo obscuro. El borde libre de la aleta caudal manchado.

Discusion - La especie más próxima a Odontesthes orientalis De Buen es la especie tipo del género, el Odontesthes perugiae Evermann y Kendall (1907) capturado en Argentina, pero sin localidad precisa por pérdida de la etiqueta.

Odontesthes perugiae Evermann ỳ Kendall (no de los autores posteriores) tiene características que permiten distinguirlo, es un Pejerrey largo y de cuerpo redondeado, midiendo la mayor altura el 13.7 por ciento de la longitud estándar, con cabeza aplanada por arriba, fuertes mandíbulas dotadas de dientes agudos, y con el término de los maxilares rebasando la posición del borde anterior de los ojos. Su pectoral moderádamente larga queda bien distanciada del origen de las ventrales, y las dorsales se atrasan en su posición, teniendo la primera su origen casi a nivel del comienzo de la anal.

Comparativamente Odontesthes orientalis tiene los labios gruesos, la boca bien separada de los ojos, los dientes muy pequeños y más avanzadas las dorsales.

El tamaño de los ejemplares tipo de ambas especies son semejantes, por ello las comparaciones son más seguras. El tipo de Odontesthes perugiae (núm. 55572 U.S.N.M.) mide 140 milímetros y el tipo de Odontesthes orientalis (Departamento Oceanográfico del SOYP) (V/T/1054 M. H. N. M.) 127 milímetros. 
Subgénero TUPA De Buen, nov. (1)

Odontesthes platensis (Berg).

Atherinichthys platensis Berg 1895, p. 27 (primera descripción).

Odontesthes platensis Jordan y Hubbs 1919, p. 64 (en lista, sinonímia, distribución) - Pozzi 1945, p. 247 (distribución) - De Buen 1950 a, p. 99 (lista, sinonímia, distribución).

Odontesthes platensis Devincenzi 1924, p. 208, lám. XIV (algunas características) - Devincenzi y Barattini 1928, lám. XX (figura defectuosa).

Basilichthys bonariensis var. platensis Lahille 1929, p. 315 (descripciones), p. 342 (sinonímia, distribución). Diagramas 9 y 10 - Lahille 1930, p. 103, fig. 2 bis (algunas características) - Pozzi y Bordalé 1935, p. 19 (en lista).

Basilichthys platensis Marrero 1950, p. 99. fig. (descripción, distribución)

Localidad Tipo - Mar del Plata.

Distribucion - Desembocadura de Rio Negro a Mar del Plata en la costa argentina. Penetra en el Mar de Solís cuando las aguas salinas se adentran en él (Montevideo).

Material - Ejemplar de la colección del Museo de Historia Natural de Montevideo (V/T/1000 M.H.N.M.) de 227.2 milímetros de longitud total y 191.2 milímetros de longitud estándar, con la etiqueta siguiente : (Odontesthes platensis - Pejerrey - Rio de la Plata, Montevideo 1917).

Otro ejemplar de la misma procedencia (V/T/1001 M.H.N.M.)

Descripcion - Cuerpo alto y grueso, con perfil dorsal y ventral no muy pronunciados (figura 29). La mayor altura del cuerpo, medida justo delante de la primera dorsal, pero con escasa variación a partir del tercio posterior de las pectorales apoyadas, es el $18.3-18.6$ por ciento de la longitud estándar. A nivel del tercio posterior de las pectorales se encuentra el meyor grosor, que mide el 12.6 - 14.7 por ciento de la longitud estándar. Tiene pedúnculo caudal relativamente alto, midiendo el mínimo 38.4 - 38.5 por ciento de la cabeza.

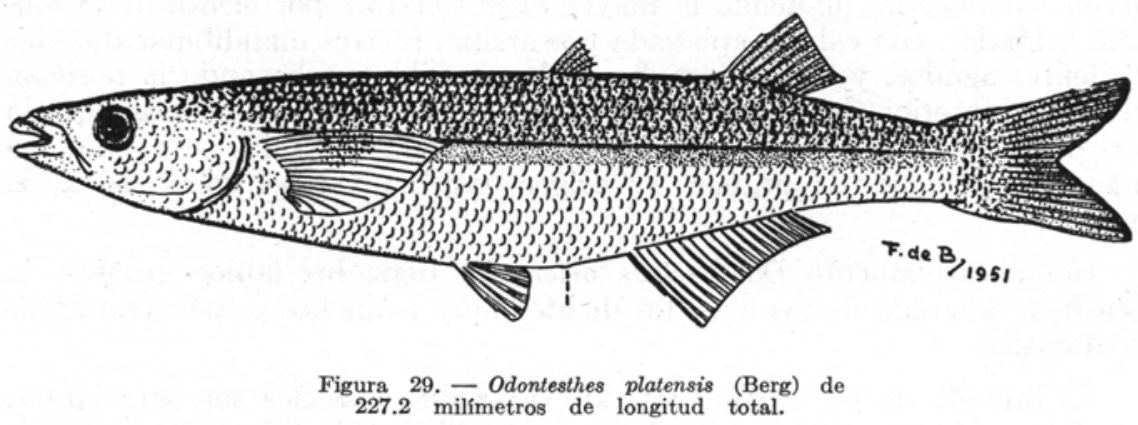

Cabeza cónica, dorsalmente convexa y de borde ventral adelgazado pero redondeado. Morro romo, labios poco abultados, avanzando algo

(1) Tupa, dios bueno de los indigenas 
la mandíbula inferior con respecto a la posición de la superior. Boca protractil, con su hendedura suávemente caida, casi horizontal. La prolongación lateral del maxilar queda casi totalmente oculta por la piel, tiene el borde recto y una cresta dorsal poco pronunciada, terminando en punta lanceolada. Mide la cabeza el 22.8-23.4 de la longitud estándar.

La hendedura bucal llega a distancia del borde anterior del ojo, tanto como el diámetro ocular. El maxilar, con la boca cerrada, en la parte que asoma de la piel, queda prácticamente a nivel del borde anterior de la órbita.

Los orificios nasales anteriores se levantan en corto y pequeño tubo, y los posteriores en foseta alargada, casi horizontal.

Los ojos con poco diámetro, midiendo la órbita el 19.8 - 22.6 por ciento de la cabeza; tienen párpados adiposos que cubren en parte los bordes anterior y posterior. De la longitud de la cabeza son, la preórbita el 33.5 - 36 por ciento, la postórbita el 47.2 - 48 por ciento y la interórbita el 33.8 - 37.6 por ciento.

Hay escamas en todo el cuerpo, menudas y por tanto numerosas, que se extienden por el limbo de la caudal, cubriendo próximamente un tercio de su superficie. En línea longitudinal se cuentan 77 - 78 escamas y transversalmente $16-17$, originándose entre el comienzo de las aletas dorsales 11 - 14 series transversales.

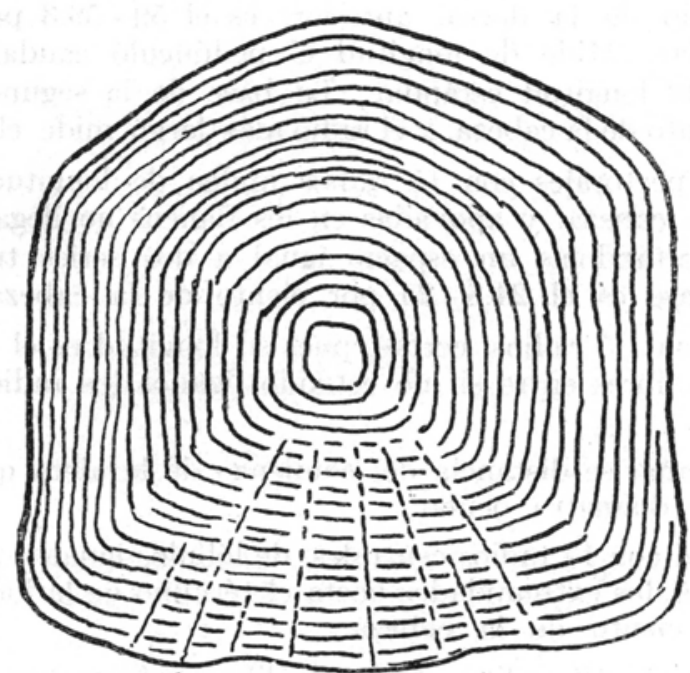

Figura 30. - Escama del lomo de Odontesthes platensis (Berg).

Cubren las escamas la mayor parte de la cabeza ; por el dorso avanzau siguiendo la línea central hasta el espacio entre los orificios nasales, dejando a ambos lados areas desnudas, por ello el límite anterior de invasión tiene forma curva convexa. Las piezas operculares son escamosas y por bajo 
de los ojos hay tres series longitudinales. No hay escamas en la base de la segunda dorsal y de la anal.

No faltan las dos series de escamas dotadas de tubos mucosos, la dorsal se extiende con cierta regularidad y la ventral es, al parecer, fráncamente irregular.

En las escamas del lomo (figura 30) la zona libre, de frente liso, avanza en ángulo romo, y la embutida con numerosos radios (ocho en uno de los ejemplares) posee lados suávemente cóncavos, borde posterior con tenues ondulaciones no profundas y angulos muy redondeados. Las dos zonas, libre y embutida, no se separan claramente entre si, al estar ambas dotadas de numerosas estrias. No es lisa, por tanto, la zona libre.

En la hendedura branquial bordea y sobresale la membrana branquióstega. Branquispinas en número de $5+18$ en el primer arco branquial, son más cortas que las láminas branquiales enfrentadas a ellas, y están dotadas de doble fila de dientes en su cara interna.

Dientes pequeños, ganchudos, en ambas mandíbulas.

La primera dorsal originada una escama por delante del orificio anal, tiene escasa altura y posee 5 radios. La segunda dorsal con 1/9-10 radios tiene su origen algo por delante de la mitad de la base de la anal, y termina a la par de esta última aleta. El espacio predorsal, del morro a la base del primer radio de la dorsal anterior, es el 59-59.3 por ciento de la longitud estándar. Mide de longitud el pedúnculo caudal el 18.9-20.5 por ciento de la longitud estándar. La base de la segunda dorsal es el 36 - 39.7 por ciento de la cabeza, y el radio más largo mide el 45 por ciento.

Las aletas pectorales con 15 radios miden de longitud el $77.8-86.5$ por ciento de la cabeza, y apoyadas en los flancos no llegan al origen de las ventrales, faltándolas un espacio igual a dos series transversales de escamas. Su base es el 24.8-25 por ciento de la cabeza.

Ventrales con $1 / 5$ radios, cortas, pues su longitud es el 40.5 por ciento de la cabeza, y libres entre si, no estando ligados los radios internos por una membrana.

El orificio anal se distancia del comienzo de la aleta que sigue, como dos tercios del diámetro ocular.

Aleta caudal con 17 radios centrales, de lóbulos iguales, midiendo desde cualquiera de las dos extremidades hasta el término de la longitud estándar el 84-90 por ciento de la cabeza.

Anal con 1/17 - 18 radios, de borde libre suávemente cóncavo, mide de base el 75 - 75.5 por ciento de la cabeza, y el radio más largo el 45 - 46 por ciento de la misma.

El color de los ejemplares conservados es pálido, obscurecido el lomo por la presencia de líneas cromáticas en el borde del estuche dérmico de las escamas. La banda longitudinal de los flancos es ancha y pálida. Morros apenas manchados. Ventrales y anal incoloras, pectorales muy 
suávemente manchadas en su parte media y alta, dorsales más obscuras y también la caudal, que posee el borde libre ennegrecido.

Discusion - Aunque la descripción original de Berg (1895) no es muy extensa, proporciona características para distinguir su especie de las congéneres. Es un Pejerrey alto de cuerpo (5-1/2 a 6 veces en la longitud total), con escaso diámetro ocular, que mide un quinto de la longitud de la cabeza, de ancha banda longitudinal sobre los flancos del cuerpo, y gran número de escamas en líneas longitudinal y transversal. Cuenta sobre la banda pigmentada de 68 a 79 escamas.

Posee la siguiente fórmula para sus aletas: D. IV-V, I/10-11, A. 1/1819, P. 15-16.

En los ejemplares estudiados por Devincenzi (1924), procedentes de Montevideo, se contaban 77-80 escamas en línea longitudinal y transversalmente $6+2+10-11=18-19$, y en sus aletas : $1 \mathrm{D}$. IV-V, 2 D. $1 / 10-11$, A. $1 / 18$.

YACI De Buen, nov. gen.

Atherinopsinae con la cavidad general extendida entre los arcos hemales, llegando hasta mediar la base de la aleta anal ; pero el embudo hemal no tiene paredes laterales, pues las hemispinas al formar arcos, son delgadas y unidas entre si por membranas. El cuerpo es alto y grueso, con el lomo levantado y el vientre en curva pronunciada y saliente. Escaso número de escamas en línea longitudinal (48-49 en el genotipo). Numerosas branquispinas $(15+48$ en el genotipo) en el primer arco branquial. 47 vértebras. Escamas del lomo más anchas que altas. Pocos radios en la primera dorsal $(3-4)$ y el origen de esta aleta al mismo nivel del origen de la anal.

Por la forma del cuerpo y la reducción en el número de radios de la primera dorsal, tiene semejanzas con Thyrinops Hubbs y Melaniris Meek, pero sus características anatómicas alojan estos últimos en otra subfamilia (Menidiinae). Además Yaci tiene pectorales de diferente forma, las ventrales están más retrasadas y es menos extensa la base de la anal.

El nombre de Yaci se ha tomado de Luna en idioma indígena.

El poseer los arcos hemales sencillos, sin formar un cerrado tubo hemal, liga a $Y$ aci con Odontesthes perugiae y $O$. orientalis, aunque otros caracteres los separan facilmente, pero haciendo pensar que la subfamilia Atherinopsinae definida por su morfología interna no es muy homogénea.

Dentro de Atherinopsinae (sensu Schultz 1949) Yaci puede diferenciarse de los restantes géneros por tener el premaxilar protractil (no protractil en Basilichthys Girard, Atherinopsis Girard, y Atherinops 'Steindachner) y menos de 50 escamas en línea longitudinal (más de 50 en Leuresthes Jordan y Gilbert, Odontesthes Evermann y Kendall = ? Austromenidia Hubbs, y Hubbsiella Breder). 


\section{Yaci retropinnis De Buen, nov. sp.}

Holotipo - Ejemplar de 156 milímetros de longitud total y 134 milímetros de longitud estándar, coleccionado en el Museo de Historia Natural de Montevideo (V/T/1048 M.H.N.M.)

Localidad Tipo - Embalse de Rio Negro (R.O. del Uruguay), en la margen derecha de la boca del arroyo Chileno. Pesca con red de playa en la Campaña de 1947 (Dr. Fernando de Buen).

Descripcion - De cuerpo alto y grueso. El lomo se alza hasta llegar a la segunda dorsal, descendiendo rápidamente hasta llegar a un pedúnculo de poca altura. Ventralmente forma curva pronunciada, que se continúa desde la mandíbula inferior hasta la aleta anal. (figura 31).

El cuerpo a nivel de las ventrales tiene de altura el 19.5 por ciento de la longitud estándar, pero la mayor altura se mide a nivel del ano, con amplitud igual al 20.3 por ciento de la longitud estándar. La pérdida de altura del pedúnculo caudal es rápida, midiendo al terminar la segunda dorsal el 41.2 por ciento de la cabeza y en la altura mínima el 32.5 por ciento de la misma cabeza.

El máximo grosor del cuerpo es el 13.5 por ciento de la longitud estándar.

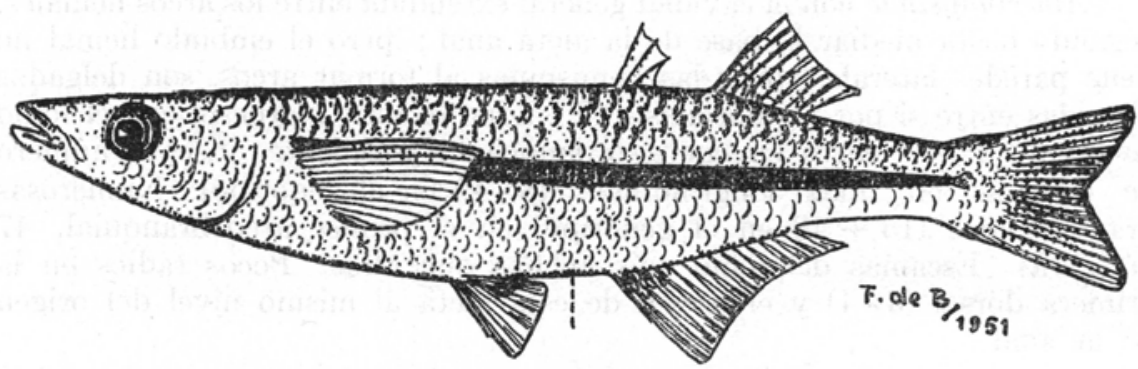

Figura 31. - $\begin{gathered}\text { Holotipo de } \\ \text { maci retropinnis De Buen, }\end{gathered}$

Dorso de la cabeza amplio y casi plano, apenas convexo. Ventralmente asciende en curva hasta el extremo del labio inferior. La boca se abre en la parte alta y el morro es muy agudo visto lateralmente. De no tener en cuenta la membrana branquióstega la longitud de la cabeza es igual al 25.5 por ciento de la longitud estándar, pero de tenerla en cuenta pasaría a ser el 27.4 por ciento.

Boca muy protractil. Labio superior delgado y cubierto lateralmente por la piel procedente del labio inferior. Hendedura bucal recta e inclinada. El maxilar se prolonga en espátula, tiene el borde anterior hendido y posee una quilla longitudinal encima.

Termina la hendedura bucal a distancia del borde anterior de los ojos, igual o algo menos del diámetro ocular. El extremo del maxilar, en buena parte de su superficie cubierto por la piel, llega a la altura, o poco menos, del borde anterior de los ojos. 
Los ojos, bordeados por párpados adiposos y algo cubiertos por delante, miden horizontalmente el 20.7 por ciento de la cabeza. De la longitud de la cabeza son : el 35.4 por ciento la preórbita, el 44 por ciento la postórbita y el 35.4 por ciento la interórbita.

Todo el cuerpo está cubierto de escamas, que se extienden por la cabeza, a excepción de la zona del morro; ocupan buena extensión del limbo de aleta caudal, y las hay también en la base de los primeros radios de la segunda dorsal y de la anal. En línea longitudinal se cuentan 49 escamas y en serie transversal nueve. Entre los orígenes de las dorsales se colocan ocho series transversales.

Son escamosas las piezas operculares, formando dos series longitudinales inmediátamente debajo de los ojos. El espacio preorbitario, el morro y la parte del interorbitario son desnudos.

Las escamas dotadas de tubo mucoso forman dos series, una al comenzar la línea longitudinal, terminando a distancia del origen de la primera dorsal de diez series transversales, y la otra ventral, iniciada cerca del borde y sucesívamente más alta, para entrar por el centro del pedúnculo caudal. La serie dorsal comienza cubriendo media escama la banda pigmentaria de los flancos y sube una escama para formar una serie discontínua de cinco. La serie ventral pasa en contacto con las ventrales o una escama por encima, distanciándose dos al llegar a la anal, luego tres y así sucesivamente por escalones hasta entrar en el pedúnculo caudal.

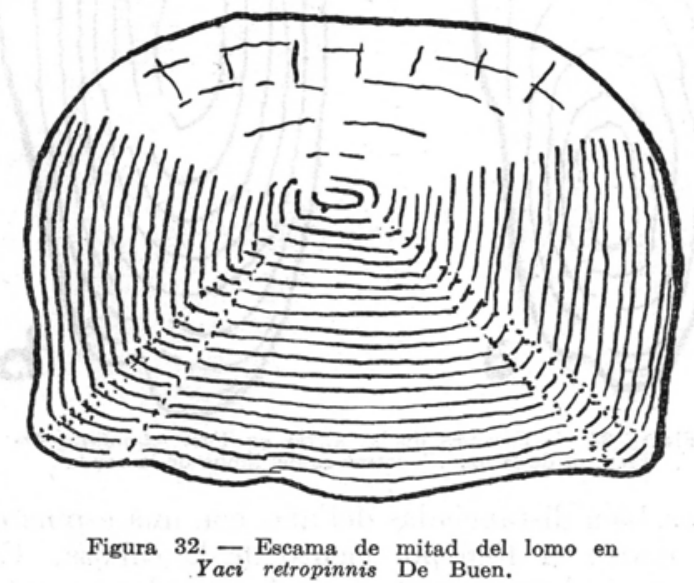

Mediado el cuerpo, sobre el lomo, las escamas son más anchas que altas, considerando altura el espacio entre las mitades del frente y el borde posterior. El frente entero, se prolonga en curva por los lados, que a su final forman una sinuosidad cóncava y destacan angulos romos. (figura 32).

Se reducen mucho de tamaño las escamas que invaden la segunda dorsal. la anal y la caudal. Las escamas arrancadas en los primeros radios de la 
anal y en la parte extrema de su invasión en el limbo de la aleta caudal tienen forma oval alargada y no poseen radios. (figura 33).

Dientes extremádamente pequeños en ambas mandíbulas. Con 48 branquispinas en la rama inferior del primer arco branquial.

Los orígenes de la primera dorsal y de la anal quedan a la misma altura. La primera dorsal con solo tres radios, se distancia del morro el 62.8 por ciento de la longitud estándar, y su origen se aparta de la última vértebra el 38 por ciento de la misma longitud estándar. La segunda dorsal con 1/10 radios comienza a la altura del noveno radio blando de la anal. Las dos aletas, anal y segunda dorsal, terminan al mismo nivel. Mide la base de la segunda dorsal el 36.9 por ciento de la cabeza y su radio más largo el 44 por ciento.

Las aletas pectorales son amplias, de extremo agudo; llegan al origen de las ventrales y las pasan tanto como la anchura de una escama; su longitud es el 82.2 por ciento de la cabeza y su base mide el 26.6 por ciento de la misma.

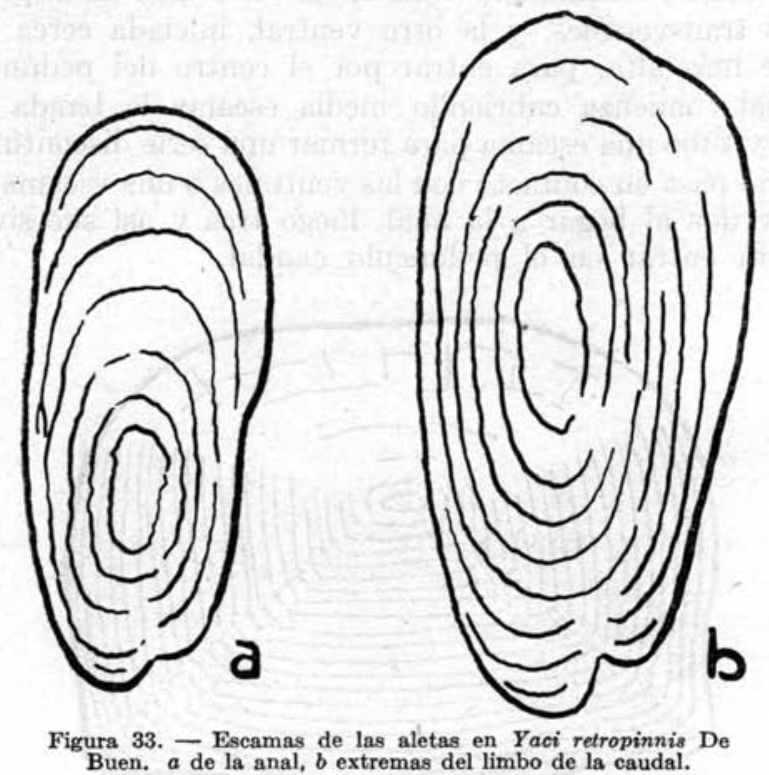

Las ventrales, bien distanciadas del ano, con una espina delgada y cinco radios ramosos, miden el 45.6 por ciento de la cabeza. Están separadas entre sí, aunque en la base poseen pequeña membrana entre ellas y cada una se liga al cuerpo por otra membrana de muy modesta extensión.

El orificio anal se distancia de la aleta que sigue como dos tercios del diámetro horizontal de la órbita.

Aleta caudal, con 17 radios centrales, con lóbulos simétricos, tiene iguales las distancias entre la última vértebra y los extremos de los lóbulos de la aleta, midiendo el 76.5 por ciento de la longitud de la cabeza. 
La aleta anal tiene $1 / 17$ radios, mide su base el 73.6 por ciento de la cabeza, y su radio más largo el 53 de la misma. Su borde libre es ligéramente cóncavo.

De color pálido, blaneo amarillento, con la parte alta del lomo manchada suávemente en el borde de los estuches dérmicos de las escamas. La banda longitudinal de los flancos, ancha como una escama o poco más, tiene forma y recorrido regular, llegando desde la axila hasta el término del pedúnculo caudal.

Ligeramente obscuros, sin formar verdaderas manchas, la región supercefálica y los labios. En la segunda dorsal apenas algunos cromatóforos manchan la zona escamosa, en la caudal se ennegrecen las puntas de los radios. Las restantes aletas incoloras.

Otro Ejemplar - Desgracíadamente desconocemos con exactitud la cuenca fluvial donde fué pescado. Mide 191 milímetros de longitud total y fué donado por el profesor Paul Schurman al Museu de Historia Natural de Montevideo en mayo de 1932, procedente del Departamento de Florida.

Son pocas las diferencias que se observan al comparar con el Holotipo de Yaci retropinnis. Tiene sin embargo más extensa la distancia predorsal, medida hasta el origen de la primera dorsal (en el Holotipo 62.8 por ciento de la longitud estándar.)

Cuenta 48 escamas en línea longitudinal y 8 en serie transversal. En sus aletas 1D. 4, 2 D. 1/9, P. 14, A. 1/18. Mide de la longitud estándar, por ciento: 18.3 la máxima altura del cuerpo; 12.5 el mayor grosor; 79 la distancia predorsal, hasta la primera dorsal ; 19.1 la longitud del pedúnculo caudal ; y 24.5 la longitud de la cabeza. De la longitud de la cabeza, por ciento, son : 45 entre los orígenes de las dos dorsales; 30 la altura mínima del pedúnculo caudal ; 83 la longitud de la pectoral y 25 su base ; 37.5 la base de la segunda dorsal y 43.7 el radio más largo ; 42.5 la longitud de las ventrales y 80 la base de la aleta anal.

No hay verdadero embudo hemal, las hemispinas al formar arcos son delgadas y están únicamente unidas entre si por membranas. Se cuentan 47 vértebras.

La vejiga natatoria entra en los arcos hemales y llega hasta la mitad de la base de la aleta anal.

Las branquispinas son largas, de mayor longitud que las láminas branquiales enfrentadas. En el centro de la rama inferior del primer arco branquial miden 8 milímetros las branquispinas y 5 milímetros las láminas branquiales. Se cuentan 63 branquispinas en ese primer arco, según la fórmula $15+48$.

\section{El género KRONIA}

A los varios autores que han comentado la efectividad de este género, les escapó un caracter distintivo que Miranda Ribeiro (1915) precisa para Kronia al describirla, "ventrales ligadas entre si". 
Jordan y Hubbs (1919) creen que las diferencias entre Kronia de Miranda Ribeiro y Odontesthes de Evermann y Kendall estriban solamente en tener el primero el borde sublaciniado en las escamas, los dientes en bandas y acaso diferente forma en la cabeza. Schultz (1948) preocupado por estabelecer un sistema de los Atherinidae, basado principalmente en la diferente amplitud de la cavidad visceral y la penetración de la vejiga natatoria en el embudo hemal, olvida también el preciso caracter de la unión de las aletas ventrales, claramente expresado por Miranda Ribeiro, suponiendo que Kronia es sinónima de Odontesthes.

Kronia, dedicada al farmacéutico de Iguape, colector del único ejemplar, Ricardo Krone, tiene por tipo a Kronia iguapensis, que según su autor Miranda Ribeiro, tiene forma alargada, anteriormente gruesa (subcilíndrica), con altura del cuerpo igual al 16.7 por ciento de la longitud. La cabeza aguda es el 21.5 por ciento de la longitud del cuerpo, con región preorbitaria adiposa y poros mucosos en el borde maxilar. Los ojos miden el 20 por ciento de là cabeza y el espacio interorbitario es el doble del diámetro ocular. Las escamas del cuerpo, con borde suávemente ondulado (sublaciniadas), se serian en número de 54 en línea longitudinal y hay transversalmente 11 . Tiene branquispinas largas y dentadas (villosas) y dientes en bandas en ambas mandíbulas. La primera dorsal con cinco radios, comienza a la altura del ano, y la segunda dorsal con nueve radios, se origina a nivel de la parte posterior de la anal. Ventrales ligadas entre si. Las pectorales. no llegan al nivel del origen de las ventrales, se distancian un espacio igual a tres series de escamas. La anal posee 19 radios y la caudal tiene los lóbulos desiguales. El holotipo, ejemplar único de la especie, mide 265 milímetros y fué capturado en Iguape, San Pablo (Brasil).

El prof. Paulo de Miranda Ribeiro revisó nuevamente el holotipo para proporcionar a Schultz algunas características, quien las dá a conocer acompañadas de una figura esquemática de la región anterior cefálica y de una escama (Schultz 1948, p. 9). La cavidad visceral llega hasta equidistar del ano y del origen de la anal, estrechándose para entrar en el embudo hemal. El primer radio de la segunda dorsal queda a la altura del número 14 de la anal. El espacio que media entre el origen de ambas dorsales es la cuarta parte de la distancia predorsal, hasta el origen de la primera dorsal. Las escamas del cuerpo tienen el borde libre liso y las hay en los primeros radios de la anal. En línea longitudinal se serian 60 ? escamas y transversalmente, 11 bajo la primera dorsal, 9 bajo la segunda. Primera dorsal con 5 radios, segunda dorsal con $81 / 2$, pectoral con 14 y anal con 21 .

La localidad tipo, que conocemos al través del trabajo de W. Besnard (1950), debe corresponder a un medio dulceacuícola o pobremente salino. La amplia cuenca de Ribeira de Iguape derrama grandes volúmenes cerca de la ciudad de Iguape, asentada al Norte de las extensas lagunas del sistema Iguape-Cananéia.

Con las características de la subfamilia Atherinopsinae y las ventrales unidas entre si por una membrana, como acontece en Kronia, hay en la costa atlántica del Uruguay dos poblaciones independientes que describire- 
mos, como Kronia rex sobre ejemplares obtenidos dentro del puerto de La Paloma o sus proximidades, y Kronia alba procedente de la Laguna de Rocha. Ambas difieren de la especie tipo, de Kronia iguapensis:

Kronia alba por tener más alto el cuerpo, más larga la cabeza, los ojos de más diámetro, la interórbita mucho más reducida, los dientes más fuertes y mejor definidos, mayor número de radios en la segunda dorsal, pectoral notablemente más larga y origen de la segunda dorsal más avanzado.

Kronia rex por tener el cuerpo más grueso y de mayor altura, los ojos de mayor diámetro, menor el espacio interorbitario, las escamas con líneas radiales y borde libre entero, el origen de la primera dorsal algo atrás de la posición del ano, el término de la pectoral más próximo al origen de las ventrales y más avanzado el comienzo de la segunda dorsal.

Las diferencias entre las tres especies podemos destacarlas comparando algunos caracteres.

1. Altura máxima del cuerpo $\mathbf{1 6 . 7}$ por ciento de la longitud.

2. Cabeza aguda, el 21.5 por ciento de la longitud del cuerpo.

3. Diámetro del ojo 20 por ciento de la cabeza.

4. Espacio interorbitario doble del diámetro ocular.

5. Escamas del lomo con el borde libre irregularmente entero, sin líneas radiales en la zona embutida.

6. Con 54 (60 ?) escamas en línea longitudinal y 11 en serie transversal.

7. Dientes pequeños en bandas.

8. Origen de la primera dorsal a nivel del ano.

9. Comenzando la segunda dorsal sobre el radio 14 de la anal, y con 9 radios (81/2).

10. Las pectorales apoyadas no llegan hasta el origen de las ventrales, les falta el espacio ocupado por tres series de escamas.

11. Anal con 19 (21) radios.

Kronia iguapensis Miranda Ribeiro.

1. Altura máxima del cuerpo 19.1 por ciento de la longitud estándar.

2. Cabeza el 23.5-24 por ciento de la longitud estándar.

3. Diámetro del ojo 25-26.4 por ciento de la cabeza.

4. Espacio interorbitario 1.1 a 1.4 veces mayor que el ojo.

5. Escamas del lomo de borde libre ondulado, con algunas líneas radiales en la zona embutida.

6. Con $54-55$ escamas en línea longitudinal y 11 en serie transversal.

7. Dientes fuertes $\mathrm{y}$ bien aparentes.

8. Origen de la primera dorsal a nivel del ano.

9. Comenzando la segunda dorsal antes de la mitad de la base de la anal, y con $1 / 10$ radios.

10. Las pectorales apoyadas pasan, hacia atrás, el origen de las ventrales. 
11. Anal con 1/19-21 radios.

Kronia alba De Buen.

1. Altura máxima del cuerpo 17.5-19.6 por ciento de la longitud estándar.

2. Cabeza 20.6-23 por ciento de la longitud estándar.

3. Diámetro del ojo 24.8-29.2 por ciento de la cabeza.

4. Espacio interorbitario 1.25 a 1.50 veces mayor que el ojo.

5. Escamas del lomo de borde libre entero, con algunas líneas en la zona embutida.

6. Con $55-56$ escamas en línea longitudinal y $12-13$ en serie transversal.

7. Dientes pequeños.

8. Origen de la primera dorsal con el espacio de una escama más atrás del nivel del ano.

9. Comenzando la segunda dorsal a nivel de la mitad de la base de la anal, y con $1 / 8-9$ radios.

10. Las pectorales apoyadas no llegan hasta el origen de las ventrales, las falta el espacio de una escama y media.

11. Anal con 1/18-19 radios.

Kronia rex De Buen.

Limitando nuestro estudio a las especies halladas hasta hoy en aguas uruguayas, destacaremos características genéricas y diferencias específicas.

Kronia Miranda Ribeiro 1915, p. 9. Genotipo Kronia iguapensis Miranda Ribeiro 1915, p. 10. Localidad del holotipo (ejemplar único) Iguape (São Paulo, Brasil).

La vejiga natatoria entra en el embudo hemal. Las aletas ventrales unidas entre si ; sus radios internos se ligan en toda su extensión por una membrana. Aleta caudal con lóbulos desiguales, siendo más largo el superior. Las escamas del lomo de forma cuadrangular, con borde libre entero $\mathrm{u}$ ondulado $\mathrm{z}$ escasas líneas radiales en la zona embutida. Las branquispinas, tan largas como las láminas branquiales enfrentadas, tienen en su cara interna doble fila de dientes bien aparentes. En el comienzo de la segunda dorsal y de la anal no hay escamas o tienen poca extensión. Origen de la primera dorsal sobre el ano o poco más atrás, y de la segunda dorsal sobre la mitad de la base de la anal o poco antes.

- Escamas del lomo de frente ondulado. Las aletas pectorales apoyadas pasan algo la posición del origen de las ventrales. La segunda dorsal comienza poco antes de la mitad de la base de la anal. Origen de la primera dorsal a nivel del ano. Cabeza 23.5 - 24 por ciento de la longitud estándar. Distancia del extremo del morro a la base de la primera dorsal el 56.6 - 58.5 por ciento de la longitud estándar. Altura 
mínima del pedúnculo caudal el 39.4 - 42 por ciento de la cabeza. Distancia preorbitaria el $30-32.2$ por ciento de la cabeza. Espacio interorbitario el 31.7 - 35.8 por ciento de la cabeza. $54-55$ escamas en línea longitudinal y 11 en serie transversal. Branquispinas $7+21$. Anal con 1/19-21 radios. (Laguna de Rocha)

Kronia alba De Buen.

- Escamas del lomo de frente entero. Las aletas pectorales apoyadas no llegan a la posición del origen de las ventrales. La segunda dorsal comienza sobre la mitad de la base de la anal. Origen de la primera dorsal algo detrás del ano. Cabeza 20.9-23 por ciento de la longitud estándar. Distancia del extremo del morro a la base del primer radio de la dorsal anterior el 59-62.5 por ciento de la longitud estándar. Altura mínima del pedúnculo caudal el $45-47.6$ por ciento de la cabeza. Distancia preorbitaria el $33.5-36.3$ por ciento de la cabeza. Espacio interorbitario el 36.5 - 39 por ciento de la cabeza. 55-57 escamas en línea longitudinal y $12-13$ en serie transversal. Branquispinas $8+23$. Anal con 1/18 - 20 radios. (Costa de Rocha).... Kronia rex De Buen.

Kronia alba De Buen, nov. sp.

Holotipo - De 149 milímetros de longitud total. V/T/1068 M.H. N.M.

Localidad Tipo - Laguna de Rocha (Departamento de Rocha, Uruguay). Coletor Dr. Fernando de Buen.

Descripcion - Cuerpo alargado, con poco abultado vientre (figura 34). La mayor altura del cuerpo, colocada por delante de la primera dorsal, mide el 19.1 por ciento de la longitud estándar. El mayor grosor del cuerpo, a"nivel de las pectorales, es el 13.2 por ciento de la longitud estándar. Pedúnculo caudal relativamente alto, siendo su altura mínima el 42 por ciento de la cabeza.

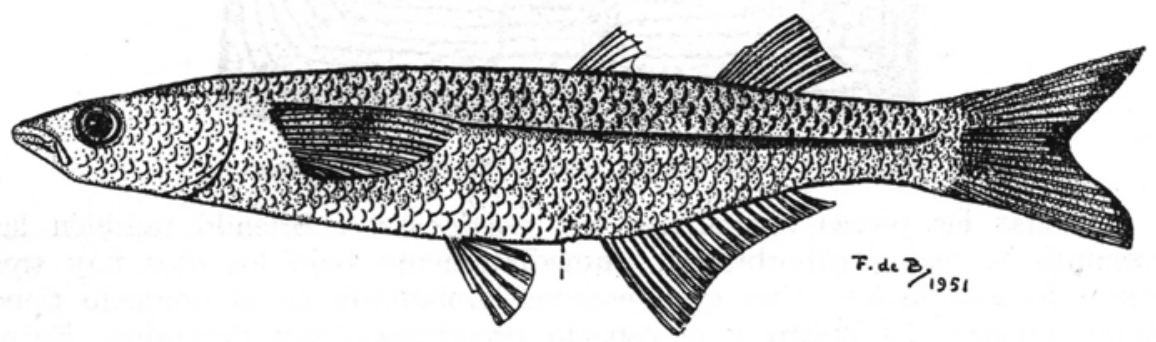

Figura 34. - Holotipo de Kronia alba De Buen. Longitud total 149 milímetros.

Cabeza prismática triangular, dorsalmente plana $\mathrm{y}$ de borde ventral agudo, mide el 24 por ciento de la longitud estándar. El morro es saliente en angulo romo, los labios poco abultados de piel granulosa. Hendedura 
bucal suávemente caida. La boca protractil. El maxilar lateralmente prolongado en espátula.

El término de la hendedura bucal se distancia del borde ocular algo más de la mitad del diámetro del ojo. El maxilar se extiende hacia abajo y atrás hasta muy cerca del nivel del borde anterior de la orbita.

Orificios nasales anteriores levantados en colgajo, abriendose por fuera de la arista lateral de la cabeza, y por dentro de ella los orificios posteriores rasgados en hojal y sin realce.

Ojos de buen diámetro bordeados por párpados adiposos, miden horizontalmente el 26.4 por ciento de la cabeza. Comparados con la longitud de la cabeza, son : el 30 por ciento la preórbita, el 49.2 por ciento la postórbita y el 31.7 por ciento la interórbita. El espacio dorsal entre los ojos es casi plano, señalándose apenas una cresta media longitudinal.

Las escamas cubren todo el cuerpo, la mayor parte de la región cefálica y la base de la caudal. En línea longitudinal se cuentan 54 escamas y transversalmente 11. Entre los orígenes de las dorsales se inician 10 series transversales.

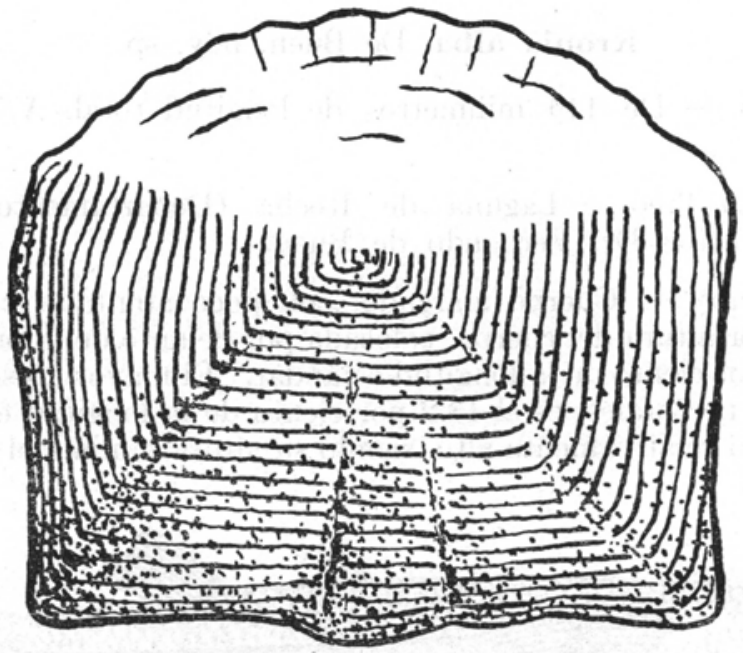

Figura 35. - Escama del lomo de Kronia alba De Buen.

Todas las piezas operculares son escamosas, cubriendo también las escamas la región suborbitaria. Inmediátamente bajo los ojos hay tres series longitudinales. Una gran escama implantada en el opérculo tiene tubo mucoso. El morro y el espacio preorbitario son desnudos. Entre los ojos no forman las escamas series definidas, siendo las centrales de tamaño mayor.

Las escamas con tubo mucoso tienen especial distribuición. Las hay en el opérculo, también en el limbo de la aleta caudal. En el cuerpo se orientan en serie longitudinal dos escamas por encima de la banda pigmentada 
de los flancos, terminando en la sexta transversal por delante de la dorsal primera. Otra línea de escamas con tubo mucoso sigue la silueta del vientre, pasando por encima de la aleta anal, a distancia de 2-3 escamas.

Las escamas del cuerpo, arrancadas en el lomo, tienen forma cuadrangular con la zona libre adelantada (figura 35). Los lados de la zona embutida son suavemente cóncavos, destacando angulos romos. El borde posterior tiene pocas sinuosidades, en número de una o dos, correspondiendo a escasos radios. El frente es suávemente ondulado.
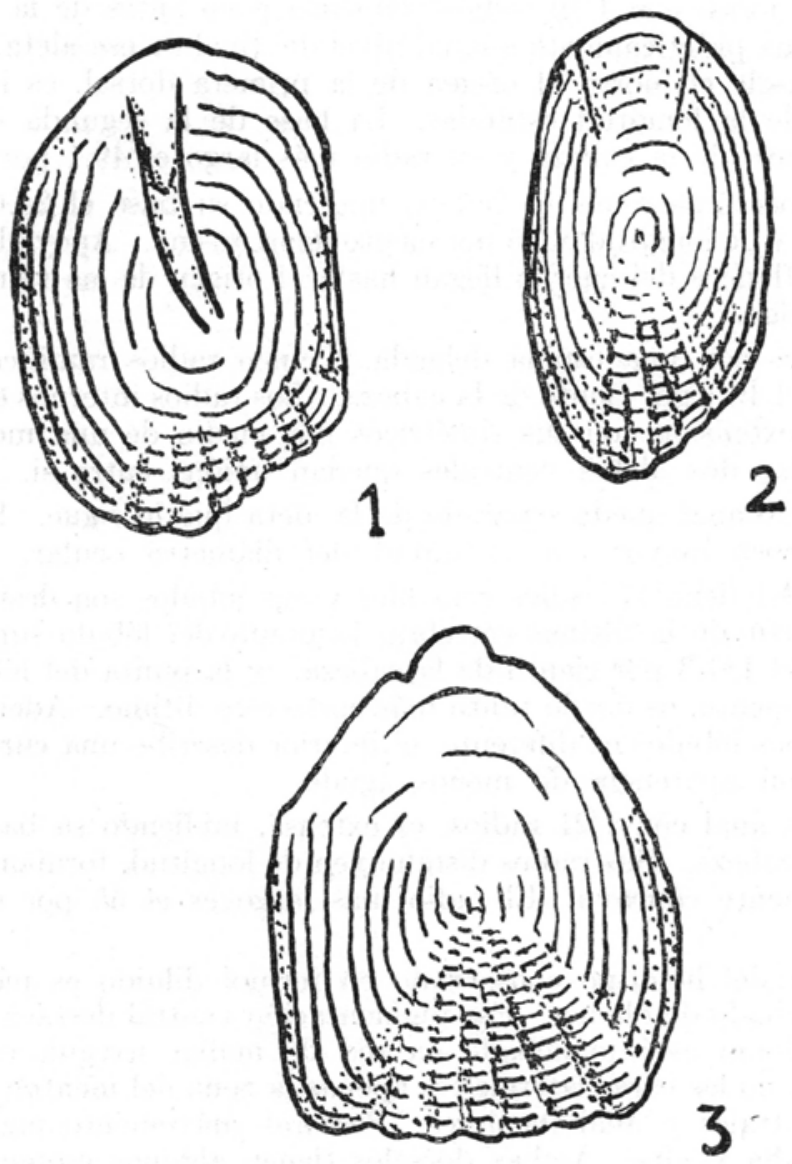

Figura 36. - Escamas de Kronia alba De Buen, arrancadas en el limbo de la aleta caudal : 1 con tubo mucoso, 2 terminales y 3 iniciales.

No hay escamas sobre las aletas dorsales, tampoco en las pectorales, en las ventrales y en la anal. Sobre la caudal invaden parte de su limbo.

Las escamas asentadas en el limbo de la caudal cambian de forma, las más próximas al pedúnculo caudal son alargadas (figura 36), con la zona 
libre muy adelantada, teniendo en el frente muy pocos mamelones bien destacados, y mayor número de radios, que originan un borde posterior ondulado; los lados son rectos o convexos. Las escamas más avanzadas en el limbo caudal son ovales, con la zona libre poco destacada y radios en número reducido. Hay algunas escamas con tubos mucosos.

En la hendedura branquial apenas sale la membrana branquióstega, ocupando el borde posterior la margen libre del opérculo.

La primera dorsal tiene su origen a nivel del ano y cuenta con 5 radios. La segunda dorsal con 1/10 radios comienza poco antes de la mitad de la anal y termina prácticamente a igual nivel del final de esa aleta. El espacio predorsal, desde el morro al origen de la primera dorsal, es igual al 58.5 por ciento de la longitud estándar. La base de la segunda dorsal, es el 44.2 por ciento de la cabeza y su radio más largo el 49.1 por ciento.

Aletas pectorales con 15 radios, midiendo su base el 24.6 por ciento de la cabeza y de longitud el 95 por ciento de la misma. Apoyadas las pectorales en los flancos del cuerpo llegan hasta el origen de las ventrales y aún las pasan algo.

Ventrales con una espina delgada y cinco radios ramificados, miden de longitud el 49.1 por ciento de la cabeza. Los radios internos están ligados en toda su extensión con sus simétricos por medio de una membrana, de forma que las dos aletas ventrales quedan unidas entre si.

El orificio anal queda separado de la aleta que lo sigue. El distanciamiento es poco mayor que la mitad del diámetro ocular.

La caudal tiene 17 radios centrales y sus lóbulos son desiguales. Midiendo a partir de la última vértebra, la punta del lóbulo superior queda distanciada el 111.3 por ciento de la cabeza, y la punta del lóbulo inferior el 102.9 por ciento, es por lo tanto más corto este último. Además el borde libre de ambos lóbulos es diferente, el inferior describe una curva más pronunciada, con aparencia de menos agudo.

La aleta anal con 1/21 radios, es extensa, midiendo su base el 91 por ciento de la cabeza. Sus radios disminuyen de longitud, formando un borde libre suávemente cóncavo. El radio más largo es el 55 por ciento de la cabeza.

El color del holotipo conservado en formol diluido es pálido, con el vientre manchado de blanco. Esa pigmentación ventral destaca del colorido general. El lomo está manchado en red de mallas irregulares. El dorso de la cabeza, no las caras laterales, y apenas la zona del menton, están manchados. Ventrales y anal incolores. Pectoral suávemente pigmentada en su parte media y alta. Ambas dorsales tienen algunos cromatóforos y la caudal está modestamente ennegrecida en su borde distal.

La banda longitudinal de los flancos es estrecha, pigmentándose con mayor intensidad su borde superior. Ocupa aproximádamente el ancho de una escama. Comienza encima y casi en contacto con la base del radio más alto de la pectoral, y al retroceder desciende, para dirigirse rectamente desde el nivel de las ventrales hasta su término sobre la última vértebra, donde sufre ligera inflexión hacia arriba. 
VARIACION (Paratipos) - Dos paratipos de 92 (V/T/1069 M.H.N.M.) y 148.5 milímetros de longitud total, capturados en la Laguna de Rocha (Departamento de Rocha. Uruguay). En la colección del Departamento Oceanográfico del SOYP.

Uno de los paratipos tiene 28 branquispinas en el primer arco branquial, correspondiendo a la fórmula $7+21$. Son tan largas como las láminas branquiales enfrentadas y poseen es su cara interna doble fila de dientes.

Con 47 vértebras, de ellas 25 abdominales y 22 caudales.

Premaxilar con pala ancha y bien señalada escotadura (figura 37 ). Su rama, alta y eréctil, no se encorva.
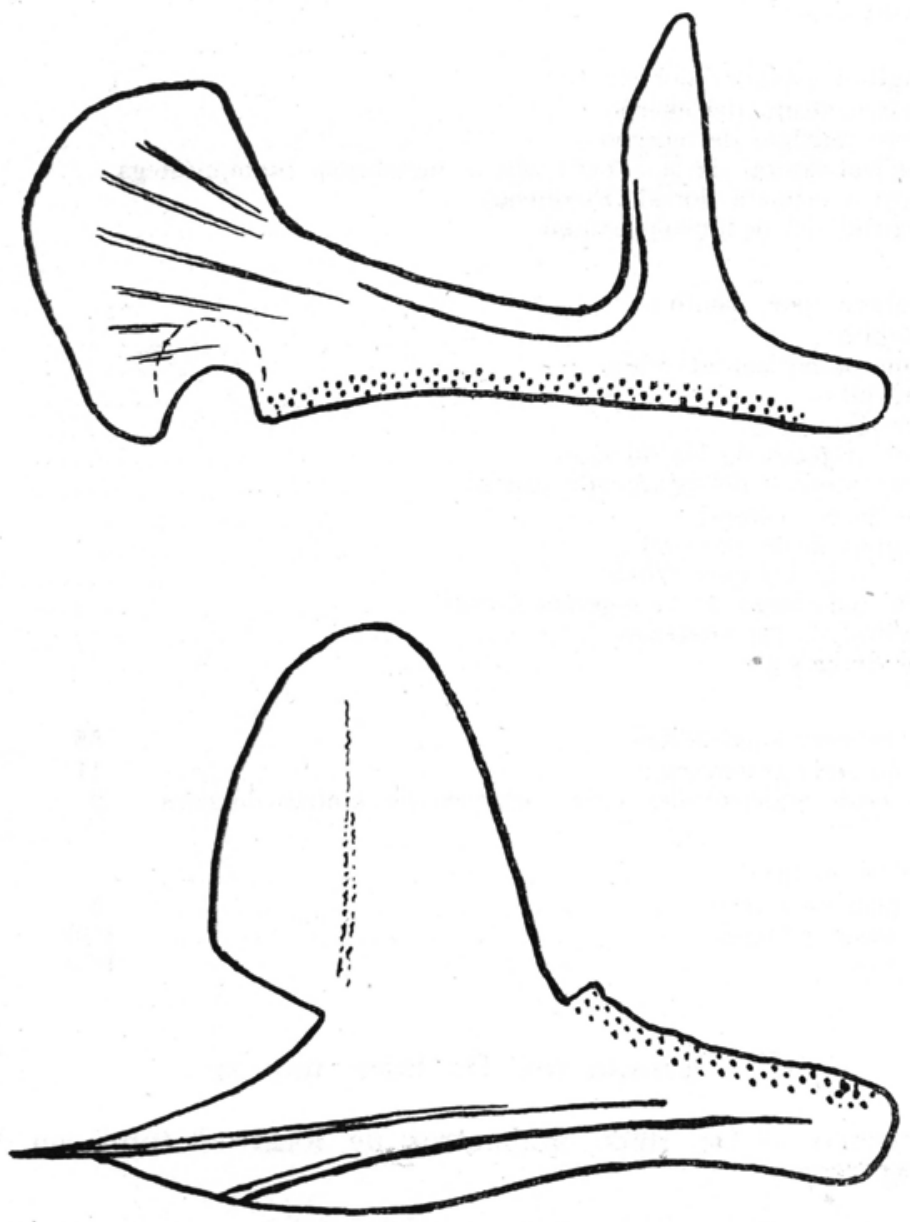

Figura 37. - Premaxilar arriba, mandíbula abajo, de Kronia alba De Buen. La banda dentaria punteada. 
La mandíbula surcada a lo largo tiene el extremo en punta. La silueta del borde inferior es curva, cóncava delante y convexa detrás. Lámina muy amplia y de forma casi oval, truncada sobre el seno y con borde interno suávemente curvo.

Dientes de la mandíbula superior fuertemente ganchudos, mayores los colocados en primera fila. Detrás de ellos, formando dos y hasta tres filas de distribución irregular, hay otros dientes igualmente ganchudos, que dirigen la punta hacia dentro.

Los dientes implantados en la mandíbula inferior son sensiblemente más pequeños $\mathrm{y}$ menos ganchudos.

En los dos paratipos se observan los siguientes caracteres, expresados en porcentajes:

De la longitud estándar por ciento :

Maxima altura del cuerpo $15-19.1$

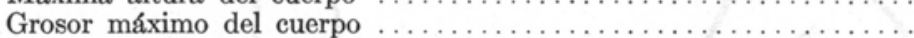

$11.7-13$

Longitud lateral de la cabeza, sin la membrana branquióstega ....

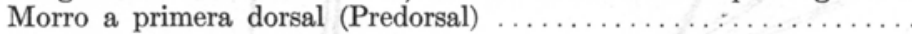

Longitud del pedúnculo caudal

$22.8-23.5$

$56.6-58.5$

$20-20.8$

De la cabeza por ciento:

Preórbita ..........................................

Diámetro horizontal órbita ................................

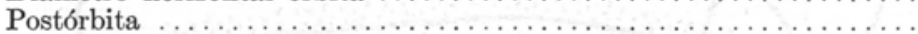

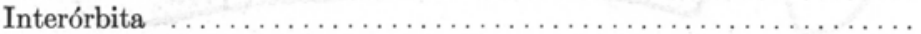

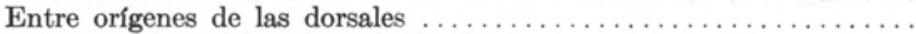

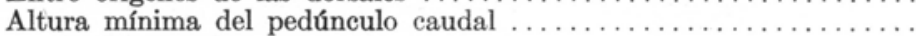

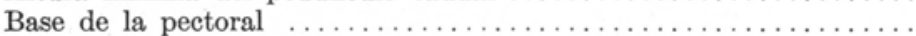

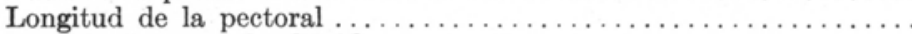

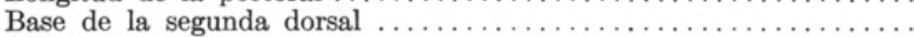

Radio más largo de la segunda dorsal $\ldots \ldots \ldots \ldots \ldots \ldots \ldots \ldots . . . . . . .$.

Longitud de las ventrales

$31.5-32.2$

$25-28.7$

$43-46$

$31.5-35.8$

$55.5-66$

$36-39.4$

$28.6-34.4$

$91.5-96.5$

$39.3-43$

53.5

Base de la anal

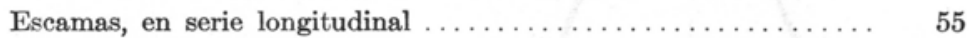

en serie transversal . . . . . . . . . . . . . . . . . 11

series transversales entre orígenes de ambas dorsales 9

Radios de las aletas,

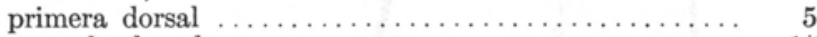

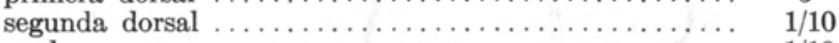

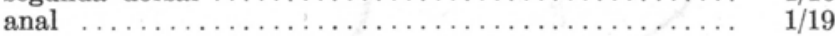

Kronia rex De Buen, nov. sp.

Holotipo - De 166.5 milímetros de longitud total, en V/T/1050 M.H.N.M.

Localidad Tipo - La Paloma (Departamento de Rocha. Uruguay). Coletor Dr. Fernando de Buen. 
DESCRIPCION - Cuerpo alargado, pero grueso (figura 38). La mayor altura, colocada sobre el origen de la dorsal primera, es el 17.5 por ciento de la longitud estándar. El mayor grosor del cuerpo, sobre el origen de las ventrales y algo por delante, es el 14.2 por ciento de la longitud estándar. Comparando grosor con altura, aquel es el 84 por ciento de la altura. El pedúnculo caudal tiene de altura mínima el 45 por ciento de la cabeza.

La cabeza de forma prismático triangular, con el dorso suávemente convexo y el inferior redondeado. Mide la cabeza 20.6 por ciento de la longitud estándar. Morro romo, con labios delgados. La hendedura bucal caida hacia atrás. Boca bien protractil. Maxilar prolongado en espátula, oculto en parte por la piel.

El término de la hendedura bucal se aparta del borde ocular como dos terceras partes del diámetro del ojo, y el maxilar en su extremidad inferior queda fráncamente delante del borde anterior de la órbita.

Orificios nasales anteriores realzados en modesto brocal, los posteriores abiertos en ojal inclinado transversalmente.

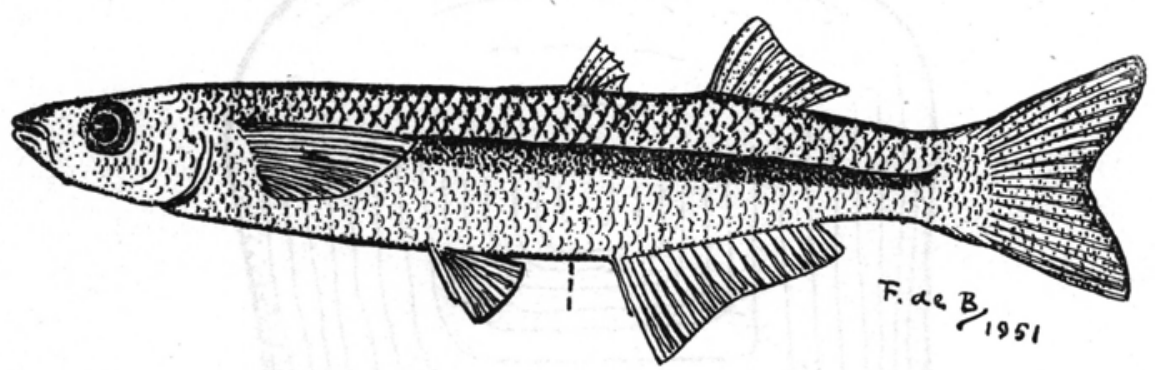

Figura 38. - Holotipo de Kronia rex De Buen. De 166.5 milímetros de longitud total.

Ojos grandes, siendo la órbita en su diámetro horizontal el 28.4 por ciento de la cabeza. Los ojos, rodeados por párpados adiposos, están cubeirtos por ellos en parte de la zona anterior. De la longitud de la cabeza es la preórbita el 36.3 por ciento, la postórbita el 41.5 por ciento y la interórbita el 38 por ciento. El ancho espacio dorsal entre los ojos es suávemente convexo y liso, sin marcarse crestas o irregularidades bien aparentes.

Cubren las escamas todo el cuerpo, invaden la casi totalidad de la cabeza y se extienden por la base de la caudal. En línea longitudinal hay 57 y en serie transversal 12, contándose entre los orígenes de las dos dorsales 10 series transversales.

En la hendedura branquial sobresale ampliamente la membrana branquióstega, marginando el borde libre del opérculo.

Tienen tubos mucosos escamas del borde opercular y en dos series longitudinales, una superior colocada dos escamas por encima de la banda coloreada de los flancos, y otra inferior que sigue a todo lo largo del perfil ventral. La serie del lomo se inicia en la escama 11 de la línea longitudi- 
nal, queda un espacio formado por las escamas 12 y 13 desprovistas de tubo, seguido por las escamas tubuladas números 14 a 16, con tendencia a ascender en su posición, y terminan los tubos mucosos sobre las escamas 18 y 19 . En el vientre la serie comienza cerca de la abertura branquial con marcada irregularidad, destacando algunas escamas inmediátamente encima; en llegando a nivel de anal se aparta tres longitudinales y al término de la base de esa aleta asciende para ocupar el centro del pedúnculo caudal.

Las escamas del lomo tienen forma cuadrangular con la zona libre poco avanzada, convexa y de frente prácticamente entero, destacando menudas ondulaciones mál definidas (figura 39). La zona embutida tiene lados ligéramente cóncavos y el borde posterior con pocas sinuosidades, correspondientes a la escasez de radios. Los angulos son romos.

Invaden las escamas el limbo de la aleta caudal y se alargan con tendencia a la forma oval. Algunas tienen tubos mucosos (figura 40).

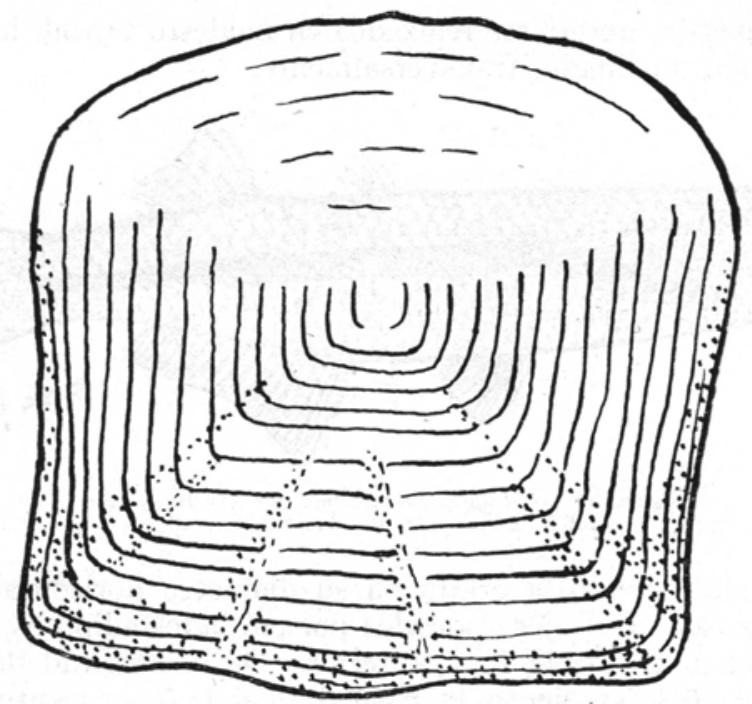

Figura 39. - Escama del lomo de Kronia rex De Buen.

Dientes pequeños en ambas mandíbulas. En la superior la primera fila bien ordenada, y por detrás de ella grupos de dientes más pequeños y dispuestos sin orden. En la mandíbula inferior dos filas, la interna revuelta hacia dentro.

El origen de la dorsal primera queda una escama más atrás de la posición del ano, y equidistante del término de la longitud estándar y el borde opercular. La primera dorsal tiene cinco radios, y el espacio predorsal, desde el extremo del morro al pie del primer radio de aquella aleta, es el 59.8 por ciento de la longitud estándar.

La segunda dorsal con 1/9 radios, tiene su origen sobre la mitad de la base de la anal y termina casi a su nivel o con retraso de un radio. La base de la aleta es el 43 por ciento de la cabeza y el radio más largo el 45 por ciento. 
Pectorales con 16 radios, midiendo su base el 27.6 por ciento de la cabeza, y su longitud el 95 por ciento. Apoyadas las pectorales no llegan a nivel del origen de las ventrales, quedando un espacio intermedio igual a una serie longitudinal y media de escamas.

Las ventrales con una espina y cinco radios ramificados, están unidas entre sí por una membrana. Sus radios internos, apoyados en el vientre, se unen en toda su longitud. Miden de largo las ventrales el 45 por ciento de la cabeza, quedando muy distanciadas de la abertura anal. Tienen de longitud esas aletas 13 milímetros y desde su extremidad al orificio anal 7 milímetros.

Caudal con 17 radios centrales. Tiene lóbulos desiguales. Desde la última vértebra hasta la punta del lóbulo superior hay una distancia igual al 116 por ciento de la cabeza, y hasta la punta del lóbulo inferior un espacio igual al 107 por ciento. El borde libre de la aleta caudal es más convexo en su mitad inferior que en la mitad superior, y la punta inferior es más aguda.
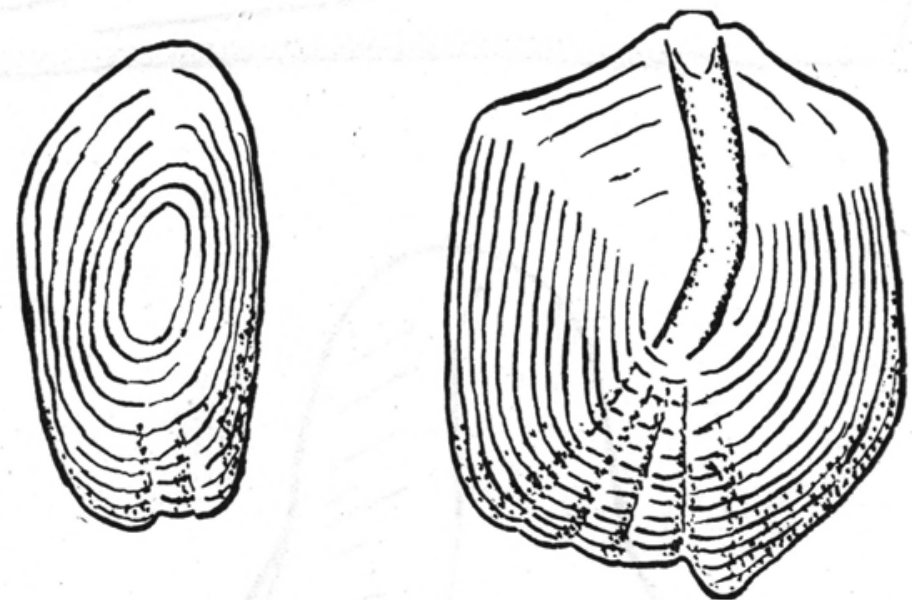

Figura 40. - Escamas de la base de la caudal en Kronia rex De Buen. A la izquierda terminales, a la derecha con tubo mucoso.

La aleta anal con 1/20 radios, mide en su base el 104 por ciento de la cabeza. Su borde libre es suávemente cóncavo, midiendo el radio más largo el 53.5 por ciento de la cabeza.

Color del ejemplar conservado, pálido con el lomo reticulado por asociación de trazos asentados en el borde del estuche dérmico de las escamas. El morro se mancha apenas. La banda longitudinal, ancha como una escama, se extiende desde la parte alta de la base de la pectoral hasta la última vértebra, donde sufre pequeña inflexión final dirigida hacia arriba.

Aletas ventrales y anal incoloras, muy suávemente manchadas las dorsales. Las pectorales difusamente manchadas hacia la mitad de su limbo, y débilmente la caudal, con mayor intensidad en el extremo de los radios. 
VARIAcION (Paratipos) - Cuatro paratipos de 155 a 235 milímetros de longitud total, capturados en La Paloma (Departamento de Rocha. Uruguay). Tres ejemplares colectados por el señor Agustín Mazzella, y el
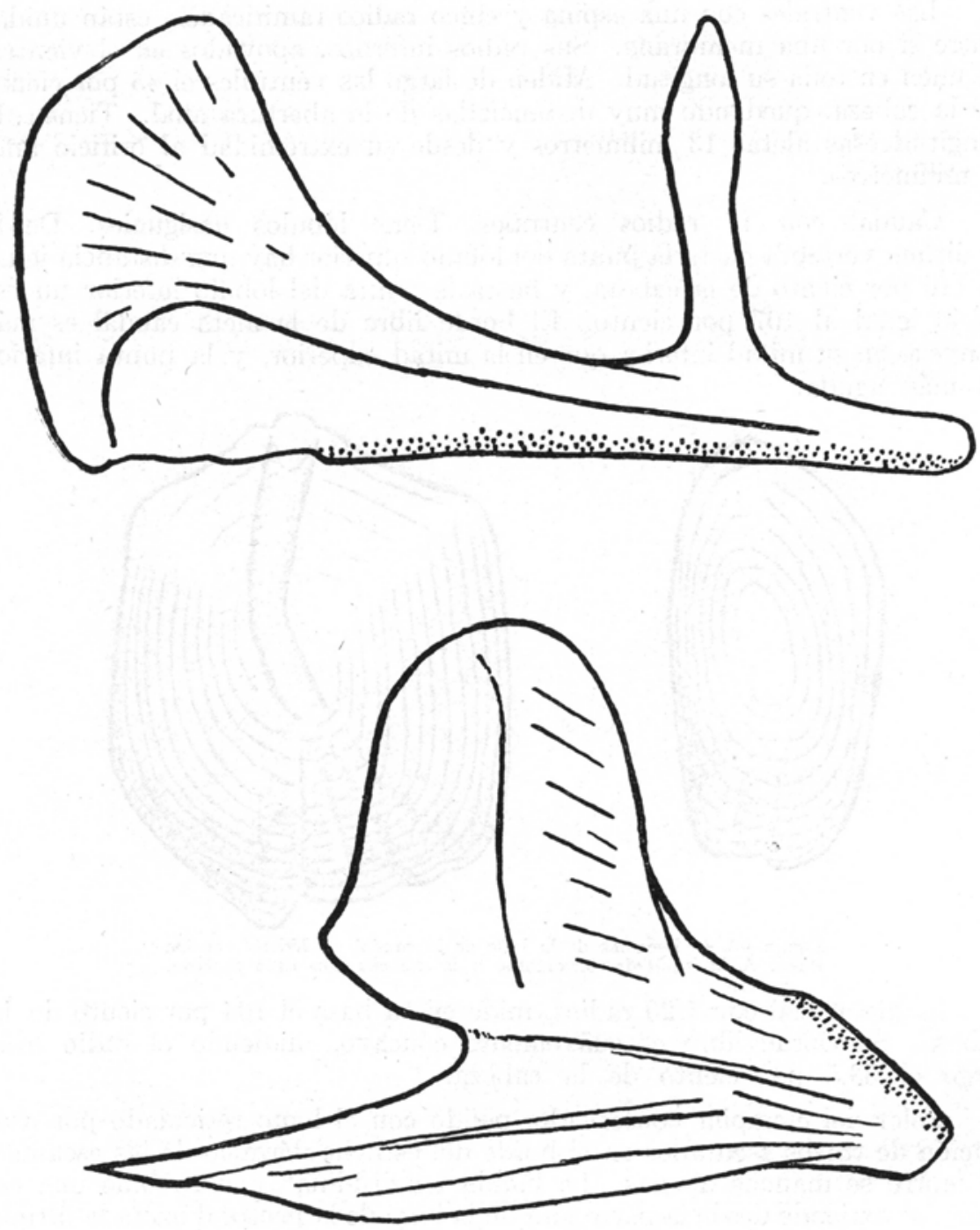

Figura 41. - Premaxilar arriba, mandíbula abajo, de Kronia rex De Buen. Banda dentaria punteada.

de mayor tamaño pescado por nosotros dentro del puerto de La Paloma empleando red de playa el dia 26 de mayo de 1951. 
En uno de $\operatorname{los}^{2}$ paratipos hay 31 branquispinas en el primer arco branquial, 8 en la rama superior y 23 en la inferior. Son tan largas como las láminas branquiales y poseen en su cara interna doble fila de dientecitos.

Con 47 vértebras, de ellas 23 abdominales y 24 caudales. El origen de la anal queda a la altura de la segunda vértebra caudal, el origen de la primera dorsal a nivel de la primera caudal y el origen de la segunda dorsal en la vertical de la novena caudal.

Cuerpo del premaxilar de borde inferior recto, sin escotadura, pala ancha que apenas sobresale hacia abajo. El borde posterior de la pala forma angulo muy abierto y romo ; abajo se prolonga en lámina delgada, señalando los límites con la parte más gruesa profunda sinuosidad. En el área delgada y laminar se asienta la banda dentaria. (figura 41).

La rama del premaxilar erectil y no inclinada, no supera en altura a la pala, quedando ambas casi a igual nivel, su ápice es agudo y posee un suave estrechamiento a manera de cuello cerca de su base.

La mandíbula, surcada a lo largo, tiene extremo en punta aguda, borde inferior recto, y la lámina levantada en vela, suávemente cóncava en los bordes interno y externo; el seno de margenes curvas, no agudas, delimita arriba el angulo romo y saliente.

La suma de medidas y recuentos en todos los paratipos dán los siguientes valores, calculados en tanto por ciento:

De la longitud estándar, por ciento:

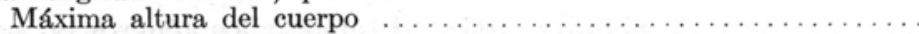

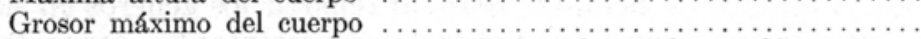

Longitud lateral de la cabeza, sin la membrana branquióstega ....

Morro a primera dorsal (Predorsal)

$17.8-19.6$

Longitud del pedúnculo caudal

$13.4-18.0$

$20.9-23.0$

$59.0-62.5$

$18.8-21.0$

De la cabeza, por ciento:

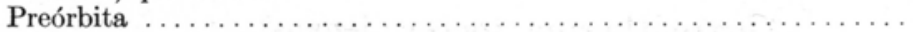

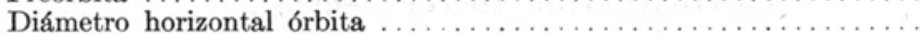

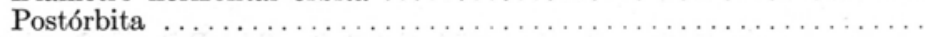

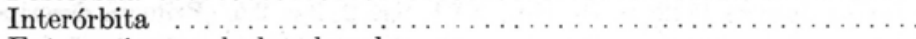

Entre orígenes de las dorsales

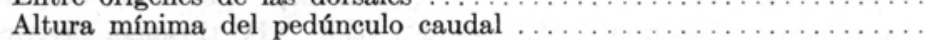

Base de la pectoral

Longitud de la pectoral

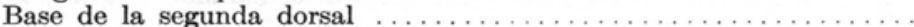

Radio más largo de la segunda dorsal

Longitud de las ventrales

Base de la anal

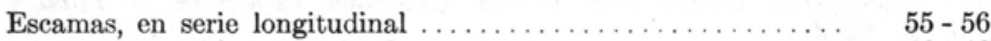
en serie transversal ............................. $12-13$ series transversales entre orígenes de ambas dorsales $9-10$

Radios en las aletas :

Primera dorsal

Segunda dorsal ........................ 1/8 9

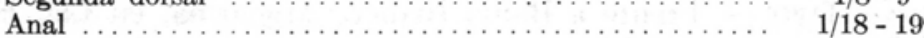

Pectoral ............................... $14-15$ 


\title{
El género AUSTROATHERINA Marrero.
}

\author{
Austroatherina Marrero 1950, p. 113
}

El genotipo Atherina incisa Jenyns tiene porte muy distinto de los que vimos anteriormente sobre formas de la fauna uruguaya. El cuerpo es extremádamente largo y grueso, siendo la mayor altura el 12.4-14 por ciento de la longitud estándar ; las pectorales cortas, su término apartado del origen de las ventrales; la abertura anal bien apartada de la aleta que sigue, colocada mediando próximamente entre el término de las ventrales y la anal; la segunda dorsal muy retrasada; las escamas del cuerpo con mamelones salientes del frente, que pueden tomar aspecto dentado ; los dientes mandibulares de vario tamaño, déstacando algunos más crecidos ; la cavidad general termina inmedíatamente detrás del ano y no se prolonga en el embudo hemal, constituido por arcos sencillos, que no llegan a formar una pared contínua.

Las características que acabamos de mencionar llevarían al género Austroatherina a la subfamilia Taeniomembrasinae (sensu Schultz 1948). Las branquiales del primer arco branquial, de forma laminar alargada, lo diferencian de Craterocephalus McCulluch. La forma del premaxilar lo distinguen de los restantes géneros (Alepidomus Hubbs, Taeniomèmbras Ogilby, Allanetta Whitley, Prasenus Whitley, Atherinomorus Fowler, Hypoatherina Schultz).

Aceptando el criterio de Schultz (1948) al repartir los géneros en subfamilias, Austroatherina se aparta mucho de los representantes conocidos de Taeniomembrasinae, y acaso sería aconsejable llevarlo a una nueva subfamilia, que no propongo al no disponer del necesario material de comparación.

\section{Austroatherina incisa (Jenyns).}

Atherina incisa Jenyns 1842, p. 79. lám. XVI, figs 2, $2 a, 2 b$, (Primera descripción). Atherinichthys incisa Günther 1861, p. 405 (descripción tomada de Jenyns).

Menidia uruguayensis Devincenzi 1924, p. 205, lám. XIV (Primera descripción) - Devincenzi y Barattini 1928, lám. XX (figura defectuosa e incompleta) - Devincenzi $1939 a$, p. 21, fig. 7 (diagrama con medidas según técnica de Lahille) - Pozzi 1945, p. 247 (localidades).

Basilichthys incisus Lahille 1929 , p. 320 (caracteres principales), p. 343 (sinonimia, distribución). Diagrama 14 - Lahille 1930, p. 105, figs 4-6, 8-11 y 13 (descripción) - Pozzi y Bordalé 1935, p. 20 y 40 (lista).

Basilichthys uruguayensis Lahille 1929, p. 344 (sinonimia, caracteres) - Pozzi y Bordalé 1935 , p. 20 (lista)

Kirlandia uruguayensis Fowler 1943, p. 326 (algunos caracteres).

Odontesthes incisus Pozzi 1945, p. 247 (localidades).

Odontesthes uruguayensis De Buen $1950 a$, p. 100 (lista, sinonimia, distribución). Austroatherina incisa Marrero 150, p. 115, fig. (descripción, distribución).

Localidad Tipo - Frente a Bahia Blanca, Argentina, en Lat. S $39^{\circ}$ y Long. W $61^{\circ}$. 
Distribucion - De Mar del Plata a Bahia Blanca en Argentina, costas de Montevideo en Uruguay.

Material - Ejemplar tipo de Menidia uruguayensis Devincenzi. Montevideo, 1918, longitud total 104.5 milímetros (V/T/1024 M.H.N.M.).

Ejemplar de 100 milímetros de longitud total, identificado por el Dr. Devincenzi como Basilichthys microlepidotus (Jenyns). De la Escollera Este de Montevideo, 12 agosto 1921. (Coletor Banchero). (V/T/1025 M.H.N.M.).

Ejemplar de 109 milímetros de longitud total, identificado como Menidia uruguayensis Devincenzi. De la Escollera Este de Montevideo, 18 agosto 1921 (Coletor Banchero). (V/T/1026 M.H.N.M.).

Ejemplar de 142 milímetros de longitud total, identificado como Menidia uruguayensis Devincenzi. Mercado de Montevideo, 5 julio 1931 (Colector Banchero) (V/T/1027 M.H.N.M.).

Tres ejemplares de 128 a 162 milímetros de longitud total, capturados en aguas de Montevideo el 9 de agosto de 1938 (V/T/1005 - 1007 M.H.N.M.).

Cuatro ejemplares de 124 a 144 milímetros de longitud total adquiridos en el Mercado de Montevideo en 1938 (V/T/1009 - 1012 M.H.N.M.).

Descripcion - Cuerpo muy alargado, con lomo redondeado y también el vientre, pero en éste último destacando el borde (figura 42). La mayor altura se mide debajo de la primera dorsal, pero es poca la diferencia detrás y delante de ella. Igualmente el mayor grosor se mantiene en larga porción del cuerpo, aunque se mide el máximo aproximádamente a nivel de las ventrales. De la longitud estándar es la máxima altura el 12.4 - 14 por ciento y el mayor grosor el $9-10.9$ por ciento.

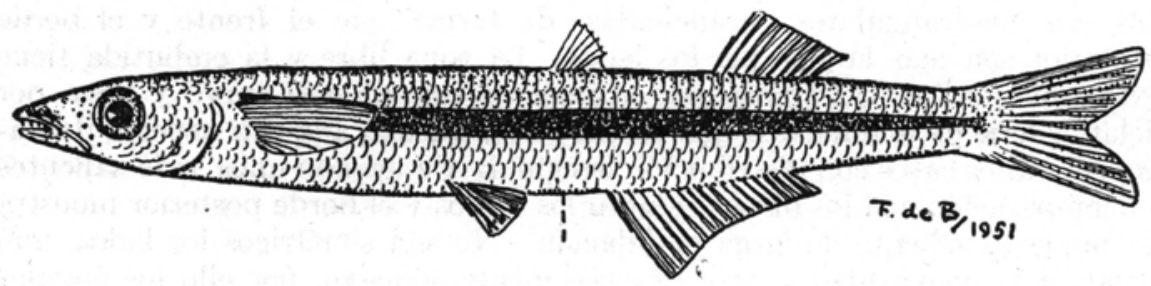

Figura 42. - Austroatherina incisa (Jenyns) procedente
de la costa de Montevideo (Uruguay).

Es largo el pedúnculo caudal, midiendo de 17.7 a 20 por ciento de la longitud estándar, y su altura mínima el 31.3 - 33.5 por ciento de la cabeza.

La cabeza, descontando la membrana branquióstega, es el 20.2-22 por ciento de la longitud estándar; dorsalmente es convexa y plana lateralmente, terminando el borde ventral en arista roma. Los labios no abultan, siendo amplio el superior y angosto el inferior. La hendedura bucal horizontal al comienzo cae a su término lateral. Es muy protractil la boca y el maxilar se prolonga lateralmente hasta casi llegar al borde inferior de la cabeza. 
El término de la hendedura bucal se distancia de la vertical trazada desde el borde anterior de los ojos cuatro quintas partes del diámetro ocular, y llega apenas a la misma vertical el extremo del maxilar.

Los orificios nasales anteriores se levantan en pequeño y corto tubo, los posteriores están rasgados transversalmente.

Los ojos tienen gran diámetro, que mide 25-39.3 por ciento de la cabeza. En buena parte los cubren los párpados adiposos. De la cabeza por ciento, son : 32.2 - 39 la preórbita, 39.4 - 44.5 la postórbita, y 32.2 - 39.3 la interórbita.

Las escamas cubren todo el cuerpo, la mayor parte de la cabeza y se extienden por el limbo de la aleta caudal. En línea longitudinal se cuentan 64 - 74 escamas y en serie transversal 8-9. Entre los orígenes de ambas dorsales comienzan 14-15 series transversales.

Las piezas operculares tienen escamas, pero todo el morro es desnudo, bordeando el ojo un tubo mucoso que dá en el espacio preorbitario cinco ramas con los correspondientes orificios externos. Avanzan las escamas por el dorso de la cabeza hasta los oríficios nasales posteriores, pero dejando a ambos lados areas desnudas. La zona dorsal del morro es translúcida.

Hay dos series de escamas dotadas de tubo mucoso, una dorsal y la otra ventral. La serie dorsal está muy espaciada, en uno de los ejemplares hay tubos mucosos en las escamas números $2,4,7,9,13,16,19$ y 22 , quedando la última a dos series longitudinales de la banda pigmentada de los flancos, y a once series transversales del origen de la primera dorsal. Igualmente irregular es la serie ventral, que pasa sobre las aletas ventrales a distancia de dos escamas, y por encima de la anal separada tres escamas.

Las escamas arrancadas del lomo, debajo de la primera dorsal, (figura 43) son cuadrangulares ensanchadas, de forma que el frente y el borde posterior son más largos que los lados. La zona libre y la embutida tiene extensión similar. El frente sale apenas, es suávemente curvo y lleva por delante serie de mamelones, que en ocasiones pueden adquirir aspecto dentado, en ambos casos con distribución irregular, destacando unos más salientes en comparación con los otros. Faltan los radios y el borde posterior muestra un modesto saliente de larga ondulación. No son simétricos los lados, uno tiende a la convexidad y otro es suávemente cóncavo, por ello los ángulos son dispares, más pronunciado el correspondiente al lado cóncavo.

No se observan escamas sobre las aletas a excepción de la caudal. La hendedura branquial, poco inclinada, no tiene en la mayor parte de su recorrido el borde saliente que corresponda a la membrana branquióstega, unicamente destaca en lo más alto, prolongándose la membrana en forma hemicircular con pequeña escotadura central.

El premaxilar espatulado a su término posee pequeña muesca en el borde anterior y realza el lomo sin formar verdadera quilla. El extremo es redondeado, no agudo.

Disecado el premaxilar se observa la presencia de amplia pala y alta rama. La rama, inclinada, tiene el borde interno suávemente convexo, 
algo más pronunciada la convexidad en el borde externo, y el ápice agudo. El seno redondeado y poco profundo; la pala sin escotadura, tiene el borde en ángulo muy obtuso y curvo (figura 44).

La mandíbula de cuerpo delgado y borde casi recto, tiene el extremo en punta roma. La lámina es amplia, señalando apenas el ángulo y con seno poco profundo, su ápice redondeado y el borde interno suávemente convexo.

Los dientes se disponen en una sola fila, son menudos a excepción de dos por lado, fuertes, ganchudos y salientes, que se disponen en la mitad interna de la banda. En el premaxilar son algo más crecidos los dientes colocados en la sínfisis.

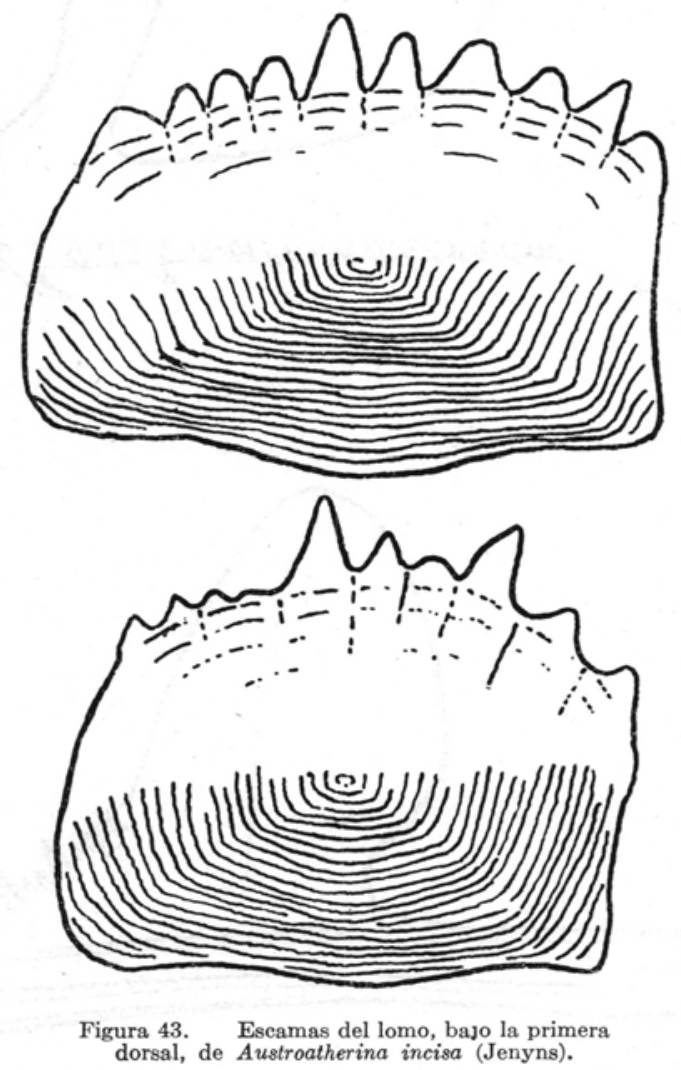

Con $6+27$ branquispinas en el primer arco branquial, de forma laminar alargada. Las de la mitad de la rama inferior son más cortas que las láminas branquiales opuestas.

La primera dorsal con 5 - 6 radios tiene su origen por encima del orificio anal o muy poco más atrás. La segunda dorsal con $1 / 8$ - 10 radios comienza a nivel del radio blando 12 de la anal. La distancia predorsal, del morro 
al origen de la primera dorsal, es el $57-62.2$ por ciento de longitud estándar. La base de la segunda dorsal mide $41.8-46$ por ciento de la cabeza, y el radio más largo el $35.8-44.5$ por ciento de la misma.

Las aletas pectorales, con 12 - 14 radios, tienen de base $23.3-39.3$ por ciento de la cabeza y de longitud $68-89$ por ciento, quedando apoyadas
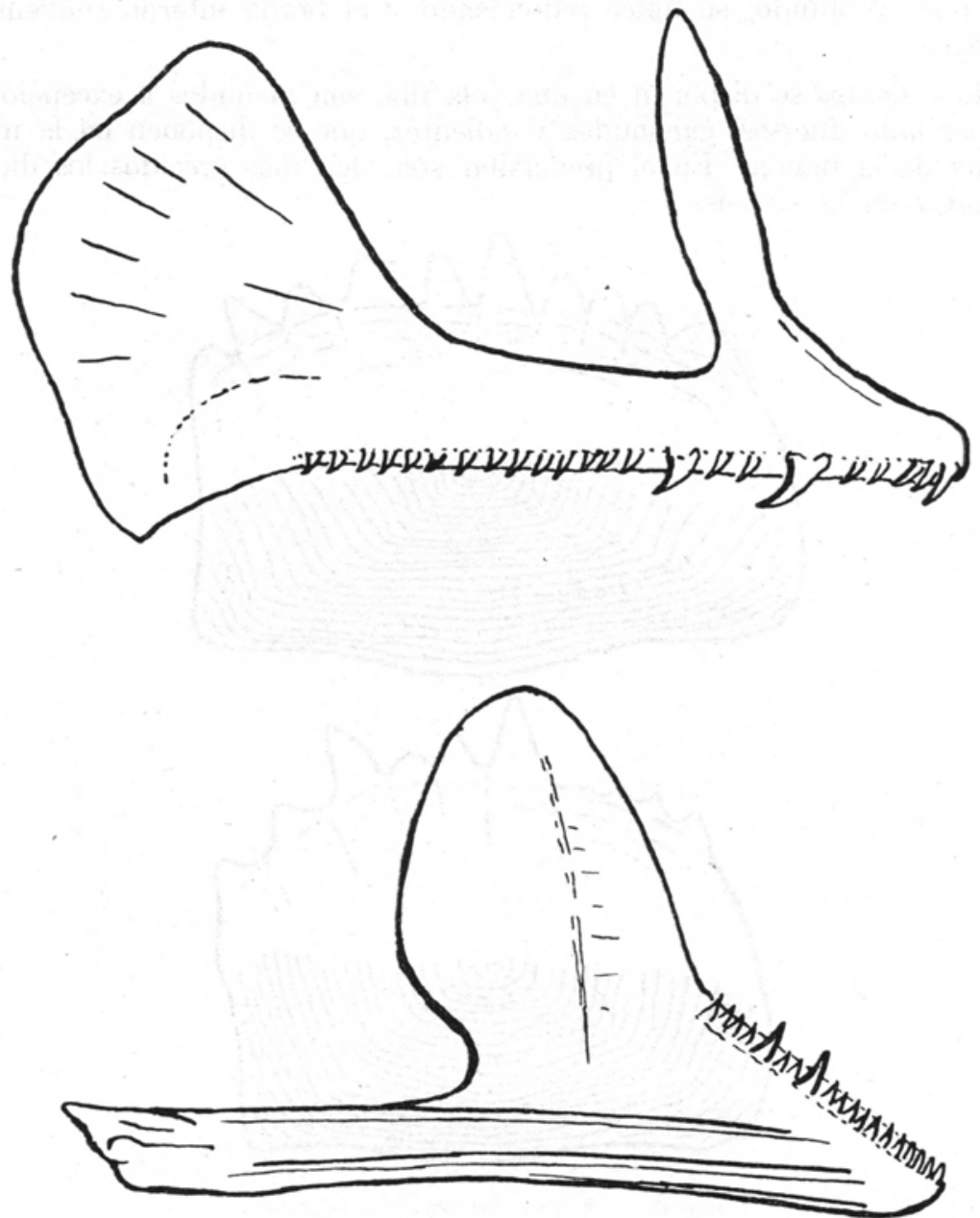

Figura 44. - Premaxilar arriba y mandíbula abajo, en Austroatherina incisa (Jenyns). En las bandas dentarias se han dibujado los dientes.

en los flancos muy distanciadas del origen de las ventrales, tanto como siete series transversales y mucho más que el diámetro ocular.

Las ventrales bien separadas entre sí, con $1 / 5$ radios, tienen de largo $39.7-50$ por ciento de la cabeza. 
Se aparta el orificio anal del origen de la aleta anal tanto como un diámetro ocular.

La aleta anal, contando con 1/16 - 20 radios, tiene de base el 92 - 101.2 por ciento de la cabeza y mide el radio más largo el 35.5 - 50 por ciento de la misma.

La caudal con 17 radios centrales posee lóbulos simétricos, midiendo desde el término de la longitud estándar hasta cualquiera de las dos extremidades de la aleta el 83.7 - 89 por ciento de la cabeza.

Color muy pálido, con banda pigmentada de los flancos ancha como una línea longitudinal de escamas. En el lomo hay cromatóforos sueltos. Son prácticamente incoloras las aletas, únicamente una suave pigmentación invade el limbo de la caudal, faltando el borde ennegrecido en el ápice de los radios.

La cavidad general termina inmediátamente detrás del ano, siendo su límite recto y transversal. Falta el verdadero embudo hemal, los arcos hemales son sencillos y no parece que por ellos penetre la vejiga natatoria.

Se cuentan 48 vértebras, según fórmula $21+27$.

Discusion - El distinguido naturalista Charles Darwin, durante la campaña a bordo del "Beagle", logró frente a Bahia Blanca y a cierta distancia de la costa, varios ejemplares que Jenyns (1842) describió como nuevos con el nombre de Atherina incisa.

Según Jenyns su Atherina incisa es delgada y alargada, midiendo su mayor altura la novena parte de la longitud total y la sexta parte la cabeza. Sus dientes son menudos, midiendo los ojos próximamente un tercio de la longitud de la cabeza y el espacio interorbitario tanto como el diámetro ocular. La margen opercular es casi recta. Las escamas poseen 2 a 3 procesos en su borde libre, separados por incisiones, que pueden adquirir forma irregular ; son más anchas que altas, no poseen radios y su borde posterior es irregularmente sinuoso. La primera dorsal comienza al nivel del espacio entre el término de las ventrales apoyadas y el origen de la anal. La base de la segunda dorsal es más extensa que la distancia entre ambas dorsales. La aleta anal tiene su origen a la altura del término de la primera dorsal.

Los autores estadounidenses no consideraron esta especie tan típica, Jordan y Hubbs (1919) no la incluyen en su monografía de los Aterínidos, y lo más extraordinario es que tampoco se menciona en la revisión reciente de Schultz (1948).

El olvido de los autores no puede achacarse a Lahille, a quien debemos (1930) un estudio preciso de la especie de Jenyns, acompañado de buena figura (figura 4 en página 106), con representación de las escamas y mediciones en serie de esquemas.

He podido revisar el ejemplar tipo de Menidia uruguayensis Devincenzi, perteneciente a la colección del Museo de Historia Natural de Montevideo (V/T/1024 M.H.N.M.). Tiene aspecto juvenil, con escasa pigmentación y la zona supracerebral transparente. 
El holotipo de Menidia uruguayensis Devincenzi, procedente de la bahia de Montevideo, mide 104,5 milímetros de longitud total y 89 de longitud estándar. Son de la longitud estándar, por ciento: 12.4 la altura máxima del cuerpo, 9 el grosor máximo, 20.3 la cabeza, 58.4 la distancia entre el extremo del morro y el origen de la primera dorsal, y el 19.1 entre los términos de la segunda dorsal y la longitud estándar. Posee 1 D. 5, 2 D. $1 / 8$, A. $1 / 16$, P. 14 , C. 17 , V. $1 / 5$. Cuenta con 64 escamas en línea longitudinal y 8 en serie transversal. Las escamas del lomo tienen el frente fuertemente dentado, con irregularidad (figura 45). De la longitud de la cabeza, por ciento, son : 39 la preórbita, 33.5 la órbita, 44.5 la postórbita, 33.5 la interórbita, 89 la distancia entre el origen de ambas dorsales. 33.5 la mínima altura del pedúnculo caudal, 30.7 la base de la pectoral y 89 su longitud, 41.8 la base de la segunda dorsal y 44.5 su radio más largo, 50 la longitud de las ventrales, 92 la base de la anal y 50 su radio más largo, y 89 la distancia entre el término de la longitud estándar y cualquiera de las dos puntas de la caudal.

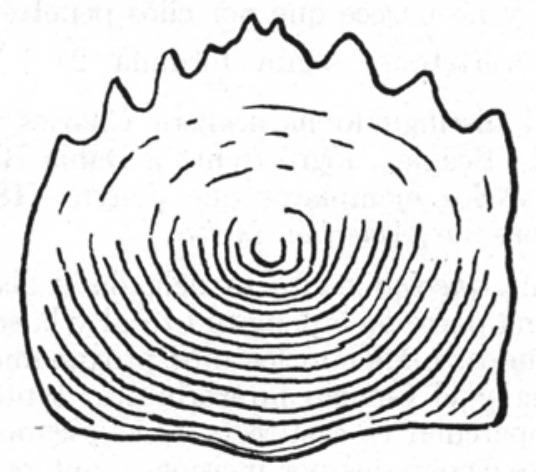

Figura 45. Escama del lomo del holotipo de Menidia uruguayensis Devincenzi

No encontramos al comparar el holotipo y otros ejemplares identificados por el Dr. Devincenzi como uruguayensis diferencias que justifiquen el separarla de incisa de Jenyns.

\section{SUMARIO}

Trata o presente trabalho dos Peixe-Rei da fauna uruguaia, descrevendo-se nêle cinco espécies novas, um gênero e um subgênero.

Inicialmente, lembra o autor que, na fauna uruguaia, bem como nas da Argentina e Brasil, ainda não se efetuaram estudos aprofundados a respeito dos representantes da família Atherinidae. O que se tem feito, até o presente, tem tido por base material colhido acidental e dispersivamente em escassas localidades ou então tomando-se como ponto de partida trabalhos nem sempre moldados em métodos ictiológicos capazes de permitir a sua incorporação no âmbito da Ciência universal. Daí o fato de surgirem dificuldades insuperáveis que impedem o estudo comparativo e a distinção clara entre as várias unidades específicas que compõem o grupo.

Cuida-se, pois, neste trabalho, de reunir e selecionar conhecimentos sôbre os Peixe-Rei das águas uruguaias, efetuando-se o estudo comparativo das formas colecionadas, 
propondo-se a sua ordenação na sistemática em voga. Tratando-se de exemplares de importância econômica, muito apreciados quer para o consumo, quer para atividades esportivas, faz-se referência especial à sua criação artificial, setôr tão importante que, dentro da Piscicultura, já se destaca o capítulo referente à Aterinicultura.

Depois de fazer um histórico a respeito dos autores que se pronunciaram sôbre alguns gêneros existentes no Atlântico sul e que frequentam também águas interiores do Uruguai e Argentina, passa o autor a considerar a Aterinicultura em si, citando o exemplo do México que a ela se tem dedicado, com sucesso, na sua Estação Limnológica de Patzcuaro. Mostra, então, o que aí se tem feito nesse sentido, em relação a Eslopsarum bartoni bartoni.

Considera-se, em seguida, a Biometria dos Peixe-Rei, discutindo-se todos os seus elementos descritivos. Demorando-se em considerações sôbre o gênero Odontesthes, analisa o autor as espécies que dele fazem parte, descrevendo $O$. humensis nov. esp., $O$. guazu nov. esp. e referindo-se a $O$. orientalis De Buen. Cria o subgênero Tupa e o gênero Yaci, o primeiro abrigando $O$. platensis (Berg) e o segundo $Y$. retropinnis De Buen, nov. sp.

Refere-se o autor ao gênero Kronia de Miranda Ribeiro (1915), recordando que aos vários autores que se reportaram à validez do gênero escapou um caráter distintivo e muito importante: "ventrais ligadas entre si". Descreve $K$. alba nov. sp. e $K$. rex nov. sp. Manifesta-se, a seguir, sôbre o gênero Austroatherina Marrero e à espécie $A$ incisa (Jenyns) = Menidia uruguayensis Devincenzi.

Todas as diagnoses acham-se acompanhadas de desenhos elucidativos, figurando ao todo, no trabalho, 44 desenhos e uma fotografia.

\section{SUMMARY}

This paper records the "Peixe-Rei" fishes from the uruguayan fauna, giving a description of five new species, one genus and one sub-genus.

The author reminds initially that for the time being no exaustive studies have been published concerning specimens of the family Atherinidæ belonging to the fauna of Uruguay, Argentine and Brazil. The only works available on the subject are based on widely scattered and occasionally gathered material or on some other work not always founded on sound ichthyological methods and according to general scientific principles. This situation is the source of insurmountable difficulties in the comparative study and clear distinction of the various specific units that form the group.

It is therefore the aim of this work to present a selective collection of the available literature concerning the "Peixe-Rei" of uruguayan waters, making a comparative study of the preserved forms and proposing their classification according to the current systematic methods. The species under study being of economical importance, not only for food but also from the sportive point of view, special reference is made of artificial hatching, this section being already so important that a new branch of fish culture has been created, the Atherinoculture.

A retrospective study is made of the authors that have investigated the existing genera in the South Atlantic and that are also found in inland waters of Uruguay and Argentine following with a special description of the Atherinoculture pointing out the example of Mexico that has obtained good results in its Limnologic Station at Patzcuaro. The author presents a description of the researches concerning Eslopsarum bartoni bartoni carried out at the Station.

The Biometry of the "Peixe-Rei" is discussed in all its descriptive elements. Extensive considerations are made regarding Odontesthes followed by an analysis of the species included in this genus and a description of $O$. humensis nov. sp., $O$. guazu nov. sp. is given with a special reference to $O$. orientalis De Buen. The author creates the sub-genus Tupa and the genus Yaci, the first mentioned including $O$. platesis (Berg) and the second $Y$. retropinnis De Buen, nov. sp.

Reference is made to the genus Kronia of Miranda Ribeiro (1915), pointing out that the several authors who have studied the validity of this genus overlooked a most important and distinctive character, i. e. : "ventral fins fused". A description of $K$. alba 
nov. sp. and $K$. rex nov. sp. is given. The writer presents his views on the genus Austroatherina Marrero and the species $A$. incisa (Jenyns) $=$ Menidia uruguayensis Devincenzi. photo.

All analysis are accompanied by explanatory figures totalling 44 drawings and one

\section{BIBLIOGRAFIA}

Batley, Reeve M.

1951. The authorship of names proposed in Cuvier and Valenciennes "Histoire Naturelle des Poissons". Copeia 3 (Ichthyological Notes), pp. 249-251.

Berg, Carlos

1895. Enumeración sistemática y sinonímica de los peces de las costas argentina

BESNARD, W. y uruguaya. An. Mus. Nac. Buenos Aires. IV, pp. 1-120.

1950. Considerações gerais em tôrno da região lagunar de Cananéia - Iguape. Bol. Inst. Paulista de Oceanogr. I, 1, pp. 9-26, figs. 1-2, 1 mapa.

Bigelow, Henry B. y William W. Welsh

1925. Fishes of the Gulf of Maine. Bull. U. S. Bur. Fish. XL. I, pp. 1-567, figs. 1-278.

Bruno Videla, Pedro H.

1944. Algunos controles efectuados sobre peces existentes en la región de los lagos. Inst. Zootecnia. Fac. Agronomia y Veterinaria. Buenos Aires. Tomo III, fasc. 1, pp. 1-34.

Buen, Fernando de

1940. Huevos, crias, larvas y jóvenes de Chirostoma del lago de Pátzcuaro. Estación Limnológica de Pátzcuaro. Trabajos núm. 3, pp. 1-14, láms. I-IV.

1944. Limnobiología de Pátzcuaro. An. Inst. Biol. México. XV. 1, pp. 261-312.

1945. Investigaciones sobre ictiología mexicana. I. Atherinidae de aguas continentales de México. An. Inst. Biol. México. XVI. 2, pp. 275-532.

1950 a. El Mar de Solís y su fauna de peces $\left(2 .^{\mathrm{a}}\right.$ parte). La fauna de peces del Uruguay. Publ. Cient. S.O.Y.P. Montevideo. Núm. 2, pp. 45-144.

1950 b. Contribuciones a la ictiología. I. Una nueva especie de Atherinidae (Odontesthes orientalis De Buen). Publ. Cient. S.O.Y.P. Montevideo, núm. 3, pp. 145-152.

Carcelles, Alberto y Aurelio Pozzi

1933. Apuntes para la fauna del golfo San Matias. Bol. Centro Naval, pp. 1-18 (Tirada Mus. Hist. Nat.). Buenos Aires.

Clark, Eugene y James M. Moulton

1949. Embriological notes on Menidia. Copeia. 2 (Ichthyological notes), pp. 152-154, fig. 1 .

Cuvier y Valenciennes

1835. Histoire Naturelle des Poissons. X, pp. 1-358.

Devincenzi, Garibaldi, J.

1924. Peces del Uruguay. An. Mus. Nac. Montevideo. pp. 139-290, láms. XIIIXXIV.

1925. El primer ensayo sobre ictiología del Uruguay. La clase "Peces" de la Zoología de don Dámaso A. Larrañaga. An. Mus. Nac. Montevideo. Ser. II. 1, núm. 6, pp. 295-323.

1939 a. Peces del Uruguay. Notas complementarias. III. An. Mus. Hist. Nat. Montevideo. II. IV. 13, pp. 1-39.

$1939 \mathrm{~b}$. Notas ictiológicas sobre peces de la región patagónica. Análisis de la obra de J. R. Norman: Coast Fishes II. The Patagonian Region. Discovery Report, vol. XVI. 1937. An. Mus. Hist. Nat. Montevideo. II. IV. 14, pp. 1-21.

Devincenzi, Garibaldi J. y Luis P. Barattini

1928. Album ictiológico del Uruguay. An. Mus. Hist. Nat. Montevideo. Ser. II (Suplemento). Láms I-XXIV. 
Devincenzi, Garibaldi J. y Gerard W. Teague

1924. Ictiofauna del rio Uruguay medio. An. Mus. Hist. Nat. Montevideo. Ser II. 4, pp. 1-103, con 87 figs. y V láms.

Eigenmann, Carl H.

$1909 \mathrm{a}$. Catalogue of the fresh-water fishes of tropical and South temperate America. Reports Princeton Univ. Exped. Patagonia 1896-1899 (III. 2. Zoology) 1905-1911, pp. 375-511.

$1909 \mathrm{~b}$. The fresh-water fishes of Patagonia and an examination of the Archiplata-Archhelenis theory. Reports Princeton Univ. Exped. Patagonia 1896-1899 (III. 1. Zoology) Part. III, pp. 225-374, pl. XXX-XXXVII.

Evermann, B. W. y W. C. Kendall

1907. Notes on a collection of the fishes from Argentina, South America, with descriptions of three new species. Proceed. U. S. Nat. Mus. XXXI, pp. 67-108.

Fowler, HenRY W.

1943. Notes and descriptions of new or little known fishes from Uruguay. Proc. Acad. Nat. Scien. Philadelphia. XCV, pp. 311-334, figs. 1-22.

1944. Results of the fifth George Vanderbilt expedition (1941). Bahamas, Caribbean Sea, Panama, Galápagos Archipelago and Mexican Pacific Islands. Acad. Nat. Sc. Philad. Monographs 6, pp. I-VI y 1-582.

Gonzalez Regalado, Tomás y Vicente Masterrigo

1948. Piscicultura. El Pejerrey. Publ. Misc.., núm. 268. Dir. Piscicult. Pesca y Caza Marítima., pp. 1-51.

Günther, Albert

1861. Catalogue of the Acantopterygian fishes in the Collection of the British Museum. III, pp. I-XXV y 1-586.

Hildebrand, Samuel F.

1923. Notes on habits and development of eggs and larvae of the Silversides Menidia menidia and Menidia beryllina. Bull. U. S. Bur. Fish. XXXVIII., pp. 113-120, figs. 85-98.

Hildebrand, Samuel F. y William C. Schroeder

1928. Fishes of Chesapeake Bay. Bull. U. S. Bur. Fish. XLIII. I, pp. 1-366, figs. 1-211.

HubBs, CARL L.

1920. Notes on the Atherine fishes of Colombia. Occas. papers Mus. Zool. Univ. Mich. 88, pp. 1-6.

1921. An ecological study of the life-history of the freshwater atherine fish Labidesthes sicculus. Ecology,. II. 4, pp. 262-276.

JENYNS, LEONARD

1842. Fish. The Zoology of the voyage on H.M.S. Beagle, under the Command by Captain Fitzroy, R. N. during the years 1832 to 1836 (Edited and superintended by Charles Darwin). IV. London, pp. V-XVI y 1-169, láms. I-XXIX.

Jordan, David Starr y Carl Leavitt Hubbs

1919. Studies in Ichthyology. A Monographic review of the family of Atherinidae or Silversides. Leland Stanf. Junior Univ. Publ. Univ. Ser., pp. 1-87, figs. $1-42$.

Kuntz, Albert y Lewis Radcliffe

1918. Notes on the embryology and larval development of twelve teleostean. fishes. Bull. U. S. Bur. Fish. XXXV, pp. 87-134, figs. 1-126.

Lahille, F.

1929. El Pejerrey. Bol. Min. Agric. XXVIII. 3, pp. 261-395, diagramas 1-31.

1930. Los pejerreyes de Quequén. An. Mus. Nac. Hist. Nat. "Bernardino Rivadavia". XXXVI, pp. 97-120 (Ictiologia núm. 14).

Larrañaga, Damaso Antonio

1923. Escritos. Instituto Histórico y Geográfico del Uruguay. II, pp. 5-512. 
Lourenço Gomes, A.

1947. A small collection of fishes from Rio Grande do Sul, Brazil. Miscell. Publ. Mus. Zool., Univ. Mich. 67, pp. 1-40, láms. I-III.

Mac Donagh, Emiliano J.

1931. El Pejerrey de la laguna del Monte (Guaminí) en 1927-1928. Notas prelim. Mus. La Plata. I, pp. 291-321, figs. 1-2.

1938. Los peces de las aguas termales de Barreto (Córdoba) y la ecología de la zona. Rev. Mus., La Plata. I. Zool., pp. 45-87, figs. 1-29, láms. I-II.

Marrero Y Galindez, Almanzor

1950. Flecha de plata. Atherínidos argentinos. Pejerreyes y Laterinos. pp. $1-157$, figs. y graf.

Miranda Ribeiro, Alipio de

1915. Fauna brasiliense. Peixes. V (Eleutherobranquios Aspirophoros). Physoclisti. Arch. Mus. Nac. Rio de Janeiro. XVII (Paginación por familias).

1918. Lista de peixes brasileiros do Museu Paulista (3. ${ }^{\mathrm{a}}$ parte). Rev. Mus. Paul. X., pp. 759-783.

Myers, George S. y Charles B. Wade

1942. The Pacific American Atherinid fishes of the genera Eurystole, Nectarges, Coleotropis, and Melanorhinus. Allan Hancock Pacific exped. 9. 5., pp. 113-149, láms. 17-19.

Norman, J. R.

1937. Coast fishes. Part II. The patagonian region (including the strait of Magellan and the Falkland islands). Discovery Reports, XVI, pp. 1-150.

Paiva Carvalho, J.

1943. Nota preliminar sôbre a fauna ictiologica do litoral Sul do Estado de São Paulo. Boletim de Indústria Animal. pp. 27-81.

Perugia, A.

1891. Appunti sopra alcuni pesci sud-americani conservati nel Museo Civico di Storia Naturale di Genova. Ann. Mus. Civico Stor. Nat. Genova. Ser. 2 , vol. X (XXX), pp. 605-657.

Pozzi, Aurelio J.

1945. Sistemática y distribución de los peces de agua dulce de la República Argentina. Gaea. An. Soc. Argent. Est. Geogr. VII. 2, pp. 239-292.

Pozzi, Aurelio J. y Luis F. Bordalé

1935. Cuadro sistemático de los peces marinos de la República Argentina. An. Soc. Cien. Argent. CXX, pp. 145-189.

Ringuelet, RaUL

1942 a. El Pejerrey (Odonthestes bonariensis) del embalse Anzulón (La Rioja). Notas Mus. La Plata. VII, Zoologia 58. pp. 177-200, figs. 1-7.

1942 b. Ecologia alimenticia del Pejerrey (Odonthestes bonariensis). Con notas limnológicas sobre la laguna de Chascomus. Rev. Mus. La Plata. II. Zool., pp. 427-461.

1943. Piscicultura del Pejerrey o Aterinicultura. Editorial Suelo Argentino. VI, pp. 1-162, figs. 1-26.

Schultz, Leonard P.

1948. A revision of six subfamilies of Atherine fishes, with descriptions of new genera and species. Proceed. U. S. Nat. Mus. 98, pp. 1-48, láms. 1-2.

Soriano Señorans, Juan

1950. Nota preliminar sobre Loricaria (Loricaria) devincenzii n. sp. de la cuenca del Rio Uruguay. Rev. Fac. Human. y Cien. Montevideo, V, pp. 265-266.

\section{Steindachner, - Franz}

1867. Ichthyologische Notizen (VI), III. Uber einige Fischarten aus dem La Plata-Strome. Sitzb. Kais. Akad. Wissensch. I, pp. 29-36.

Thompson, Will F.

1916. Fishes collected by the United States Bureau of Fisheries Streamer "Albatros" during 1888 between Montevideo, Uruguay, and Tome, Chile, on the voyage through the straits of Magellan. Proc. U. S. Nat. Mus., 50, pp. 401-476, láms. 2-6. 